Cochrane Database of Systematic Reviews

\title{
Abdominal ultrasound for diagnosing abdominal tuberculosis or disseminated tuberculosis with abdominal involvement in HIV- positive individuals (Review)
}

Van Hoving DJ, Griesel R, Meintjes G, Takwoingi Y, Maartens G, Ochodo EA

Van Hoving DJ, Griesel R, Meintjes G, Takwoingi Y, Maartens G, Ochodo EA.

Abdominal ultrasound for diagnosing abdominal tuberculosis or disseminated tuberculosis with abdominal involvement in HIVpositive individuals.

Cochrane Database of Systematic Reviews 2019, Issue 9. Art. No.: CD012777.

DOI: 10.1002/14651858.CD012777.pub2. 
TABLE OF CONTENTS

HEADER 1

ABSTRACT

PLAIN LANGUAGE SUMMARY

SUMMARY OF FINDINGS

BACKGROUND

Figure 1.

OBJECTIVES

METHODS

RESULTS

Figure 2.

Figure 3.

Figure 4.

Figure 5.

DISCUSSION

Figure 6.

AUTHORS' CONCLUSIONS

ACKNOWLEDGEMENTS

REFERENCES

CHARACTERISTICS OF STUDIES

DATA

Test 1. Abnormal abdominal ultrasound (higher quality).

Test 2. Abnormal abdominal ultrasound (lower quality).

Test 3. Ascites.

Test 4. Splenic lesions.

Test 5. Abdominal lymph nodes.

Test 6. Splenomegaly.

Test 7. Hepatomegaly.

ADDITIONAL TABLES

APPENDICES

CONTRIBUTIONS OF AUTHORS

DECLARATIONS OF INTEREST

SOURCES OF SUPPORT

DIFFERENCES BETWEEN PROTOCOL AND REVIEW

INDEX TERMS 


\section{Abdominal ultrasound for diagnosing abdominal tuberculosis or disseminated tuberculosis with abdominal involvement in HIV-positive individuals}

Daniel J Van Hoving1 1 , Rulan Griesel2 ${ }^{2}$, Graeme Meintjes ${ }^{3}$, Yemisi Takwoingi4 ${ }^{4}$ Gary Maartens ${ }^{2}$, Eleanor A Ochodo 5

1Division of Emergency Medicine, University of Cape Town and Stellenbosch University, Cape Town, South Africa. ${ }^{2}$ Division of Clinical Pharmacology, Department of Medicine, University of Cape Town, Cape Town, South Africa. ${ }^{3}$ Department of Medicine, University of Cape Town, Cape Town, South Africa. ${ }^{4}$ Institute of Applied Health Research, University of Birmingham, Birmingham, UK. ${ }^{5}$ Centre for Evidencebased Health Care, Faculty of Medicine and Health Sciences, Stellenbosch University, Cape Town, South Africa

Contact address: Daniel J Van Hoving, Division of Emergency Medicine, University of Cape Town and Stellenbosch University, Faculty of Health Sciences, University of Cape Town, Anzio Road Observatory, Cape Town, 7701, South Africa. nvhoving@sun.ac.za, niel.vanhoving@uct.ac.za.

Editorial group: Cochrane Infectious Diseases Group.

Publication status and date: New, published in Issue 9, 2019.

Citation: Van Hoving DJ, Griesel R, Meintjes G, Takwoingi Y, Maartens G, Ochodo EA. Abdominal ultrasound for diagnosing abdominal tuberculosis or disseminated tuberculosis with abdominal involvement in HIV-positive individuals. Cochrane Database of Systematic Reviews 2019, Issue 9. Art. No.: CD012777. DOI: 10.1002/14651858.CD012777.pub2.

Copyright (c) 2019 The Authors. Cochrane Database of Systematic Reviews published by John Wiley \& Sons, Ltd. on behalf of The Cochrane Collaboration. This is an open access article under the terms of the Creative Commons Attribution-Non-Commercial Licence, which permits use, distribution and reproduction in any medium, provided the original work is properly cited and is not used for commercial purposes.

\section{A B S T R A C T}

\section{Background}

Accurate diagnosis of tuberculosis in people living with HIV is difficult. HIV-positive individuals have higher rates of extrapulmonary tuberculosis and the diagnosis of tuberculosis is often limited to imaging results. Ultrasound is such an imaging test that is widely used as a diagnostic tool (including point-of-care) in people suspected of having abdominal tuberculosis or disseminated tuberculosis with abdominal involvement.

\section{Objectives}

To determine the diagnostic accuracy of abdominal ultrasound for detecting abdominal tuberculosis or disseminated tuberculosis with abdominal involvement in HIV-positive individuals.

To investigate potential sources of heterogeneity in test accuracy, including clinical setting, ultrasound training level, and type of reference standard.

\section{Search methods}

We searched for publications in any language up to 4 April 2019 in the following databases: MEDLINE, Embase, BIOSIS, Science Citation Index Expanded (SCI-EXPANDED), Social Sciences Citation Index (SSCI), Conference Proceedings Citation Index- Science (CPCI-S), and also ClinicalTrials.gov and the WHO International Clinical Trials Registry Platform to identify ongoing trials.

\section{Selection criteria}

We included cross-sectional, cohort, and diagnostic case-control studies (prospective and retrospective) that compared the result of the index test (abdominal ultrasound) with one of the reference standards. We only included studies that allowed for extraction of numbers of true positives (TPs), true negatives (TNs), false positives (FPs), and false negatives (FNs). Participants were HIV-positive individuals

Abdominal ultrasound for diagnosing abdominal tuberculosis or disseminated tuberculosis with abdominal involvement in HIV-positive

Copyright (C) 2019 The Authors. Cochrane Database of Systematic Reviews published by John Wiley \& Sons, Ltd. on behalf of The Cochrane

Collaboration. 
aged 15 years and older. A higher-quality reference standard was the bacteriological confirmation of Mycobacterium tuberculosis from any clinical specimen, and a lower-quality reference standard was a clinical diagnosis of tuberculosis without microbiological confirmation. We excluded genitourinary tuberculosis.

\section{Data collection and analysis}

For each study, two review authors independently extracted data using a standardized form. We assessed the quality of studies using a tailored Quality Assessment of Diagnostic Accuracy Studies-2 (QUADAS-2) tool. We used the bivariate model to estimate pooled sensitivity and specificity. When studies were few we simplified the bivariate model to separate univariate random-effects logistic regression models for sensitivity and specificity. We explored the influence of the type of reference standard on the accuracy estimates by conducting separate analyses for each type of reference standard. We assessed the certainty of the evidence using the GRADE approach.

\section{Main results}

We included 11 studies. The risks of bias and concern about applicability were often high or unclear in all domains. We included six studies in the main analyses of any abnormal finding on abdominal ultrasound; five studies reported only individual lesions.

The six studies of any abnormal finding were cross-sectional or cohort studies. Five of these (83\%) were conducted in low-or middle-income countries, and one in a high-income country. The proportion of participants on antiretroviral therapy was none ( 1 study), fewer then $50 \%$ ( 4 studies), more than $50 \%$ ( 1 study), and not reported ( 5 studies). The first main analysis, studies using a higher-quality reference standard (bacteriological confirmation), had a pooled sensitivity of $63 \%$ (95\% confidence interval (CI) 43\% to 79\%; 5 studies, 368 participants; very low-certainty evidence) and a pooled specificity of $68 \%(95 \% \mathrm{Cl} 42 \%$ to $87 \%$; 5 studies, 511 participants; very low-certainty evidence). If the results were to be applied to a hypothetical cohort of 1000 people with HIV where $200(20 \%)$ have tuberculosis then:

- About 382 individuals would have an ultrasound result indicating tuberculosis; of these, 256 (67\%) would be incorrectly classified as having tuberculosis (false positives).

- Of the 618 individuals with a result indicating that tuberculosis is not present, 74 (12\%) would be incorrectly classified as not having tuberculosis (false negatives).

In the second main analysis involving studies using a lower-quality reference standard (clinical diagnosis), the pooled sensitivity was $68 \%$ (95\% Cl $45 \%$ to $85 \%$; 4 studies, 195 participants; very low-certainty evidence) and the pooled specificity was $73 \%(95 \% \mathrm{Cl} 41 \%$ to $91 \%$; 4 studies, 202 participants; very low-certainty evidence).

\section{Authors' conclusions}

In HIV-positive individuals thought to have abdominal tuberculosis or disseminated tuberculosis with abdominal involvement, abdominal ultrasound appears to have $63 \%$ sensitivity and $68 \%$ specificity when tuberculosis was bacteriologically confirmed. These estimates are based on data that is limited, varied, and low-certainty.

The low sensitivity of abdominal ultrasound means clinicians should not use a negative test result to rule out the disease, but rather consider the result in combination with other diagnostic strategies (including clinical signs, chest $x$-ray, lateral flow urine lipoarabinomannan assay (LF-LAM), and Xpert MTB/RIF). Research incorporating the test into tuberculosis diagnostic algorithms will help in delineating more precisely its value in diagnosing abdominal tuberculosis or disseminated tuberculosis with abdominal involvement.

26 September 2019

Up to date

All studies incorporated from most recent search

All studies identified during the most recent search (4 Apr, 2019) have been incorporated in the review, and one ongoing study identified

\section{PLAIN LANGUAGE SUMMARY}

\section{Abdominal ultrasound for diagnosing abdominal tuberculosis or disseminated tuberculosis with abdominal involvement in people with HIV}

\section{Why is improving tuberculosis diagnosis in people with HIV important?}

Diagnosing active tuberculosis in people living with HIV is challenging. People with advanced immunosuppression have high rates of extrapulmonary tuberculosis (tuberculosis outside the lungs).

What is the aim of this review? 
The aim of this review is to find out how accurate an ultrasound examination of the abdomen (abdominal ultrasound) is for diagnosing tuberculosis in people with HIV suspected of having tuberculosis in the abdomen or widespread tuberculosis (disseminated tuberculosis) involving the abdomen.

\section{What was studied in the review?}

Abdominal ultrasound can be done after other tests (e.g. the chest x-ray did not indicate tuberculosis ) or it can be done before other tests in people suspected of having tuberculosis. This review focuses on situations where other tests are not available.

\section{What are the main results in this review?}

We found 11 studies, but only six were relevant for the main analyses. The six studies were divided into two groups. In the first group tuberculosis was diagnosed by identifying the organism causing tuberculosis from any specimen (microbiological confirmation). For the second group, tuberculosis was diagnosed when healthcare personnel suspected tuberculosis and started anti-tuberculosis treatment, but without identifying the organism (clinical diagnosis). Three studies provided results for both groups.

The review included five studies (a total of 879 participants) with microbiological confirmation. The results showed that if abdominal ultrasound were to be used in a group of 1000 people with HIV where $200(20 \%)$ have tuberculosis then:

- About 382 individuals would have an ultrasound result indicating tuberculosis; of these, 256 (67\%) would be incorrectly classified as having tuberculosis (false positives).

- Of the 618 individuals with a result indicating that tuberculosis is not present, 74 (12\%) would be incorrectly classified as not having tuberculosis (false negatives).

\section{How reliable are the results of the studies in this review?}

Microbiological confirmation is likely to be a reliable method for deciding whether people really have tuberculosis; clinical diagnosis is likely to be less trustworthy. We found problems in both groups with how studies were conducted. Decreasing the number of false positive results may make abdominal ultrasound appear more accurate than it is. Numbers shown are an average across studies. As estimates from individual studies varied, we cannot be sure that abdominal ultrasound will always produce these results. Not enough people have been studied for us to be confident about the results.

\section{Who do the results of the review apply to?}

Studies included in the main analyses were done in Cambodia, India, South Africa, South Sudan, Spain, and Tanzania. Reasons for including people differed between the studies. Four studies used trained radiologists (specialists) or sonographers; two used doctors trained in ultrasound (non-specialists), and two included people without any suspicion of tuberculosis. Across the studies, the percentage of people with a final diagnosis of tuberculosis ranged from $18 \%$ to $64 \%$.

\section{What are the implications of this review?}

If the test is used to rule in the disease in the absence of other evidence, then, the chance of diagnosing someone with tuberculosis when they actually do not have it is high. Chances of missing a diagnosis of tuberculosis when the test is positive are lower, but a negative test alone is probably insufficient to rule out the disease. These findings should be considered when deciding whether or not to use abdominal ultrasound to test for tuberculosis involving the abdomen and how to interpret the results in the context of other clinical and diagnostic test information.

\section{How up-to-date is this review?}

The review authors searched for studies up to 4 April 2019. 


\section{SUMMARY OF FINDINGS}

\section{Summary of findings 1. Summary of findings for abdominal ultrasound (any abnormality)}

Review question: Should abdominal ultrasound be used to diagnose abdominal tuberculosis or disseminated tuberculosis with abdominal involvement in HIV-positive individuals?

Patient or population: HIV-positive individuals

Setting: Healthcare facility

Index test: Abdominal ultrasound

Reference standard: We considered two reference standards. The higher-quality reference standard was bacteriological confirmation of $M$ tuberculosis (any clinical specimen including (i) at least one specimen culture positive for $M$ tuberculosis, (ii) microscopic identification of acid-fast bacilli on stained sputum smears, lymph node aspirate, or any other specimen; or iii) Xpert MTB/RIF positive). The lower-quality reference standard was clinical diagnosis of TB without microbiological confirmation (including cases diagnosed on the basis of: i) suggestive histology (necrotizing granulomatous inflammation), ii) x-ray abnormalities, iii) extrapulmonary cases without laboratory confirmation, and iv) anti-tuberculosis therapy initiated by a healthcare practitioner for cases with a high suspicion of tuberculosis).

Threshold: Any abnormality found on abdominal ultrasound

Study design: Cross-sectional and cohort

Limitations: A small number of studies and participants were included in the analyses. Risks of bias were generally high in the patient selection domain

\begin{tabular}{|c|c|c|c|c|c|c|}
\hline \multirow[t]{2}{*}{ Test result } & \multicolumn{3}{|c|}{$\begin{array}{l}\text { Number of results per } 1000 \text { HIV-positive individuals tested } \\
(95 \% \mathrm{Cl})\end{array}$} & \multirow{2}{*}{$\begin{array}{l}\text { Number } \\
\text { of stud- } \\
\text { ies }\end{array}$} & \multirow{2}{*}{$\begin{array}{l}\text { Num- } \\
\text { ber of } \\
\text { partici- } \\
\text { pants }\end{array}$} & \multirow{2}{*}{$\begin{array}{l}\text { Certainty of } \\
\text { the evidence } \\
\text { (GRADE) }\end{array}$} \\
\hline & Prevalence $10 \%$ & Prevalence $20 \%$ & Prevalence $40 \%$ & & & \\
\hline \multicolumn{7}{|c|}{ Bacteriological confirmation as reference standard: pooled sensitivity $=63 \%(95 \% \mathrm{Cl} 43 \%$ to $79 \%)$ and pooled specificity $=68 \%(95 \% \mathrm{Cl} 42 \%$ to $87 \%)$} \\
\hline $\begin{array}{l}\text { True positives (participants correctly classified as having tuber- } \\
\text { culosis) }\end{array}$ & $63(43$ to 79$)$ & $126(86$ to 158$)$ & $252(172$ to 316$)$ & 5 & 368 & $\begin{array}{l}\oplus \ominus \odot \odot \\
\text { VERY LOW }\end{array}$ \\
\hline $\begin{array}{l}\text { False negatives (participants incorrectly classified as not having } \\
\text { tuberculosis) }\end{array}$ & $37(21$ to 57$)$ & $74(42$ to 114$)$ & 148 (84 to 228$)$ & & & \\
\hline $\begin{array}{l}\text { True negatives (participants correctly classified as not having } \\
\text { tuberculosis) }\end{array}$ & 612 (378 to 783$)$ & 544 (336 to 696) & 408 (252 to 522 ) & 5 & 511 & $\begin{array}{l}\oplus \odot \odot \ominus \\
\text { VERY LOW }\end{array}$ \\
\hline $\begin{array}{l}\text { False positives (participants incorrectly classified as having tu- } \\
\text { berculosis) }\end{array}$ & 288 (117 to 522$)$ & 256 (104 to 464$)$ & 192 (78 to 348$)$ & & & \\
\hline
\end{tabular}

Abbreviations: $\mathrm{Cl}$ : confidence interval 
GRADE certainty of evidence (GRADEpro GDT 2015; Schünemann 2016)

High certainty: We are very confident that the true effect lies close to that of the estimate of the effect.

Moderate certainty: We are moderately confident in the effect estimate: The true effect is likely to be close to the estimate of the effect, but there is a possibility that it is substantially different.

Low certainty: Our confidence in the effect estimate is limited: The true effect may be substantially different from the estimate of the effect.

Very low certainty: We have very little confidence in the effect estimate: The true effect is likely to be substantially different from the estimate of effect.

The table displays normalized frequencies within a hypothetical cohort of 1000 people at three different tuberculosis prevalences (pre-test probabilities): $10 \%, 20 \%$ and $40 \%$. We selected prevalence values based on the range of prevalence observed across the included studies. We estimated confidence intervals based on those around the point estimates for pooled sensitivity and specificity.

\section{Explanations}

aRisk of bias: We rated one study at high risk for participant selection since it excluded people unable to produce sputum (Griesel 2019-h). We downgraded the certainty of the evidence by one level.

bIndirectness: We deemed three studies to be of high concern for applicability for receiving ultrasound in a tertiary care (referral) centre (Ndege 2019-h; Sculier 2010-h Weber 2018-h). Two studies only included asymptomatic HIV-positive participants (Bobbio 2019-l; Sculier 2010-h). We downgraded the certainty of the evidence by two levels.

CInconsistency: Point estimates were substantially different between studies. We could not explain this variability and we downgraded the certainty of the evidence by one level.

dImprecision:Three studies had a wide 95\% Cl for true positives and false negatives (Dominguez-Castellano 1998-h; Sculier 2010-h; Weber 2018-h). We downgraded the certainty of the evidence by one level.

eRisk of bias: All studies used a higher-quality reference standard. We did not downgrade the certainty of the evidence.

fImprecision: Two studies had a wide 95\% Cl for true negatives and false positives (Dominguez-Castellano 1998-h; Weber 2018-h). We downgraded the certainty of the evidence by one level. 


\section{B A C K G R O U N D}

\section{Target condition being diagnosed}

Tuberculosis is caused by the bacillus Mycobacterium tuberculosis. Although it usually affects the lungs (pulmonary tuberculosis), it can also spread to other body sites (extrapulmonary tuberculosis) (WHO 2018).

An estimated 10 million people were diagnosed with tuberculosis in 2017, and 1.6 million people died from tuberculosis (WHO 2018). Resource-limited countries are the most affected; for example, the African region of the World Health Organization (WHO) had the second highest estimated number of incident cases (2.5 million), but the highest incidence rate (237 versus 133 globally) and mortality rate (HIV-positive: 24 versus 4.0 globally; HIV-negative: 39 versus 17 globally) per 100,000 people (WHO 2018).

The probability of developing tuberculosis is higher among people living with HIV. Approximately 920,000 people diagnosed worldwide with tuberculosis in 2017 were HIV-positive (WHO 2018), with HIV prevalence among incident tuberculosis cases in the African region at $27 \%$ (WHO 2018).

The worldwide case detection rate in 2016 was only an estimated $61 \%$ (WHO 2017), reflecting a mixture of under-reporting of detected cases and underdiagnosis of tuberculosis. The low detection rate possibly relates to delays in diagnosis, which could be from problems with tuberculosis diagnostic tests (accuracy and availability), the negative influence of HIV infection on the performance of diagnostic tests, and HIV co-infection and the opportunistic conditions that complicate it (Palmieri 2002; Dawson 2010; Padmapriyadarsini 2011; Horne 2019; WHO 2017). Other factors might be weaknesses in health systems and broader social and economic influences (for example, undernourishment, poverty) on the tuberculosis epidemic (WHO 2017). The diagnosis of active tuberculosis in HIV-positive people with advanced immunosuppression is challenging due to more atypical clinical presentations; other opportunistic pulmonary infections with similar presentations; a high proportion of negative sputum smears; and high rates of extrapulmonary tuberculosis (Sharma 2005). This is illustrated by autopsy studies, which indicate a very high proportion of tuberculosis in HIV-positive adults (32\% to $47 \%$ ); almost half (46\%) of adult tuberculosis cases remained undiagnosed before death (Gupta 2015).

An estimated $14 \%$ of the 6.4 million incident tuberculosis cases in 2017 were extrapulmonary tuberculosis (WHO 2018). In people with HIV-associated tuberculosis, extrapulmonary tuberculosis accounts for up to $50 \%$ of all tuberculosis cases (Sharma 2004b; Kingkaew 2009; Namme 2013), and is often disseminated (two or more non-contiguous sites simultaneously infected) (Sharma 2005). Any anatomical site can be involved, but the commonest sites are the lymph nodes, pleura, meninges, and the abdominal cavity (Sharma 2005). Many terms are used in the literature to describe tuberculosis in the abdominal cavity. For the purposes of this Cochrane Review, we use the terms abdominal tuberculosis or disseminated tuberculosis with abdominal involvement, excluding genitourinary tuberculosis. Many abdominal structures can be affected in abdominal tuberculosis or disseminated tuberculosis with abdominal involvement, including involvement of the gastrointestinal tract, peritoneum, omentum, mesentery, intraabdominal lymph nodes, and solid organs (liver, spleen, pancreas)
(Sharma 2004b). People often present with non-specific symptoms and signs, and a high index of suspicion is therefore needed for early diagnosis and timely management. It mimics a large number of medical and surgical conditions, including malignant neoplasms, inflammatory bowel disease, chronic liver disease, and other gastrointestinal infections (Jadvar 1997).

\section{Index test(s)}

Many HIV-positive people with low CD4 counts have abdominal tuberculosis or disseminated tuberculosis with abdominal involvement. As sputum smears are frequently negative in HIVassociated tuberculosis, it is common clinical practice, supported by WHO guidelines, to reach a tuberculosis diagnosis on the basis of imaging results and clinical case definitions (Wilson 2006; WHO 2016). Ultrasound is such an imaging test that can be used as a diagnostic tool (Heller 2010a; Heller 2010b; Patel 2011; Giordani 2013; Sharma 2017), although the only WHO recommendation refers to the use of ultrasound to diagnose pericardial effusions (WHO 2006). Ultrasound uses sound waves to produce images of structures and organs within the body, and has traditionally been performed by trained specialists in dedicated radiology departments. However, the numerous advantages of ultrasound (e.g. rapidly performed, portable, non-invasive, repeatable, etc.) have led to many physicians in different specialties adopting ultrasound (Adhikari 2014). The use of ultrasound by trained medical professionals (non-radiologists) is particularly relevant in resource-limited settings. Computed tomography (CT) or magnetic resonance imaging (MRI) is expensive, mostly only available in tertiary-level settings, and require specially-trained personnel to perform and report these examinations. Many low-income and middle-income countries have a high tuberculosis burden (WHO 2018), but without widespread access to specialists and tertiarylevel imaging. However, ultrasound machines are mostly accessible and their use by non-radiologists would be of great value.

Abdominal ultrasound (an ultrasound examination evaluating the abdominal cavity) may be useful in HIV-positive people with suspected abdominal tuberculosis or disseminated tuberculosis with abdominal involvement. Ultrasound techniques to diagnosis HIV-associated tuberculosis are easily learned by non-radiologists and quick to perform (less than 10 minutes) (Heller 2010a). The ultrasound findings are non-specific, and various other diseases may present with the same features. For example, intraabdominal lymphadenopathy can be due to other infections (for example, cryptococcosis, histoplasmosis); lymphomas (nonHodgkin's lymphoma and Hodgkin's lymphoma); and Kaposi's sarcoma (Martin-Bates 1993).

\section{Clinical pathway}

Any structure or organ in the abdominal cavity (for example, gastrointestinal tract, pancreatobiliary system, peritoneum, and lymph nodes) can be affected by tuberculosis disease. The presentation varies considerably and depends on the specific organ involved (Sharma 2017); other diseases are also often mimicked (Sharma 2004a). Common presenting symptoms are abdominal pain, anorexia, bowel disturbances, fever, and weight loss. The clinical examination often reveals abdominal tenderness, ascites, and solid organ enlargement (for example, hepatomegaly, splenomegaly, or hepatosplenomegaly) (Ibrahim 2005; Mandal 2011; Sharma 2017).

Abdominal ultrasound for diagnosing abdominal tuberculosis or disseminated tuberculosis with abdominal involvement in HIV-positive 
Essential diagnostic tests for individuals who are suspected of having abdominal tuberculosis or disseminated tuberculosis with abdominal involvement include a chest $x$-ray, sputum evaluation (if able to produce) for bacteriological confirmation of tuberculosis disease (smear or culture or Xpert MTB/RIF), and blood cultures (WHO 2013b). Urine specimens remain a convenient clinical sample for the diagnosis of tuberculosis. Although conventional tuberculosis diagnostics applied to urine specimens have limited clinical utility, the use of urinary lipoarabinomannan (LAM) has been recommended by the WHO in HIV-positive adults with advanced immunosuppression (CD4 cell count of 100 cells/ $\mu \mathrm{L}$ or less) or in HIV-positive adults who are seriously ill (respiratory rate above $30 / \mathrm{min}$, temperature above $39^{\circ} \mathrm{C}$, heart rate above $120 / \mathrm{min}$ and unable to walk unaided), regardless of their CD4 cell count (WHO 2015; Shah 2016). These tests are usually done in the primary care setting and higher.

Abdominal ultrasound has become part of the initial diagnostic work-up in adults living with HIV where abdominal tuberculosis or disseminated tuberculosis with abdominal involvement is suspected (especially in those with a low CD4 count), despite the lack of robust evidence of validity from large studies (NICE 2016). The diagnostic pathway might vary in different settings if there are ultrasound findings suggestive of tuberculosis. In resource-limited settings this might be enough evidence to initiate anti-tuberculosis treatment, but in high-resource settings it would prompt sitespecific investigations which could include CT scan, paracentesis, laparoscopy, fine needle aspiration, or stool examination.

A presumptive diagnosis of abdominal tuberculosis or disseminated tuberculosis with abdominal involvement can be made in the setting of known active pulmonary tuberculosis, although fewer than half of chest radiographs are compatible with active or healed tuberculosis (Chow 2002). However, data are lacking in HIV-positive individuals.

WHO recommends immediate initiation of anti-tuberculosis therapy in people living with HIV who have clinical features of disseminated tuberculosis (WHO 2016). Bacteriological confirmation of tuberculosis from any specimen remains important, but treatment should not be delayed until results become available (Figure 1). People started on anti-tuberculosis therapy without bacteriological confirmation should be assessed after one month to evaluate the clinical response to treatment. They should be re-assessed and an alternative diagnosis sought if there is no clinical improvement. 
Figure 1. Diagnostic workup of HIV-positive individuals with suspected abdominal tuberculosis or disseminated tuberculosis with abdominal involvement

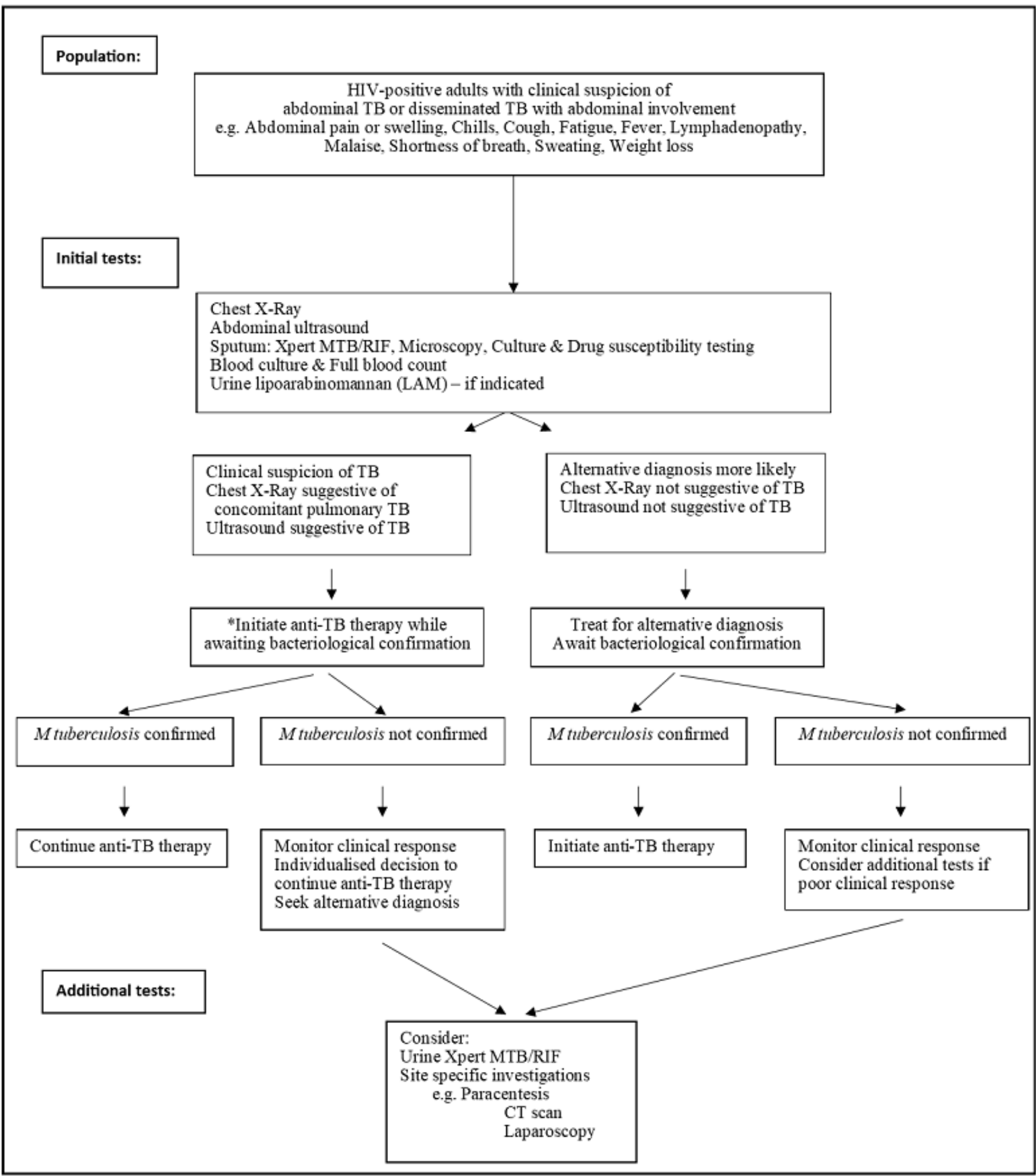

HIV: Human Immunodeficiency Virus; TB: Tuberculosis

* In high resource settings, this would most likely prompt additional site-specific investigations (additional tests) and not immediate initiation of treatment 


\section{Role of index test(s)}

Abdominal ultrasound is often combined with existing tests such as chest $x$-ray, haemoglobin, etc. to reach a diagnosis of abdominal tuberculosis or disseminated tuberculosis with abdominal involvement in clinical practice. However, all the existing tests that could inform a confirmed diagnosis may not always be available.

\section{Alternative test(s)}

Ascitic fluid analysis suggestive of abdominal tuberculosis or disseminated tuberculosis with abdominal involvement includes a leukocyte count of 150 to 4000 cells $/ \mathrm{mL}$, which consists predominantly of lymphocytes (Sharma 2004a; Sanai 2005). The ascitic fluid is usually an exudate with the protein content greater than $30 \mathrm{~g} / \mathrm{L}$ and the serum-ascites albumin gradient (SAAG) less than $11 \mathrm{~g} / \mathrm{L}$ (Sharma 2004a; Sanai 2005). Adenosine deaminase activity (ADA) of ascitic fluid (>39 IU/L) is also suggestive of abdominal tuberculosis (Riquelme 2006), while the ascites to blood glucose ratio is usually less than 0.96 (Wilkins 1984). Acidfast bacilli (AFB) smear and culture of ascitic fluid also have disappointingly low yields (Chow 2003), while Xpert MTB/RIF for peritoneal tuberculosis using peritoneal fluid has a pooled sensitivity of $59 \%$ (credible interval ( $\mathrm{Crl}) 45$ to 74 ) and a pooled specificity of $98 \%$ (Crl 96 to 99 ) (Kohli 2018).

Different imaging modalities can be useful to diagnose abdominal tuberculosis or disseminated tuberculosis with abdominal involvement. Abdominal $x$-rays are of very limited value, but can assist with the diagnosis of intestinal obstruction and perforation (Debi 2014). CT features include thickening of the peritoneum, omentum, and bowel wall; lymph nodes (especially if these have hypodense centres due to caseous necrosis); and ascites with strands, debris, and fine septations (Sharma 2004a; Lee 2012). The excellent soft tissue resolution and multiplanar acquisition of MRI have resulted in it being used to evaluate solid organs and lymphadenopathy (Joshi 2014). However, CT and especially MRI are expensive and access is very limited in resource-limited settings. Barium studies may be useful for intrinsic bowel abnormalities such as strictures, fistulae, and erosions (Sharma 2004a; Debi 2014).

Colonoscopy with biopsy is a useful non-operative diagnostic procedure to obtain material for histology and culture (Kim 1998). Mucosal nodules and transverse ulcers in the bowel are very suggestive of tuberculosis, with definitive results obtained from tissue sent for polymerase chain reaction (PCR), Ziehl-Neelsen stain, and culture (Kim 1998; Sharma 2004a). Laparoscopy is useful in two ways: (i) it allows visual inspection of the peritoneum; and (ii) it permits specimens for histology, AFB stain, and culture to be obtained. However, imaging modalities as described above provide a safer, less invasive and less expensive alternative, but may be less specific since they are unable to provide a definitive microbiological diagnosis (Sanai 2005).

Most studies relating to the diagnosis of tuberculosis were done in HIV-negative people and the true diagnostic accuracy of the above tests in those living with HIV remains uncertain. Expanded clinical case definitions were developed to diagnose smearnegative tuberculosis in HIV-positive people living in resourcelimited settings (Wilson 2006), including abdominal tuberculosis or disseminated tuberculosis with abdominal involvement (Wilson 2006; WHO 2016). For example, a person presenting with symptoms and signs suggestive of abdominal tuberculosis or disseminated tuberculosis with abdominal involvement can be started on antituberculosis treatment if the ascitic fluid consists of a lymphocytic exudate along with either a fever of $38^{\circ} \mathrm{C}$ or more on two occasions or drenching sweats for more than two weeks (Wilson 2006). In this study, the positive predictive value for abdominal lymph nodes diagnosed by ultrasound was $94 \%$ (Wilson 2006). Augmented by the use of objective criteria to monitor response to treatment within the first eight weeks, this approach has reasonable diagnostic accuracy (Wilson 2006).

\section{Rationale}

Multiple studies of various quality and designs have looked at the use of abdominal ultrasound as a diagnostic tool for abdominal tuberculosis or disseminated tuberculosis with abdominal involvement, with varying sensitivity, specificity, and predictive values for diagnosing tuberculosis (Monill-Serra 1997-l; Mugala 2006; Sinkala 2009-l; Sculier 2010-h; Patel 2011). Abdominal ultrasound may be used alone, in combination with existing tests (chest radiograph, full blood count), or as an add-on following negative results from existing tests (smear microscopy, sputum Xpert MTB/RIF, sputum culture, chest radiograph). The role of abdominal ultrasound as an add-on test is an important clinical question because it may reflect the way that abdominal ultrasound is used in practice, especially in resource-limited settings. However, after a scoping search, we did not find any studies that have evaluated the accuracy of ultrasound as an add-on test or in combination with other tests.

\section{O B JECTIVES}

To determine the diagnostic accuracy of abdominal ultrasound for detecting abdominal tuberculosis or disseminated tuberculosis with abdominal involvement in HIV-positive individuals.

\section{Secondary objectives}

To investigate potential sources of heterogeneity in test accuracy, including clinical setting, ultrasound training level, and type of reference standard.

\section{METHODS}

\section{Criteria for considering studies for this review}

\section{Types of studies}

We included cross-sectional, cohort, or diagnostic case-control studies (prospective and retrospective) that compared the result of the index test (abdominal ultrasound) with one of the reference standards (see Reference standards). Case-control studies may overestimate sensitivity and specificity, but we include them because we anticipated identifying few relevant studies. We only included studies in which the study authors reported the numbers of true positives (TPs), true negatives (TNs), false positives (FPs), and false negatives (FNs), or where we were able to derive the data from reported statistics. We also wrote to all study authors where data were missing. We excluded descriptive studies (for example, case series).

\section{Participants}

We included all HIV-positive individuals (aged 15 years and older) with a clinical suspicion of abdominal tuberculosis or disseminated tuberculosis with abdominal involvement (excluding

Abdominal ultrasound for diagnosing abdominal tuberculosis or disseminated tuberculosis with abdominal involvement in HIV-positive 
genitourinary tuberculosis), who were investigated using an abdominal ultrasound examination. We also considered studies that included confirmed cases of abdominal tuberculosis and controls. We did not place any restrictions on setting. Although abdominal ultrasound can be used to evaluate children, microbiological confirmation of tuberculosis is far more difficult than in adults, and so we excluded children where possible.

\section{Index tests}

We included studies that evaluated the accuracy of abdominal ultrasound. We did not place any restrictions on the type of ultrasound machine used or the qualification of the person performing the ultrasound, but recorded these data. A positive result was an ultrasound scan with abnormal findings suggestive of abdominal tuberculosis or disseminated tuberculosis with abdominal involvement, including, but not limited to, free abdominal fluid, abdominal lymph nodes, hepatic lesions, and splenic lesions. A negative result was an ultrasound scan with no abnormal findings.

\section{Target conditions}

Active disease due to $M$ tuberculosis - either abdominal tuberculosis or disseminated tuberculosis with abdominal involvement.

\section{Reference standards}

We used a hierarchy of reference standards. The reference standard diagnosis typically relates to microbiological confirmation (microscopy or culture), although histopathological characteristics strongly support a diagnosis of active tuberculosis in clinically and epidemiologically appropriate settings. Xpert MTB/RIF assay (an automated nucleic acid amplification test) can also identify $M$ tuberculosis. A clinical diagnosis of tuberculosis is sometimes used in the absence of confirmative tests, for example, probable tuberculosis can be defined as the clinical picture of tuberculosis without objective diagnostic tuberculosis criteria and treated for tuberculosis by the attending physician. Although this approach is clinically useful, it is very subjective as it relies on the clinical gestalt of the treating physician. We therefore viewed it as a lower-quality reference standard.

The primary (higher-quality) reference standard was bacteriological confirmation of any clinical specimen including (i) at least one specimen culture positive for $M$ tuberculosis, (ii) microscopic identification of AFB on stained sputum smears, lymph node aspirate, or any other specimen; or iii) Xpert MTB/RIF positive (WHO 2013a). We considered a positive result on any of these tests as a positive result for the microbiological (higher-quality) reference standard and a tuberculosis case, since not all of the tests might have been performed or might have a positive result. The reference standard for culture was either solid or liquid culture for M tuberculosis complex (Lawn 2011). The sensitivity of smear microscopy can be increased by examining more than one sample, using fluorescence microscopy, and using physical and chemical sputum processing techniques including centrifugation, sedimentation, and bleach (Steingart 2006a; Steingart 2006b). We therefore included studies that used any of these techniques.

The secondary (lower-quality) reference standard was clinical diagnosis of tuberculosis without microbiological confirmation. A clinically diagnosed tuberculosis case is one that has been diagnosed with active tuberculosis by a healthcare practitioner and where anti-tuberculosis therapy has subsequently been initiated. This definition lacks bacteriological confirmation but includes cases diagnosed on the basis of suggestive histology (necrotizing granulomatous inflammation), x-ray abnormalities, and extrapulmonary cases without laboratory confirmation (WHO 2017). Using clinical diagnosis as a reference standard could potentially bias test accuracy because abdominal ultrasound is often used to inform the clinical decision to treat for tuberculosis (incorporation bias). We included these studies, as incorporation bias had a small effect in diagnostic accuracy estimates (Rutjes 2006), and we used an adapted version of the revised tool for the Quality Assessment of Diagnostic Accuracy Studies (QUADAS-2).

\section{Search methods for identification of studies}

\section{Electronic searches}

Vittoria Lutje (VL), the Information Specialist for the Cochrane Infectious Diseases Group (CIDG), performed literature searches up to 4 April 2019, without language restrictions. She searched MEDLINE (PubMed, 1946 to 4 April 2019); Embase (Ovid, 1947 to 4 April 2019); Biosis (Web of Science, 1926 to 4 April 2019); Science Citation Index Expanded (SCI-EXPANDED), Social Sciences Citation Index (SSCI), both 1900 to 4 April 2019, and Conference Proceedings Citation Index- Science (CPCI-S), 1990 to 4 April 2019, (all three in the Web of Science). She also searched ClinicalTrials.gov and the WHO International Clinical Trials Registry Platform (ICTRP. apps.who.int/trialsearch/) for trials in progress. The search terms and strategy are reported in Appendix 1.

\section{Searching other resources}

We examined the reference lists of relevant reviews and studies; and searched websites of the WHO, the Stop TB Partnership, and the National Institute of Allergy and Infectious Diseases (NIAID). We also performed forward citation searching of relevant articles using the PubMed 'related articles' feature, Google Scholar, and ISI citation indices. We also contacted study authors for additional information if we deemed it necessary.

\section{Data collection and analysis}

\section{Selection of studies}

Two review authors (DJvH and RG) independently judged study eligibility by examining the title and abstract of each article identified by the literature search and excluded obviously irrelevant studies. We obtained the full-text article if either review author considered the abstract to be potentially eligible. The two review authors independently assessed each full-text article against the predefined inclusion and exclusion criteria, as stated in the 'Criteria for considering studies for this review' section. The two review authors resolved any disagreements by discussion. If the review authors could not reach consensus, a third review author (GrM) made the final decision. We maintained a list of all articles excluded after full-text assessment and their reasons for exclusion in the 'Characteristics of excluded studies' table. The study selection process is also illustrated using a PRISMA flow diagram.

\section{Data extraction and management}

We developed a standardized data extraction form before two review authors (DJvH and RG) independently extracted data. The extracted data were: 
1. Details of study: first author, publication year, journal, study design, inclusion/exclusion criteria

2. Characteristics of study population: age, gender, estimated tuberculosis prevalence in study setting; estimated HIV prevalence in study setting, antiretroviral therapy (ART) status

3. Reference standard: bacteriological, clinical

4. Index test: general (abdominal ultrasound normal or abnormal), specific (individual findings on ultrasound), training level of person performing the ultrasound, additional tests (and their results)

5. Details of outcome: number of indeterminate, missing or unavailable test results, number of TP, TN, FP, and FN results

We resolved any discrepancies in data extraction by discussion, and a third review author (GrM) had the final say.

\section{Assessment of methodological quality}

We used the revised tool for the Quality Assessment of Diagnostic Accuracy Studies (QUADAS-2) to assess the risks of bias and applicability of included studies (Whiting 2011). We tailored the tool to the context of the review, as shown in Appendix 2. Two review authors (DJvH and RG) independently assessed methodological quality using the tailored QUADAS-2 tool. We resolved any disagreements through consensus or by consulting a third review author (EAO). We present the results in graphs, text, and the 'Characteristics of included studies' table.

\section{Statistical analysis and data synthesis}

In our primary meta-analyses, we used the individual participant as the unit of analysis (that is, any abnormal finding versus none) and not individual ultrasound findings. Clinically, it is also useful to know the accuracy of individual ultrasound findings, as it is plausible that some findings are better indicators of tuberculosis than others. We therefore determined the accuracy of individual ultrasound findings in secondary analyses.

We only included studies that reported test thresholds to enable us to construct $2 \times 2$ tables and also to select an appropriate method of meta-analysis. Studies used different criteria to determine the positivity of ultrasound. For example, studies may define an ultrasound scan as positive based on the presence of any abnormal abdominal finding including (but not limited to) organ enlargement, the presence or number of hepatic or splenic lesions, or the presence or size of abdominal nodes. For the primary analysis we thus defined the threshold as the presence or absence of any abnormal lesion. In order to produce clinically meaningful results, we conducted two separate sets of primary meta-analyses by estimating the pooled sensitivity and specificity for each type of reference standard (higher quality and lower quality).

For the secondary analyses (individual lesion as unit of analysis), we did not estimate the pooled sensitivity and specificity because some studies did not report thresholds and those that did used different thresholds. We only report the range of sensitivity and specificity.

We used the number of TPs, FPs, FNs, and TNs to construct $2 x$ 2 tables using the criteria specified in the studies. We plotted the estimates of sensitivity and specificity from the included studies on forest plots using Review Manager 5 software (Review Manager 2014).
We used the bivariate model (Chu 2006) to estimate pooled sensitivity and specificity at common thresholds. We fitted the models using the xtmelogit command in Stata version 15.0 (StataCorp, College Station, TX, USA).

\section{Investigations of heterogeneity}

Potential sources of heterogeneity included the type of reference standard (higher quality versus lower quality), clinical setting (any setting versus tertiary/referral hospital), and ultrasound training level (radiologist versus non-radiologist). We stratified the primary analysis by the type of reference standard. Due to the small number of included studies and sample sizes we did not investigate other sources of heterogeneity.

\section{Sensitivity analyses}

We did not perform sensitivity analyses because of the small number of included studies.

\section{Assessment of reporting bias}

We did not carry out a formal assessment of publication bias.

\section{Assessment of the certainty of the evidence}

We used the GRADE approach (Schünemann 2016) and GRADEpro Guideline Development Tool (GDT) software (GRADEpro GDT 2015) to assess the certainty of the evidence (also called the quality of the evidence). We rated the certainty of the evidence as either high (not downgraded), moderate (downgraded by one level), low (downgraded by two levels), or very low (downgraded by more than two levels) for five domains: risk of bias, indirectness, inconsistency, imprecision, and publication bias. For each domain, the certainty of evidence started as high if there were highquality observational studies (cross-sectional or cohort studies) that enrolled participants with diagnostic uncertainty. We used our judgement to classify the reason for downgrading as either serious (downgraded by one level) or very serious (downgraded by two levels).

Two review authors (DJvH and RG) discussed judgements and applied GRADE in the following way.

Risk of bias: we used the tailored QUADAS-2 to assess risks of bias.

Indirectness: we used the tailored QUADAS-2 for concerns of applicability and evaluated the studies for important differences between the populations studied (for example, age) and the setting. We made judgements on whether the differences were sufficient to lower our certainty in the results.

Inconsistency: we downgraded the certainty of the evidence for unexplained inconsistency in sensitivity and specificity estimates.

Imprecision: we considered a point estimate to be substantially different if it would alter a clinical decision. We considered the width of the $\mathrm{Cl}$, and whether a different clinical decision would be made if the lower or upper boundary of the $\mathrm{Cl}$ represented the truth. We also made judgements on the imprecision of projected ranges for TP, FN, TN, and FP for a given prevalence of tuberculosis.

Publication bias: as recommended, we did not downgrade the certainty of evidence for publication bias for the following reasons (Schünemann in press). We did not detect studies done for-profit interest. Included studies had small sample sizes and accuracy

Abdominal ultrasound for diagnosing abdominal tuberculosis or disseminated tuberculosis with abdominal involvement in HIV-positive 
estimates were low and imprecise. We did an extensive search in electronic databases and grey literature and did not identify completed studies that were unpublished. We only identified one ongoing study, the results of which are not yet registered in the Pan African Clinical Trials Registry (Trial ID: PACTR201712002829221) (PACTR201712002829221).

\section{RESULT S}

\section{Results of the search}

Our search yielded 1129 records. We identified two additional studies through contact with experts. After we removed one duplicate, we had 1130 records. We excluded 1089 records based on a review of title, abstract, or both. We retrieved 41 full-text articles and excluded 30 studies for the following reasons: descriptive study (22 studies); ineligible participant population (2 studies); no reference standard reported (2 studies); ineligible index test evaluated ( 1 study); only abnormal index test reported ( 2 studies); and not a diagnostic accuracy study (1 study). We therefore include 11 unique studies in this review (Barreiros 2008-h; Bobbio 2019l; Dominguez-Castellano 1998-h; Griesel 2019-h; Kaneria 2009-l; Monill-Serra 1997-l; Ndege 2019-h; O'Keefe 1998-h; Sculier 2010-h; Sinkala 2009-l; Weber 2018-h). We listed the excluded studies and reasons for their exclusion in the Characteristics of excluded studies section. Figure 2 shows the flow of studies through the screening process.

Figure 2. Study flow diagram.

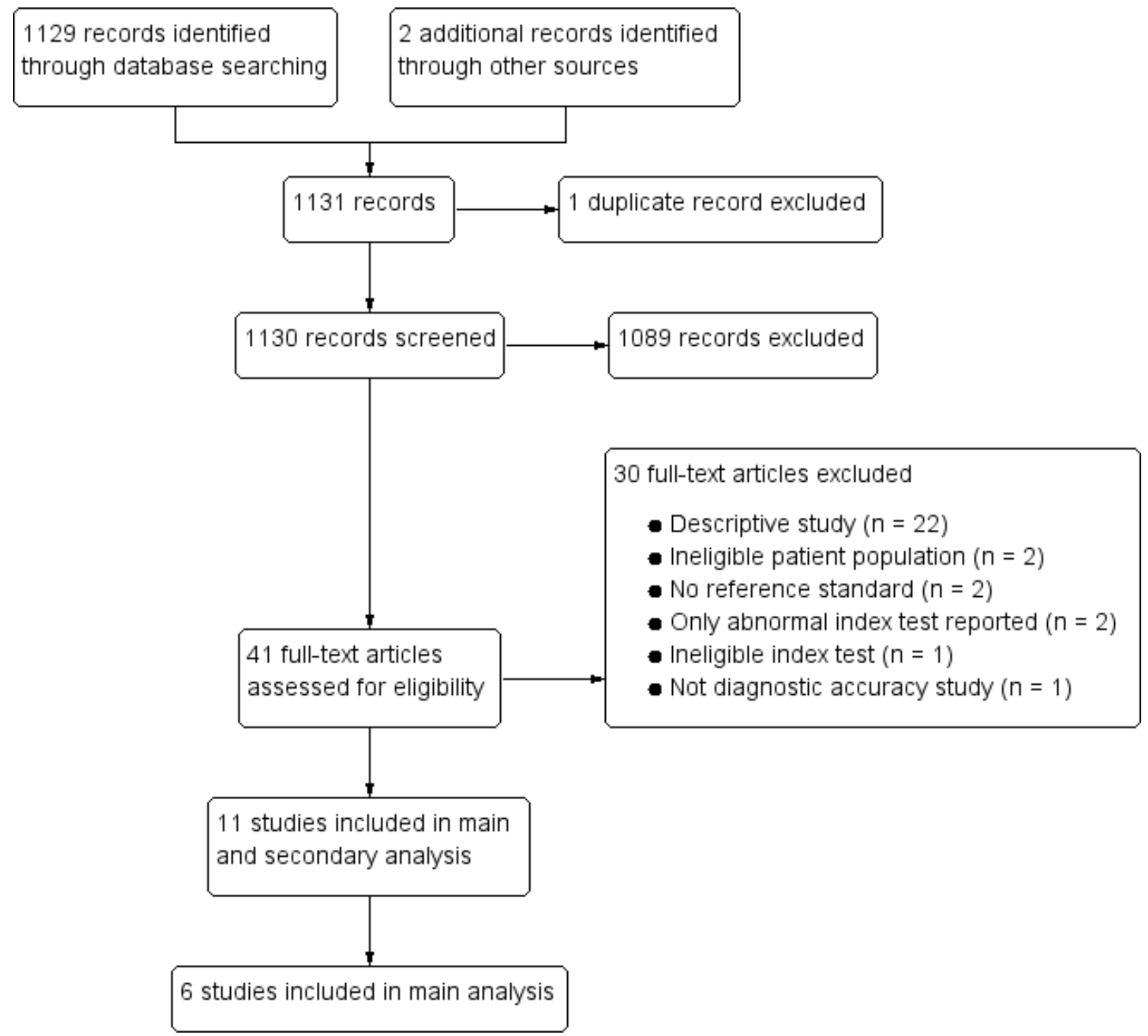

Three studies were conducted in low-income countries, three in lower-middle-income countries, two in upper-middle-income countries, and three in high-income countries. We noted poor reporting on the estimated prevalence of tuberculosis and HIV in study setting, qualification of sonographer and setting in which ultrasound was performed. Studies used different criteria to determine the positivity of ultrasound (see Characteristics of

Abdominal ultrasound for diagnosing abdominal tuberculosis or disseminated tuberculosis with abdominal involvement in HIV-positive

Copyright (c) 2019 The Authors. Cochrane Database of Systematic Reviews published by John Wiley \& Sons, Ltd. on behalf of The Cochrane Collaboration. 
included studies section). Key findings of included studies are presented in Table 1 and Table 2.

We contacted the authors of all 11 studies, of whom five responded. We received unpublished data from four studies (Weber 2018h; Bobbio 2019-l; Griesel 2019-h; Ndege 2019-h), and one study clarified the qualification of the sonographer (O'Keefe 1998-h).

\section{Methodological quality of included studies}

We present the results of the methodological assessment of the 11 studies in Figure 3. The results are reported below separately for studies included in the primary analyses (any abnormal finding) and those included in the secondary analyses (individual lesions). Studies that used a higher-quality reference standard are indicated with the suffix ' $h$ ' and studies that used a lower-quality reference standard are indicated with the suffix ' $l$ '.

Figure 3. Risk of bias and applicability concerns summary: review authors' judgements about each domain for each included study. Suffix $(\mathrm{h})$ indicates higher quality reference standard; suffix $(\mathrm{l})$ indicates lower quality reference standard.

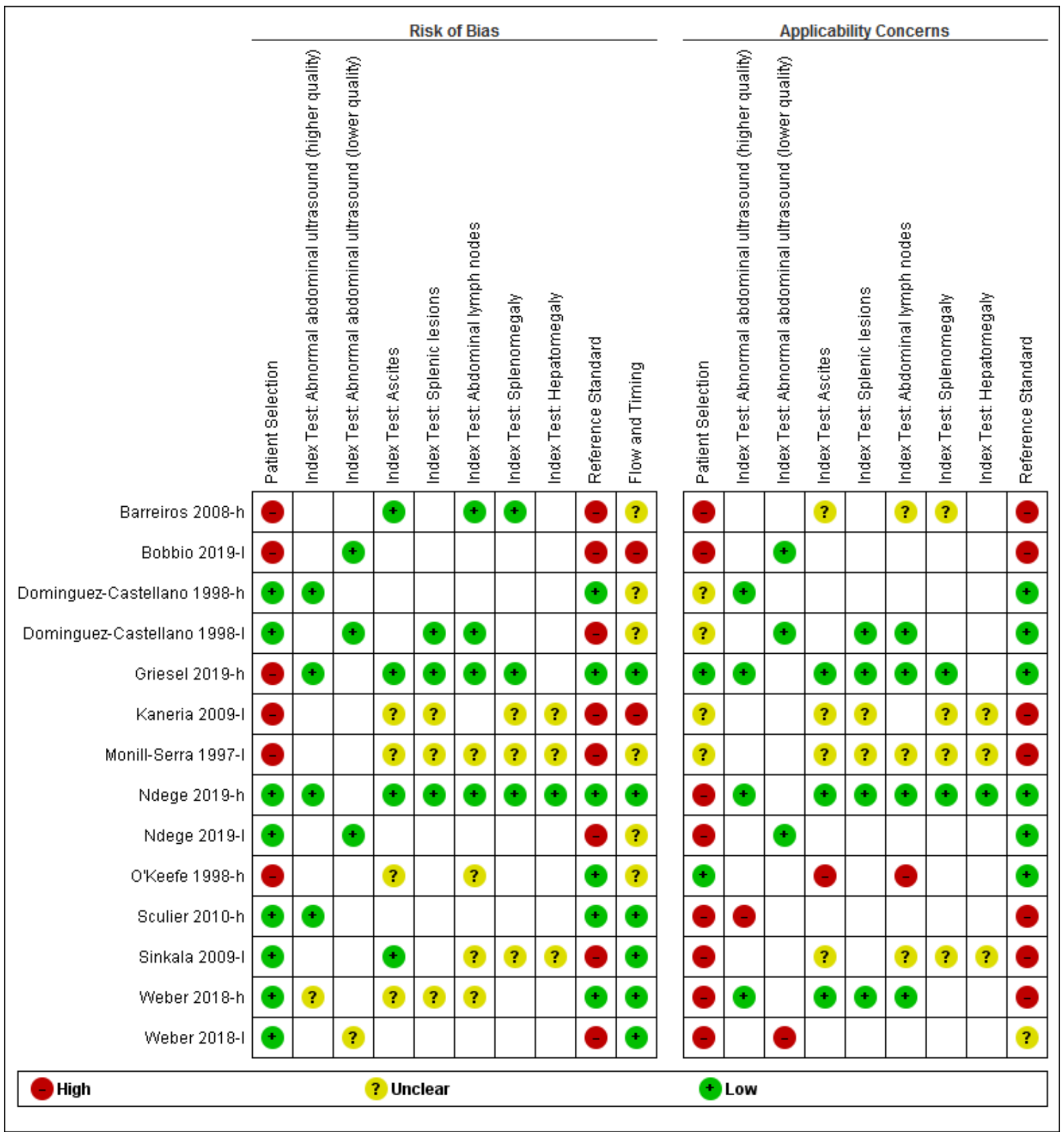

Abdominal ultrasound for diagnosing abdominal tuberculosis or disseminated tuberculosis with abdominal involvement in HIV-positive 


\section{Studies of any abnormal finding included in primary analyses}

Six studies with a higher-level reference standard contributed data (Figure 3). One study was considered to be at high risk of bias in the patient selection domain since it excluded people unable to produce sputum (Griesel 2019-h). Concerns about applicability (i.e. are there concerns that the included participants do not match the review question?) were deemed high in four studies, since they included asymptomatic people (Sculier 2010-h; Bobbio 2019-l) or were conducted in a referral or tertiary setting (Sculier 2010-h; Weber 2018-h; Bobbio 2019-l; Ndege 2019-h). One study was deemed of unclear concern as the setting in which the ultrasound was done was not reported (Dominguez-Castellano 1998-h). In the index test domain, we considered one study to be at unclear risk of bias because, although the study did specify thresholds for positivity, the test was sometimes interpreted with knowledge of the results of the reference standard (Weber 2018h). We considered the conduct and interpretation of the index test to be of high concern for applicability in one study where the ultrasound was performed by a trained radiologist (Sculier 2010-h). In the reference standard domain, all studies used a higher-quality reference standard (microbiological confirmation). We regarded two studies as being of high concern for applicability, as neither study speciated mycobacteria isolated in culture (Sculier 2010-h; Weber 2018-h). For the flow and timing domain, we considered one study to be at unclear risk of bias because the study did not report the interval between the index test and the reference standard, and it was unclear if all participants received the same reference standard (Dominguez-Castellano 1998-h).

For the main analyses (abnormal versus normal ultrasound examination), four studies with a lower-level reference standard contributed data (Figure 3). We considered one study to be at high risk of bias in the patient selection domain because it did not enrol participants consecutively or randomly (Bobbio 2019-l). Concerns about applicability (i.e. are there concerns that the included participants do not match the review question?) were deemed high in three studies since they included asymptomatic participants (Bobbio 2019-l), or the study was conducted in a referral or tertiary setting (Weber 2018-l; Bobbio 2019-l; Ndege 2019-l). We rated one study at unclear concern as the setting in which the ultrasound was done was not reported (Dominguez-Castellano 1998-I). In the index test domain, we considered one study to be at unclear risk of bias because the index test was sometimes interpreted with knowledge of the results of the reference standard (Weber 2018-l). In the reference standard domain, we considered all studies to be at high risk of bias because the studies included a lower-quality reference standard (clinical diagnosis) (Dominguez-Castellano 1998-l; Weber 2018--; Bobbio 2019-I; Ndege 2019-I). We rated one study at unclear concern for applicability since it is unclear whether all clinically diagnosed participants improved on anti-tuberculosis treatment (Weber 2018-l). In terms of the flow and timing domain, we considered one study to be at unclear risk of bias because the study did not report the interval between the index test and the reference standard, and it was unclear if all participants received the same reference standard (Dominguez-Castellano 1998-l). We judged one study to be at high risk of bias because not all participants received a reference standard and not all participants received the same reference standard (Bobbio 2019-I).

\section{Studies of individual lesions included in secondary analyses}

Nine studies contributed data (Figure 3). In the patient selection domain, we deemed five studies (56\%) to be at high risk of bias because: i) three studies used a case-control design (Monill-Serra 1997-l; Barreiros 2008-h Kaneria 2009-l); ii) one study excluded patients with a CD4 cell count of 200 or more (O'Keefe 1998-h); and iii) one study excluded patients unable to produce sputum (Griesel 2019-h). For applicability, we judged four studies (44\%) to be at high concern since one study included HIV-negative participants (Barreiros 2008-h), and the ultrasound examination was performed in a tertiary or referral centre in three studies (Sinkala 2009-l; Weber 2018-h; Ndege 2019-h). We rated three studies at unclear concern as the setting in which the ultrasound was done was not reported (Monill-Serra 1997-l; DominguezCastellano 1998-l; Kaneria 2009-l). In the index test domain we judged five studies $(56 \%)$ to be at unclear risk of bias because four studies did not specify (or it was unclear) whether index test results were interpreted without knowledge of the results of the reference standard (Monill-Serra 1997-l; O'Keefe 1998-h; Kaneria 2009-l; Weber 2018-h), and three studies did not report prespecified thresholds (O'Keefe 1998-h; Kaneria 2009-l; Sinkala 2009-I). We considered the conduct and interpretation of the index test to be of high concern for applicability in one study where the ultrasound was performed by a trained radiologist (O'Keefe 1998h); we rated four studies at unclear concern since we were not able to make a decision on the qualification of the person performing the index tests (Monill-Serra 1997-l; Barreiros 2008-h; Kaneria 2009l; Sinkala 2009-l). Five studies (56\%) used a lower-quality reference standard and were deemed at high risk of bias in the reference standard domain (Monill-Serra 1997-l; Dominguez-Castellano 1998l; Barreiros 2008-h; Kaneria 2009-l; Sinkala 2009-l). We rated five studies at high concern for applicability for the reference standard since mycobacteria isolated in culture were not speciated (MonillSerra 1997-l; Barreiros 2008-h; Kaneria 2009-l; Sinkala 2009-l; Weber 2018-h). For the flow and timing domain, we considered one study to be at high risk of bias because not all participants received a reference standard and not all participants received the same reference standard (Kaneria 2009-l). Four studies were deemed to be at unclear risk of bias since: i) three studies did not report the interval between the index test and the reference standard, and it was unclear if all participants received the same reference standard (Monill-Serra 1997-l; Dominguez-Castellano 1998-l; Barreiros 2008h); and ii) one study did not report the interval between the index test and the reference standard, and not all participants received the same reference standard (O'Keefe 1998-h).

\section{Findings}

For the diagnostic accuracy of abdominal ultrasound (main and secondary analyses), the 11 studies included 1319 participants. The median number of participants in the studies was 100 (interquartile range (IQR) 58 to 134). The proportion of tuberculosis cases in the non-case-control studies ranged from $17.5 \%$ (Sculier 2010-h) to $71.0 \%$ (Sinkala 2009-I), median $40.6 \%$ (IQR 27.5 to 53.7). Table 1 present key characteristics for each of the 11 studies. Three studies used a case-control design (Monill-Serra 1997-l; Barreiros 2008-h; Kaneria 2009-l) and eight studies used cross-sectional or cohort design (Dominguez-Castellano 1998-h; O'Keefe 1998-h; Sinkala 2009-l; Sculier 2010-h; Weber 2018-h; Bobbio 2019-l; Griesel 2019-h; Ndege 2019-h). Eight studies (73\%) were conducted in lowincome or middle-income countries, while the remaining three

Abdominal ultrasound for diagnosing abdominal tuberculosis or disseminated tuberculosis with abdominal involvement in HIV-positive 14 individuals (Review)

Copyright (C) 2019 The Authors. Cochrane Database of Systematic Reviews published by John Wiley \& Sons, Ltd. on behalf of The Cochrane Collaboration. 
studies were conducted in high-income countries. Results of the primary and secondary analyses are summarized in Table 3.

\section{Any abnormal abdominal ultrasound finding for tuberculosis detection}

We included six of the 11 studies in the primary analyses (Dominguez-Castellano 1998-h; Dominguez-Castellano 1998-l; Sculier 2010-h; Weber 2018-h; Weber 2018-l; Bobbio 2019-l; Griesel 2019-h; Ndege 2019-h; Ndege 2019-l); three studies provided data for each type of reference standard.

Five studies (879 participants) used a higher-quality reference standard (Dominguez-Castellano 1998-h; Sculier 2010-h; Weber 2018-h; Griesel 2019-h; Ndege 2019-h). Study estimates of sensitivity and specificity ranged from $35 \%$ to $82 \%$ and from $20 \%$ to $92 \%$. The pooled sensitivity and specificity were $63 \%(95 \% \mathrm{Cl} 43 \%$ to $79 \%$ ) and $68 \%(95 \% \mathrm{Cl} 42 \%$ to $87 \%)$, respectively (Figure 4).

Figure 4. Forest plot of abdominal ultrasound for detecting abdominal TB or disseminated TB with abdominal involvement. $T P=$ true positive; $F P=$ false positive; $F N=$ false negative; $T N=$ true negative. Suffix (h) indicates higher quality reference standard; suffix $(\mathrm{l})$ indicates lower quality reference standard.

Abnormal abdominal ultrasound (higher quality)

$\begin{array}{lrrrrrr}\text { Study } & \text { TP } & \text { FP } & \text { FN } & \text { TN } & \text { Sensitivity }(95 \% \text { Cl) } & \text { Specificity (95\% Cl) } \\ \text { Griesel 2019-h } & 164 & 68 & 37 & 108 & 0.82[0.76,0.87] & 0.61[0.54,0.69] \\ \text { Ndege 2019-h } & 37 & 43 & 9 & 11 & 0.80[0.66,0.91] & 0.20[0.11,0.34] \\ \text { Weber 2018-h } & 16 & 17 & 8 & 40 & 0.67[0.45,0.84] & 0.70[0.57,0.82] \\ \text { Sculier 2010-h } & 15 & 14 & 22 & 161 & 0.41[0.25,0.58] & 0.92[0.87,0.96] \\ \text { Dominguez-Castellano 1998-h } & 21 & 10 & 39 & 39 & 0.35[0.23,0.48] & 0.80[0.66,0.90]\end{array}$

Abnormal abdominal ultrasound (lower quality)

$\begin{array}{lrrrrrr}\text { Study } & \text { TP } & \text { FP } & \text { FN } & \text { TN } & \text { Sensitivity (95\% Cl) } & \text { Specificity (95\% Cl) } \\ \text { Bobbio 2019-I } & 21 & 6 & 3 & 70 & 0.88[0.68,0.97] & 0.92[0.84,0.97] \\ \text { Ndege 2019-I } & 52 & 28 & 12 & 8 & 0.81[0.70,0.90] & 0.22[0.10,0.39] \\ \text { Weber 2018-I } & 24 & 9 & 16 & 32 & 0.60[0.43,0.75] & 0.78[0.62,0.89] \\ \text { Dominguez-Castellano 1998-I } & 25 & 10 & 42 & 39 & 0.37[0.26,0.50] & 0.80[0.66,0.90]\end{array}$
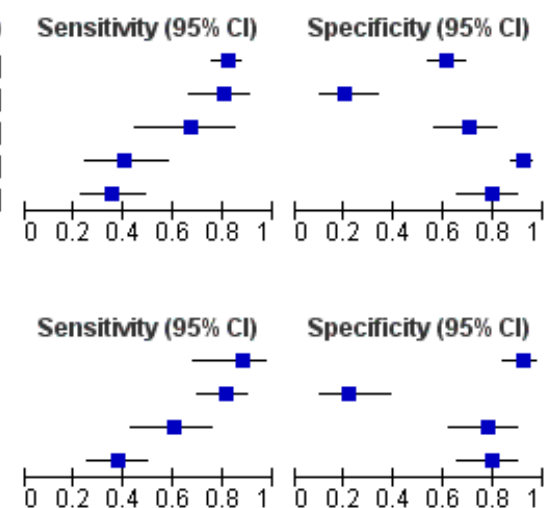

Four studies (397 participants) used a lower-quality reference standard (Dominguez-Castellano 1998-l; Weber 2018-l; Bobbio 2019-l; Ndege 2019-I). Sensitivity estimates ranged from $37 \%$ to $88 \%$ and specificity estimates ranged from $22 \%$ to $92 \%$ (Figure 4 ). The pooled sensitivity and specificity were $68 \%$ (95\% Cl $45 \%$ to $85 \%)$ and $73 \%(95 \% \mathrm{Cl} 41 \%$ to $91 \%)$, respectively.

\section{Splenic lesions on abdominal ultrasound for tuberculosis detection}

We included six studies involving 916 participants, of whom 477 had tuberculosis (Monill-Serra 1997-l; Dominguez-Castellano 1998l; Kaneria 2009-l; Weber 2018-h; Griesel 2019-h; Ndege 2019-h). Sensitivity estimates were very heterogeneous and ranged from $13 \%$ to $62 \%$. Specificity estimates were less heterogeneous and ranged from $86 \%$ to $100 \%$ (Figure 5). 
Figure 5. Forest plot of individual findings on ultrasound for detecting abdominal TB or disseminated TB with abdominal involvement. TP = true positive; $F P=$ false positive; $F N=$ false negative; $T N=$ true negative. Suffix (h) indicates higher quality reference standard; suffix $(l)$ indicates lower quality reference standard.

Ascites

Stucly

Sinkala 2009-I

Ndege 2019-h

o'Keefe 1998-h

Kaneria 2009-I

Barreiros 2008-h

Griesel 2019-h

Monill-Serra 1997-I

Weber 2018-h

Splenic lesions

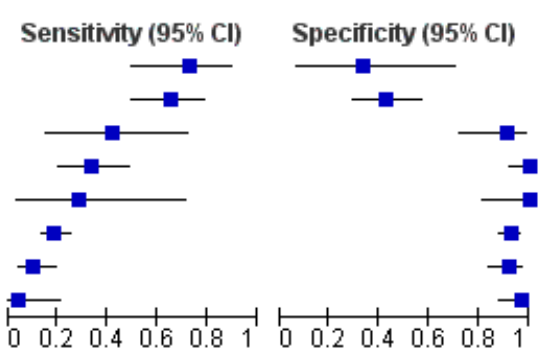

\section{Study}

Kaneria 2009-I

Griesel 2019-h

Dominguez-Castellano 1998-I

Weber 2018-h

Monill-Serra 1997-I

Ndege 2019-h

$\begin{array}{rrrrr}\text { TP } & \text { FP } & \text { FN } & \text { TN } & \text { Sensitivity }(95 \% \text { Cl) } \\ 16 & 6 & 6 & 3 & 0.73[0.50,0.89] \\ 30 & 31 & 16 & 23 & 0.65[0.50,0.79] \\ 5 & 2 & 7 & 21 & 0.42[0.15,0.72] \\ 15 & 0 & 30 & 45 & 0.33[0.20,0.49] \\ 2 & 0 & 5 & 18 & 0.29[0.04,0.71] \\ 38 & 13 & 163 & 163 & 0.19[0.14,0.25] \\ 8 & 6 & 68 & 70 & 0.11[0.05,0.20] \\ 1 & 2 & 23 & 55 & 0.04[0.00,0.21]\end{array}$

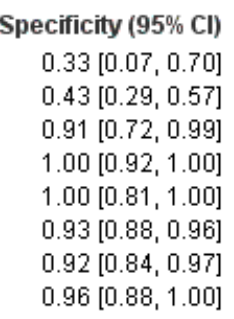

$0.96[0.88,1.00]$

Abdominal lymph nodes

\begin{tabular}{|c|c|c|c|c|c|c|c|c|c|}
\hline \multicolumn{3}{|l|}{ Stucly } & TP & FP & \multicolumn{2}{|c|}{ FN TN } & \multicolumn{2}{|c|}{ Sensitivity (95\% CI) } & Specificit \\
\hline \multicolumn{3}{|l|}{ Barreiros 2008-h } & & 7 & 1 & 11 & \multicolumn{2}{|c|}{$0.86[0.42,1.00]$} & \\
\hline \multicolumn{3}{|l|}{ O'Keefe 1998-h } & 8 & 2 & 4 & 21 & \multicolumn{2}{|c|}{$0.67[0.35,0.90]$} & \\
\hline \multicolumn{3}{|l|}{ Weber 2018-h } & 14 & 411 & 10 & 46 & \multicolumn{2}{|c|}{$0.58[0.37,0.78]$} & \\
\hline \multicolumn{3}{|l|}{ Griesel 2019-h } & 105 & $5 \quad 23$ & 96 & 153 & \multicolumn{2}{|c|}{$0.52[0.45,0.59]$} & \\
\hline \multicolumn{3}{|l|}{ Sinkala 2009-I } & $g$ & 4 & 13 & 5 & \multicolumn{2}{|c|}{$0.41[0.21,0.64]$} & \\
\hline \multicolumn{3}{|l|}{ Monill-Serra 1997-I } & 27 & 0 & 49 & 76 & \multicolumn{2}{|c|}{$0.36[0.25,0.47]$} & \\
\hline \multicolumn{3}{|l|}{ Ndege 2019-h } & 14 & 6 & 32 & 48 & \multicolumn{2}{|c|}{$0.30[0.18,0.46]$} & \\
\hline \multicolumn{3}{|c|}{ Dominguez-Castellano 1998-I } & 15 & 8 & 52 & 41 & \multicolumn{2}{|c|}{$0.22[0.13,0.34]$} & \\
\hline \multicolumn{10}{|l|}{ Splenomegaly } \\
\hline Study & TP & FP & FN & TN & \multicolumn{3}{|c|}{ Sensitivity (95\% Cl) } & \multicolumn{2}{|c|}{ Specificity (95\% Cl) } \\
\hline Kaneria 2009-I & 28 & 12 & 17 & 33 & \multicolumn{3}{|c|}{$0.62[0.47,0.76]$} & \multicolumn{2}{|c|}{$0.73[0.58,0.85]$} \\
\hline Monill-Serra 1997-I & 45 & 42 & 31 & 34 & \multicolumn{3}{|c|}{$0.59[0.47,0.70]$} & \multicolumn{2}{|c|}{$0.45[0.33,0.57]$} \\
\hline Ndege 2019-h & 18 & 18 & 28 & 36 & \multicolumn{3}{|c|}{$0.39[0.25,0.55]$} & \multicolumn{2}{|c|}{$0.67[0.53,0.79$} \\
\hline Griesel 2019-h & 47 & 20 & 154 & 156 & \multicolumn{3}{|c|}{$0.23[0.18,0.30]$} & \multicolumn{2}{|c|}{$0.89[0.83,0.93]$} \\
\hline Barreiros 2008-h & 1 & 9 & 6 & 9 & \multicolumn{3}{|c|}{$0.14[0.00,0.58]$} & \multicolumn{2}{|c|}{$0.50[0.26,0.74]$} \\
\hline Sinkala 2009-I & 1 & 1 & 21 & 8 & \multicolumn{3}{|c|}{$0.05[0.00,0.23]$} & $0.89[0$ & $52,1.00$ \\
\hline
\end{tabular}

TP FP FN TN Sensitivity $(95 \% \mathrm{Cl})$ Specificity $(95 \% \mathrm{Cl})$ $\begin{array}{llllll}28 & 5 & 17 & 40 & 0.62[0.47,0.76] \quad 0.89[0.76,0.96]\end{array}$ $\begin{array}{llllll}113 & 25 & 88 & 151 & 0.56[0.49,0.63] & 0.86[0.80,0.91]\end{array}$ $\begin{array}{llllll}20 & 4 & 47 & 45 & 0.30[0.19,0.42] & 0.92[0.80,0.98]\end{array}$ $\begin{array}{llllll}7 & 6 & 17 & 51 & 0.29[0.13,0.51] & 0.89[0.78,0.96]\end{array}$ $\begin{array}{llllll}11 & 0 & 65 & 76 & 0.14[0.07,0.24] & 1.00[0.95,1.00]\end{array}$ $8 \quad 0 \quad 56 \quad 36 \quad 0.13[0.06,0.23] \quad 1.00[0.90,1.00]$

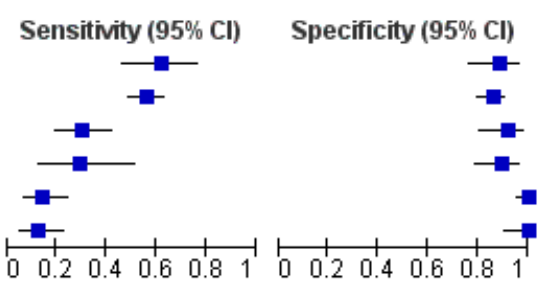

Hepatomegaly

$\begin{array}{lrrrrrr}\text { Study } & \text { TP } & \text { FP } & \text { FN } & \text { TN } & \text { Sensitivity }(95 \% \text { CI) } & \text { Specificity (95\% Cl) } \\ \text { Monill-Serra 1997-I } & 58 & 61 & 18 & 15 & 0.76[0.65,0.85] & 0.20[0.11,0.30] \\ \text { Ndege 2019-h } & 30 & 31 & 16 & 23 & 0.65[0.50,0.79] & 0.43[0.29,0.57] \\ \text { Sinkala 2009-I } & 8 & 2 & 14 & 7 & 0.36[0.17,0.59] & 0.78[0.40,0.97] \\ \text { Kaneria 2009-I } & 11 & 12 & 34 & 33 & 0.24[0.13,0.40] & 0.73[0.58,0.85]\end{array}$

ficity $(95 \% \mathrm{Cl})$ $0.61[0.36,0.83]$ $0.91[0.72,0.99]$ $0.81[0.68,0.90]$ $0.87[0.81,0.92]$ $0.56[0.21,0.86]$ $1.00[0.95,1.00]$ $0.89[0.77,0.96]$ $0.84[0.70,0.93]$

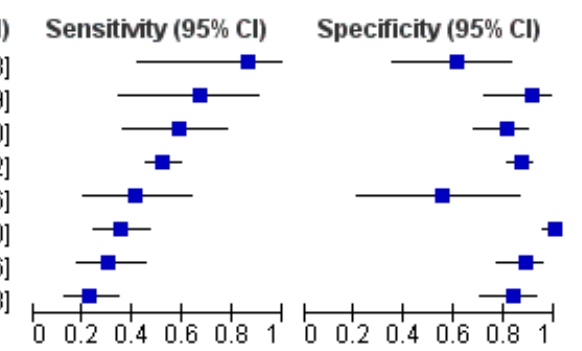

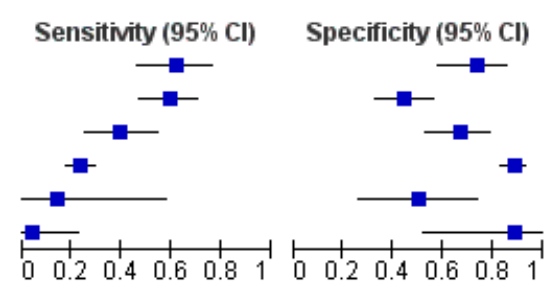

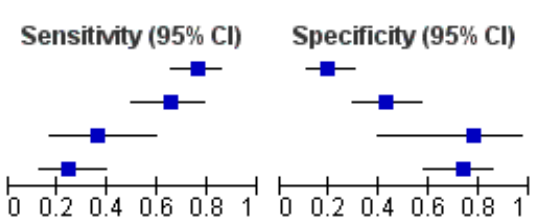

III. Intra-abdominal lymph nodes on abdominal ultrasound for tuberculosis detection

Eight studies involving 917 participants (included 455 tuberculosis cases) reported on intra-abdominal lymph nodes on abdominal ultrasound (Monill-Serra 1997-l; Dominguez-Castellano 1998-l; O'Keefe 1998-h; Barreiros 2008-h; Sinkala 2009-l; Weber 2018-h;
Griesel 2019-h; Ndege 2019-h). The sensitivities ranged from 22\% to $86 \%$ and specificities from $56 \%$ to $100 \%$ (Figure 5).

\section{Ascites on abdominal ultrasound for tuberculosis detection}

We included eight studies involving 891 participants, of whom 433 had tuberculosis (Monill-Serra 1997-l; O'Keefe 1998-h; Barreiros 2008-h; Kaneria 2009-l; Sinkala 2009-l; Weber 2018-h; Griesel 2019-

Abdominal ultrasound for diagnosing abdominal tuberculosis or disseminated tuberculosis with abdominal involvement in HIV-positive 16 individuals (Review)

Copyright (c) 2019 The Authors. Cochrane Database of Systematic Reviews published by John Wiley \& Sons, Ltd. on behalf of The Cochrane Collaboration. 
h; Ndege 2019-h). Sensitivity and specificity estimates were very heterogeneous and ranged from $4 \%$ to $73 \%$ and from $33 \%$ to $100 \%$ respectively (Figure 5).

\section{Splenomegaly}

Six studies (775 participants, 397 tuberculosis cases) reported splenomegaly (Monill-Serra 1997-l; Barreiros 2008-h; Kaneria 2009l; Sinkala 2009-l; Griesel 2019-h; Ndege 2019-h). Estimates were very heterogeneous and ranged from $5 \%$ to $62 \%$ for sensitivity and $45 \%$ to $89 \%$ for specificity (Figure 5 )

\section{Hepatomegaly}

Four studies ( 373 participants, of whom 189 had tuberculosis) were included for hepatomegaly. The sensitivity ranged from $24 \%$ to $76 \%$ and specificity from $20 \%$ to $78 \%$ (Figure 5 ).

\section{Investigations of heterogeneity}

We did not investigate heterogeneity, due to limited data.

\section{DISCUSSION}

This systematic review of the diagnostic accuracy of abdominal ultrasound for diagnosing abdominal tuberculosis or disseminated tuberculosis with abdominal involvement in HIV-positive individuals summarizes the current literature and includes 11 studies. Six studies reported on abdominal ultrasound with any abnormal finding, and nine studies reported on individual ultrasound findings. Studies were conducted in low-, middle- and high-income countries. Five studies were performed in referral or tertiary-level healthcare facilities, and in four studies the ultrasound examinations were performed by radiologists.

\section{Summary of main results}

We have summarized the main results in Summary of findings 1. An abdominal ultrasound with any abnormal finding had a pooled sensitivity of $63 \%(95 \% \mathrm{Cl} 43 \%$ to $79 \%)$ and a pooled specificity of $68 \%(95 \% \mathrm{Cl} 42 \%$ to $87 \%)$ when bacteriological confirmation was used as the (higher-quality) reference standard. The pooled sensitivity was $68 \%(95 \% \mathrm{Cl} 45 \%$ to $85 \%)$ and the pooled specificity was $73 \%(95 \% \mathrm{Cl} 41 \%$ to $91 \%)$ when the reference standard was clinical diagnosis without microbiological confirmation (lowerquality reference standard).

The sensitivity of abdominal ultrasound is of concern, due to the high chance of missing tuberculosis cases (high false negative rate). This means that HIV-positive individuals who have tuberculosis may be wrongly classified as not having tuberculosis, with a delay in initiating appropriate treatment. Ultrasound examination is operator-dependent and subjective, with the possibility of missing subtle signs. Ultrasound also evaluates anatomical changes, and abnormalities might not occur in individuals with advanced immunosuppression.

The effect of the type of reference standard used is reflected in the improvement in both the sensitivity and specificity in the lower-quality reference standard group. The primary concern with a lower-quality reference standard (clinical diagnosis) is that clinicians may overdiagnose tuberculosis for fear of missing or delaying a diagnosis that could result in excess morbidity and mortality, particularly among HIV-postive adults. This would result in an overestimation of the diagnostic accuracy of abdominal ultrasound, as fewer false positive and negative results would occur. In addition, in studies where abdominal ultrasound is part of the reference standard, incorporation bias would further result in an overestimation of diagnostic accuracy.

The estimates of sensitivity for the primary and secondary analyses were low and very heterogeneous. This means that a negative abdominal ultrasound should not be used to rule out abdominal tuberculosis or disseminated tuberculosis with abdominal involvement.

Specificity estimates were very heterogeneous, especially for hepatomegaly and splenomegaly.

\section{Application of the main meta-analytic findings to a hypothetical cohort}

The main findings of the review were illustrated by applying the results to a hypothetical cohort of 1000 HIV-positive individuals thought to have tuberculosis. We presented different scenarios where the tuberculosis prevalence varies from $10 \%$ to $20 \%$ to $40 \%$. The consequences of false positive results are probably unnecessary initiation of treatment, additional testing with subsequent morbidity, patient anxiety, and possible delay in further diagnostic evaluation. The consequences of false negative results are the continued risk of community transmission of tuberculosis and an increased risk of patient morbidity and mortality.

If the pooled estimates (from using a higher-quality reference standard) for an abdominal ultrasound with any abnormal finding are applied to a hypothetical cohort of $1000 \mathrm{HIV}$-positive individuals where $100(10 \%)$ of them actually have tuberculosis, abdominal ultrasound would be expected to miss 37 tuberculosis cases and falsely diagnose 288 people as tuberculosis cases (Summary of findings 1). For a prevalence of $20 \%$ (200 tuberculosis cases), 74 tuberculosis cases will be missed and 256 people will be falsely diagnosed as having tuberculosis (Figure 6) while for a prevalence of $40 \%$ (400 tuberculosis cases), 148 tuberculosis cases will be missed and 192 people will be falsely diagnosed as having tuberculosis (Summary of findings 1 ). 
Figure 6. Flow diagram summarizing the main results in hypothetical cohort with TB prevalence $20 \%$
Imaginary cohort
Ultrasound result
Actual diagnosis
Implications

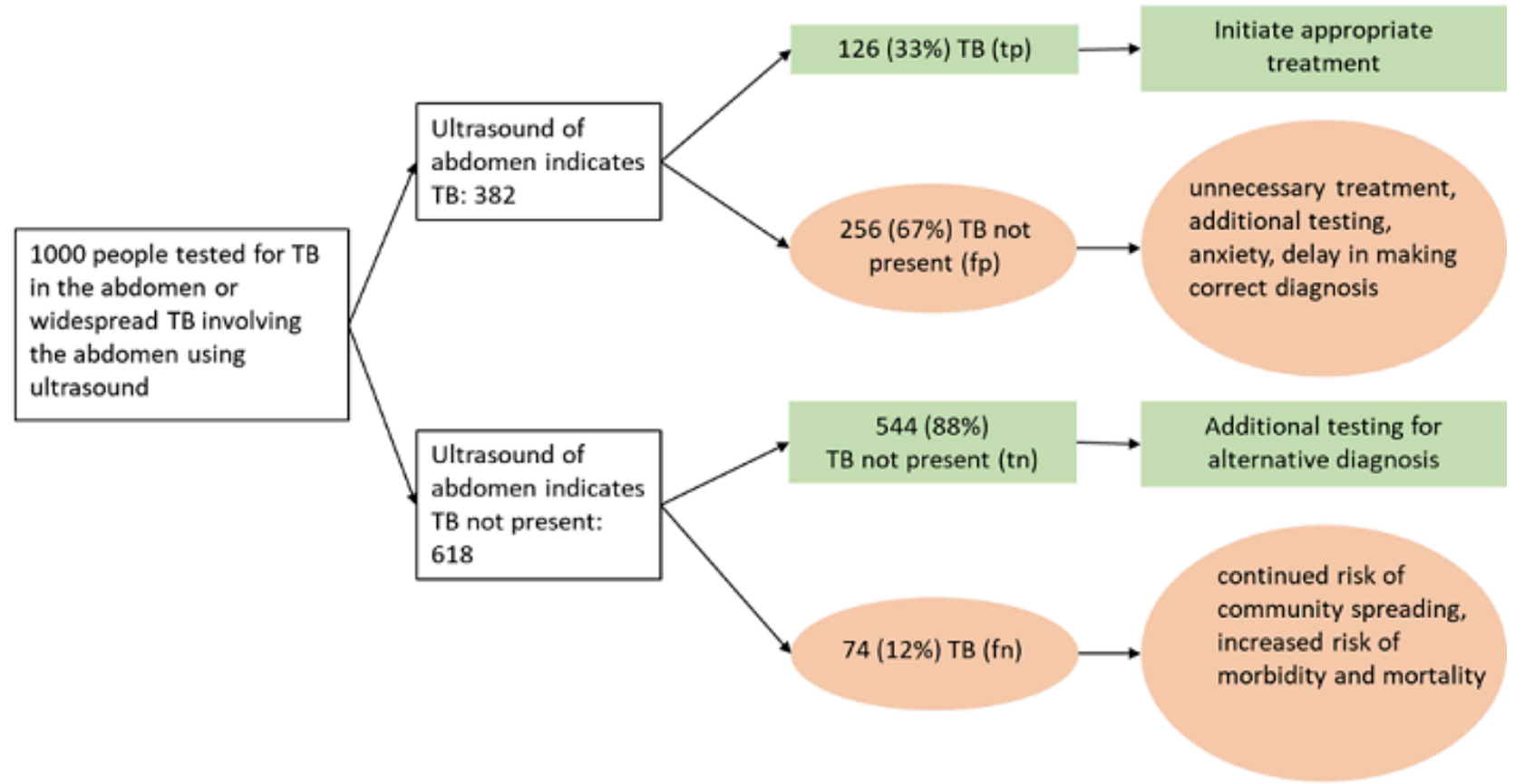

tp: true positive - test is positive (indicates TB) and patient has TB

$\mathrm{fp}$ : false positive - test is positive (indicates TB) but patient does not have TB

tn: true negative - test is negative (indicates TB not present) and patient dies not have TB

Fn: false negative - test is negative (indicates TB not present) but patient has TB

\section{Strengths and weaknesses of the review}

The findings in this review are based on comprehensive literature searches, strict inclusion criteria, and standardized data extraction. The search included studies published in all languages and we corresponded with study authors to obtain additional and unpublished data. However, as diagnostic accuracy studies are poorly indexed, we acknowledge that we may have missed some studies despite the comprehensive search.

The main limitations of the review were the small number of studies and participants included in the analyses. The results were very heterogeneous with a high false negative rate, and should therefore be interpreted with caution. The high risks of bias in the patient selection domain and the reference standard domain further weaken our confidence in the results. A further limitation in the reference standard was the use of microscopic identification of acid-fast bacilli on stained sputum smears. Although smear positivity has high specificity in high tuberculosis prevalence settings, it is not a perfect reference standard as smear will also detect non-tuberculous mycobacteria, which are found in a higher proportion in low-prevalence tuberculosis settings.

\section{Applicability of findings to the review question}

We had high concern about the applicability of the included studies to our review question. We foresee that in clinical practice abdominal ultrasound to diagnose abdominal tuberculosis or disseminated tuberculosis with abdominal involvement in HIV- positive individuals would be most beneficial when performed by non-radiologists in non-tertiary endemic settings. Most studies were performed in tertiary settings with trained radiologists or sonographers performing the ultrasound examination, and it is possible that the accuracy of abdominal ultrasound may be lower when performed in a different setting or by less experienced users. The predictive values of any diagnostic test are influenced by disease prevalence, so the inclusion of studies performed in low tuberculosis-burden countries would have decreased the positive predictive value of abdominal ultrasound. Two studies included HIV-positive participants without a clinical suspicion of tuberculosis. In these studies, abdominal ultrasound has been used as a screening test and not a diagnostic test. This will further affect the diagnostic accuracy of abdominal ultrasound and increase the risk of inappropriate additional testing and initiation of antituberculous treatment. Studies were carried out under research conditions, and it is possible that the diagnostic accuracy of abdominal ultrasound might be lower in routine practice.

\section{AUTHORS' CONCLUSIONS}

\section{Implications for practice}

Abdominal ultrasound had a sensitivity of $63 \%$ among HIVpositive individuals suspected of having abdominal tuberculosis or disseminated tuberculosis with abdominal involvement. The high false negative rate suggests that ultrasound cannot be relied on alone for the diagnosis of tuberculosis. The specificity of $68 \%$ of any abnormal finding on abdominal ultrasound further indicates

Abdominal ultrasound for diagnosing abdominal tuberculosis or disseminated tuberculosis with abdominal involvement in HIV-positive 18 individuals (Review)

Copyright (c) 2019 The Authors. Cochrane Database of Systematic Reviews published by John Wiley \& Sons, Ltd. on behalf of The Cochrane Collaboration. 
that care must be taken to not use abdominal ultrasound alone to rule in tuberculosis, as the false positive rate is high. The presence of individual findings such as ascites, splenic lesions and intraabdominal lymphadenopathy had a higher specificity as evidenced by the range of study estimates, and, if proven in large prospective studies, might be a useful indicator for tuberculosis involving the abdomen. In light of our review findings, the intended role for ultrasound is to be used with other tests, such as lateral flow urine lipoarabinomannan assay (LF-LAM), chest x-ray and Xpert MTB/RIF or Xpert Ultra, to confirm the diagnosis of abdominal tuberculosis or disseminated tuberculosis with abdominal involvement.

\section{Implications for research}

Future studies that evaluate the diagnostic accuracy of abdominal ultrasound in HIV-positive people should use a robust reference standard with speciation to ensure that tuberculosis is correctly diagnosed. Larger, prospective, well-designed studies that recruit a representative sample of participants are also needed. The role of abdominal ultrasound in addition to existing diagnostic strategies (e.g. chest x-ray, LF-LAM, Xpert MTB/RIF) needs to be evaluated, as well as its incorporation into tuberculosis diagnostic algorithms.

\section{ACKNOWLE DGEMENTS}

We acknowledge Vittoria Lutje and Joy Oliver for their assistance with the MEDLINE draft search strategy. Dr Karen R Steingart was the academic editor for this review.
Eleanor A Ochodo is supported by a grant from the Wellcome Trust Foundation (grant number: 109939). The Wellcome Trust has no role in the design, conduct, and interpretation of this review.

Graeme Meintjes is supported by the Wellcome Trust (098316), the South African Research Chairs Initiative of the Department of Science and Technology and National Research Foundation (NRF) of South Africa (Grant No 64787), NRF incentive funding (UID: 85858) and the South African Medical Research Council through its TB and HIV Collaborating Centres Programme with funds received from the National Department of Health (RFA\# SAMRC-RFA-CC: TB/HIV/ AIDS-01-2014).

Yemisi Takwoingi is supported by the UK National Institute for Health Research (NIHR) through a postdoctoral fellowship award (PDF-2017-10-059) and the NIHR Birmingham Biomedical Research Centre. The views expressed are those of the authors and not necessarily those of the NIHR or the Department of Health and Social Care.

The editorial base of the Cochrane Infectious Diseases Group is funded by UK aid from the UK government for the benefit of lowand middle-income countries (project number 300342-104). The views expressed do not necessarily reflect the UK government's official policies. 


\section{RE F E R E N C E S}

\section{References to studies included in this review}

Barreiros 2008-h \{published data only\}

Barreiros AP, Braden B, Schieferstein-Knauer C, Ignee A, Dietrich CF. Characteristics of intestinal tuberculosis in ultrasonographic techniques. Scandinavian Journal of Gastroenterology 2008;43(10):1224-31. [DOI: $10.1080 / 00365520802158606]$

\section{Bobbio 2019-I \{published and unpublished data\}}

Bobbio F, Di Gennaro F, Marotta C, Kok J, Akec G, Norbis L, et al. Focused ultrasound to diagnose HIVassociated tuberculosis (FASH) in the extremely resource-limited setting of South Sudan: a cross-sectional study. BMJ open 2019;9:e027179. [DOI: 10.1136/bmjopen-2018-027179]

\section{Dominguez-Castellano 1998-h \{published data only\}} Domínguez-Castellano A, Yáñez P, Muniaín MA, Balonga B, Ríos MJ, Rodríguez-Baño J, et al. The usefulness of abdominal echography in the diagnosis of extrapulmonary tuberculosis in patients with HIV infection. Enfermedades Infecciosas y Microbiología Clínica 1998;16(2):61-5.

Dominguez-Castellano 1998-I \{published data only\}

\section{Griesel 2019-h \{published and unpublished data\}}

Griesel R, Cohen K, Mendelson M, Maartens G. Abdominal ultrasound for the diagnosis of tuberculosis among human immunodeficiency virus-positive inpatients with WHO danger signs. Open Forum Infectious Diseases 2019;6(4):ofz094. [DOI: 10.1093/ofid/ofz094]

\section{Kaneria 2009-I \{published data only\}}

Kaneria MV, Yeole S, Patil S. Splenic microabscesses in HIV infection. A marker of disseminated tuberculosis?. Acta Anaesthesiologica Italica 2009;60(1):20-30.

\section{Monill-Serra 1997-l \{published data only\}}

Monill-Serra JM, Martinez-Noguera A, Montserrat E, Maideu J, Sabate JM. Abdominal ultrasound findings of disseminated tuberculosis in AIDS. Journal of Clinical Ultrasound 1997;25(1):1-6.

\section{Ndege 2019-h \{published and unpublished data\}}

Ndege R, Weisser M, Elzi L, Diggelmann F, Bani F, Gingo W, et al. Sonography to rule out tuberculosis in sub-Saharan Africa: a prospective observational study. Open Forum Infectious Diseases 2019;6(4):ofz154. [DOI: 10.1093/ofid/ofz154]

Ndege 2019-I \{published and unpublished data\}

\section{O'Keefe 1998-h \{published data only\}}

O'Keefe EA, Wood R, Van Zyl A, Cariem AK. Human immunodeficiency virus-related abdominal pain in South Africa. Aetiology, diagnosis and survival. Scandinavian Journal of Gastroenterology 1998;33(2):212-7.
Sculier 2010-h \{published data only\}

Sculier D, Vannarith C, Pe R, Thai S, Kanara N, Borann S, et al. Performance of abdominal ultrasound for diagnosis of tuberculosis in HIV-infected persons living in Cambodia. Journal of Acquired Immune Deficiency Syndromes 2010;55(4):500-2. [DOI: 10.1097/QAI.0b013e3181e6a703]

Sinkala 2009-I \{published data only\}

Sinkala E, Gray S, Zulu I, Mudenda V, Zimba L, Vermund SH, et al. Clinical and ultrasonographic features of abdominal tuberculosis in HIV positive adults in Zambia. BMC Infectious Diseases 2009;9:44. [DOI: 10.1186/1471-2334-9-44]

Weber 2018-h \{published and unpublished data\} Weber SF, Saravu K, Heller T, Kadavigere R, Vishwanath S, Gehring S, et al. Point-of-care ultrasound for extrapulmonary tuberculosis in India: a prospective cohort study in HIV-positive and HIV-negative presumptive tuberculosis patients. American Journal of Tropical Medicine and Hygiene 2018;98(1):266-73. [DOI: 10.4269/ajtmh.17-0486]

Weber 2018-I \{published and unpublished data\}

\section{References to studies excluded from this review}

Abiri 1985 \{published data only\}

Abiri MM, Kirpekar M, Abiri S. The role of ultrasonography in the detection of extrapulmonary tuberculosis in patients with acquired immunodeficiency syndrome (AIDS). Journal of Ultrasound in Medicine 1985;4(9):471-3. [DOI: 10.7863/ jum.1985.4.9.471]

Agarwal 2010 \{published data only\}

Agarwal D, Narayan S, Chakravarty J, Sundar S. Ultrasonography for diagnosis of abdominal tuberculosis in HIV infected people. Indian Journal of Medical Research 2010;132:77-80.

Akinkuolie 2008 \{published data only\}

Akinkuolie AA, Adisa AO, Agbakwuru EA, Egharevba PA, Adesunkanmi AR. Abdominal tuberculosis in a Nigerian teaching hospital. African Journal of Medicine and Medical Sciences 2008;37(3):225-9.

\section{Aubry 1994 \{published data only\}}

Aubry P, Reynaud JP, Nbonyingingo C, Ndabaneze E, Mucikere E. Ultrasound data on the solid organs of the abdomen in stage IV human immunodeficiency virus infection: A prospective study of 101 Central African patients. Annales de Gastroenterologie et d'Hépatologie 1994;30(2):43-52.

Barthwal 2005 \{published data only\}

Barthwal MS, Rajan KE, Deoskar RB, Sharma SK. Extrapulmonary tuberculosis in human immunodificiency virus infection. Medical Journal of the Armed Forces of India 2005;61(4):340-1. [DOI: 10.1016/S0377-1237(05)80059-0]

Abdominal ultrasound for diagnosing abdominal tuberculosis or disseminated tuberculosis with abdominal involvement in HIV-positive 
Batra 2000 \{published data only\}

Batra A, Gulati MS, Sarma D, Paul SB. Sonographic appearances in abdominal tuberculosis. Journal of Clinical Ultrasound 2000;28(5):233-45

\section{Chen 2009 \{published data only\}}

Chen HL, Wu MS, Chang WH, Shih SC, Chi H, Bair MJ. Abdominal tuberculosis in southeastern Taiwan: 20 years of experience. Journal of the Formosan Medical Association 2009;108(3):195-201. [DOI: 10.1016/S0929-6646(09)60052-8]

\section{Clarke 2007 \{published data only\}}

Clarke DL, Thomson SR, Bissetty T, Madiba TE, Buccimazza I, Anderson F. A single surgical unit's experience with abdominal tuberculosis in the HIV/AIDS era. World Journal of Surgery 2007;31(5):1087-8. [DOI: 10.1007/s00268-007-0402-8]

\section{Emby 2002 \{published data only\}}

Emby DJ, Hunter M. The value of ultrasound in the HIV-infected patient with a fever of undetermined origin. South African Medical Journal 2002;92(8):566.

\section{Feng 2016 \{published data only\}}

Feng F, Xia G, Shi Y, Zhang Z. Radiological characterization of disseminated tuberculosis in patients with AIDS. Radiology of Infectious Diseases 2016;3(1):1-8. [DOI: 10.1016/ j.jrid.2016.01.001]

\section{Giordani 2013 \{published data only\}}

Giordani MT, Brunetti E, Binazzi R, Benedetti P, Stecca C, Goblirsch S, et al. Extrapulmonary mycobacterial infections in a cohort of HIV-positive patients: ultrasound experience from Vicenza, Italy. Infection 2013;41(2):409-14. [DOI: 10.1007/ s15010-012-0336-4]

\section{Heller 2010a \{published data only\}}

Heller T, Goblirsch S, Wallrauch C, Lessells R, Brunetti E. Abdominal tuberculosis: sonographic diagnosis and treatment response in HIV-positive adults in rural South Africa. International Journal of Infectious Diseases 2010;14 Suppl 3:e108-12. [DOI: 10.1016/j.ijid.2009.11.030]

\section{Heller 2013 \{published data only\}}

Heller T, Goblirsch S, Bahlas S, Ahmed M, Giordani M, Wallrauch C, et al. Diagnostic value of FASH ultrasound and chest X-ray in HIV-co-infected patients with abdominal tuberculosis. International Journal of Tuberculosis and Lung Disease 2013;17(3):342-4. [DOI: 10.5588/ijtld.12.0679]

\section{Heller 2017 \{published data only\}}

Heller T, Mtemang'ombe EA, Huson MA, Heuvelings CC, Belard S, Janssen S, et al. Ultrasound for patients in a high HIV/ tuberculosis prevalence setting: a needs assessment and review of focused applications for Sub-Saharan Africa. International Journal of Infectious Diseases 2017;56:229-36. [DOI: 10.1016/ j.ijid.2016.11.001]

\section{Ibrahim 2005 \{published data only\}} Ibrahim M, Osoba AO. Abdominal tuberculosis. On-going challenge to gastroenterologists. Saudi Medical Journal 2005;26(2):274-80.
Jain 1995 \{published data only\}

Jain R, Sawhney S, Bhargava DK, Berry M. Diagnosis of abdominal tuberculosis: sonographic findings in patients with early disease. American Journal of Roentgenology 1995;165(6):1391-5. [DOI: 10.2214/ajr.165.6.7484572]

Kedar 1994 \{published data only\}

Kedar RP, Shah PP, Shivde RS, Malde HM. Sonographic findings in gastrointestinal and peritoneal tuberculosis. Clinical Radiology 1994;49(1):24-9.

Landoni 2002 \{published data only\}

Landoni G, Nattabi B, Opira C, Francesconi P. Abdominal tuberculosis adenitis in HIV-infected patients: is ultrasound diagnosis appropriate?. Tropical Doctor 2002;32(2):97-8. [DOI: 10.1177/004947550203200215]

\section{Ouedraogo 2016 \{published data only\}}

Ouedraogo E, Lurton G, Mohamadou S, Dillé I, Diallo I, Mamadou S, et al. Evaluation of the benefit of different complementary exams in the search for a TB diagnosis algorithm for HIV patients put on ART in Niamey, Niger. Bulletin de la Société de Pathologie Exotique 2016;109(5):368-75. [DOI: 10.1007/s13149-016-0532-z]

Patel 2011 \{published data only\}

Patel MN, Beningfield S, Burch V. Abdominal and pericardial ultrasound in suspected extrapulmonary or disseminated tuberculosis. South African Medical Journal 2011;101(1):39-42.

Porcel-Martin 1998 \{published data only\}

Porcel-Martin A, Rendon-Unceta P, Bascunana-Quirell A, AmayaVidal A, Rodriguez-Ramos C, Soria de la Cruz MJ, et al. Focal splenic lesions in patients with AIDS: sonographic findings. Abdominal Imaging 1998;23(2):196-200.

Sheikh 1999 \{published data only\}

Sheikh M, Moosa I, Hussein FM, Qurttom MA, Behbehani AI. Ultrasonographic diagnosis in abdominal tuberculosis. Australasian Radiology 1999;43(2):175-9.

Solomon 1998 \{published data only\}

Solomon A, Feldman C, Kobilski SA. Abdominal findings in AIDSrelated pulmonary tuberculosis correlated with associated CD4 levels. Abdominal Imaging 1998;23(6):573-7.

\section{Soriano 1991 \{published data only\}}

Soriano V, Tor J, Domenech E, Gabarre E, Muga R, Inaraja $\mathrm{L}$, et al. Abdominal tuberculosis in patients with acquired immunodeficiency syndrome. Medicina Clinica 1991;97(4):121-4.

\section{Spalgais 2013 \{published data only\}}

Spalgais S, Jaiswal A, Puri M, Sarin R, Agarwal U. Clinical profile and diagnosis of extrapulmonary TB in HIV infected patients: routine abdominal ultrasonography increases detection of abdominal tuberculosis. Indian Journal of Tuberculosis 2013;60(3):147-53.

Abdominal ultrasound for diagnosing abdominal tuberculosis or disseminated tuberculosis with abdominal involvement in HIV-positive 


\section{Spalgais 2017 \{published data only\}}

Spalgais S, Agarwal U, Sarin R, Chauhan D, Yadav A, Jaiswal A. Role of routine abdominal ultrasonography in intensified tuberculosis case finding algorithms at HIV clinics in high TB burden settings. BMC Infectious Diseases 2017;17(1):351. [DOI: 10.1186/s12879-017-2433-6]

\section{Tarantino 2003 \{published data only\}}

Tarantino L, Giorgio A, De Stefano G, Farella N, Perrotta A, Esposito F. Disseminated mycobacterial infection in AIDS patients: abdominal US features and value of fine-needle aspiration biopsy of lymph nodes and spleen. Abdominal Imaging 2003;28(5):602-8.

\section{Tarantino 2004 \{published data only\}}

Tarantino L, Giorgio A, De Stefano G, Scala V, Liorre G, Di Sarno A, et al. Diagnosis of disseminated mycobacterial infection in AIDS patients by US-guided fine needle aspiration biopsy of lymph nodes and spleen. Infezioni in Medicina 2004;12(1):27-33.

\section{Tshibwabwa 2000 \{published data only\}}

Tshibwabwa ET, Mwaba P, Bogle-Taylor J, Zumla A. Four-year study of abdominal ultrasound in 900 Central African adults with AIDS referred for diagnostic imaging. Abdominal Imaging 2000;25(3):290-6.

\section{Wafai 2017 \{published data only\}}

Wafai NA, Yadav SK, Singh PS, Kumar M, Singh PK, Sharma H, et al. Clinico-radiological profile of abdominal tuberculosis in HIV/AIDS patients-a study from rural central India. International Journal of Research in Medical Sciences 2017;5(5):1980. [DOI: 10.18203/2320-6012.ijrms20171829]

\section{References to ongoing studies}

PACTR201712002829221 \{published data only\}

PACTR201712002829221. Ultrasound in managing tuberculosis: A randomized controlled two-center study. apps.who.int/ trialsearch/Trial2.aspx?TrialID=PACTR201712002829221 (first received 1 December 2017). [PACTR201712002829221]

\section{Additional references}

\section{Adhikari 2014}

Adhikari S, Stolz L, Amini R, Blaivas M. Impact of point-of-care ultrasound on quality of care in clinical practice. Reports in Medical Imaging 2014;7:81-93. [DOI: 10.2147/RMI.S40095]

\section{Chow 2002}

Chow KM, Chow VC, Hung LC, Wong SM, Szeto CC. Tuberculous peritonitis-associated mortality is high among patients waiting for the results of mycobacterial cultures of ascitic fluid samples. Clinical Infectious Diseases 2002;35(4):409-13. [DOI: 10.1086/341898]

\section{Chow 2003}

Chow KM, Chow VC, Szeto CC. Indication for peritoneal biopsy in tuberculous peritonitis. American Journal of Surgery 2003;185(6):567-73. [DOI: 10.1016/s0002-9610(03)00079-5]

\section{Chu 2006}

Chu $\mathrm{H}$, Cole SR. Bivariate meta-analysis of sensitivity and specificity with sparse data: a generalized linear mixed model approach. Journal of Clinical Epidemiology 2006;59(12):1331-2. [DOI: 10.1016/j.jclinepi.2006.06.011]

\section{Dawson 2010}

Dawson R, Masuka P, Edwards DJ, Bateman ED, Bekker LG, Wood $\mathrm{R}$, et al. Chest radiograph reading and recording system: evaluation for tuberculosis screening in patients with advanced HIV. International Journal of Tuberculosis and Lung Disease 2010;14(1):52-8.

\section{Debi 2014}

Debi U, Ravisankar V, Prasad KK, Sinha SK, Sharma AK. Abdominal tuberculosis of the gastrointestinal tract: revisited. World Journal of Gastroenterology 2014;20(40):14831-40. [DOI: 10.3748/wjg.v20.i40.14831]

\section{GRADEpro GDT 2015 [Computer program]}

McMaster University (developed by Evidence Prime). GRADEpro GDT: GRADEpro Guideline Development Tool [Software]. Version accessed 04 August 2017. McMaster University (developed by Evidence Prime), 2015.

\section{Gupta 2015}

Gupta RK, Lucas SB, Fielding KL, Lawn SD. Prevalence of tuberculosis in post-mortem studies of HIV-infected adults and children in resource-limited settings: a systematic review and meta-analysis. AIDS 2015;29(15):1987-2002. [DOI: 10.1097/ QAD.0000000000000802]

\section{Heller 2010b}

Heller T, Wallrauch C, Lessells RJ, Goblirsch S, Brunetti E. Short course for focused assessment with sonography for human immunodeficiency virus/tuberculosis: preliminary results in a rural setting in South Africa with high prevalence of human immunodeficiency virus and tuberculosis. American Journal of Tropical Medicine and Hygiene 2010;82(3):512-5. [DOI: 10.4269/ ajtmh.2010.09-0561]

\section{Horne 2019}

Horne DJ, Kohli M, Zifodya JS, Schiller I, Dendukuri N, Tollefson D, et al. Xpert MTB/RIF and Xpert MTB/RIF Ultra for pulmonary tuberculosis and rifampicin resistance in adults. Cochrane Database of Systematic Reviews 2019, Issue 6. [DOI: 10.1002/14651858.CD009593.pub4]

\section{Jadvar 1997}

Jadvar H, Mindelzun RE, Olcott EW, Levitt DB. Still the great mimicker: abdominal tuberculosis. American Journal of Roentgenology 1997;168(6):1455-60. [DOI: 10.2214/ ajr.168.6.9168707]

\section{Joshi 2014}

Joshi AR, Basantani AS, Patel TC. Role of CT and MRI in abdominal tuberculosis. Current Radiology Reports 2014;2:66. [DOI: 10.1007/s40134-014-0066-8]

Abdominal ultrasound for diagnosing abdominal tuberculosis or disseminated tuberculosis with abdominal involvement in HIV-positive

Copyright $\odot 2019$ The Authors. Cochrane Database of Systematic Reviews published by John Wiley \& Sons, Ltd. on behalf of The Cochrane Collaboration. 


\section{Kim 1998}

Kim KM, Lee A, Choi KY, Lee KY, Kwak JJ. Intestinal tuberculosis: clinicopathologic analysis and diagnosis by endoscopic biopsy. American Journal of Gastroenterology 1998;93(4):606-9. [DOI: 10.1111/j.1572-0241.1998.173_b.x]

\section{Kingkaew 2009}

Kingkaew N, Sangtong B, Amnuaiphon W, Jongpaibulpatana J, Mankatittham W, Akksilp S, et al. HIV-associated extrapulmonary tuberculosis in Thailand: epidemiology and risk factors for death. International Journal of Infectious Diseases 2009;13(6):722-9. [DOI: 10.1016/j.ijid.2008.11.013]

\section{Kohli 2018}

Kohli M, Schiller I, Dendukuri N, Dheda K, Denkinger CM, Schumacher SG, et al. Xpert ${ }^{\circledR}$ MTB/RIF assay for extrapulmonary tuberculosis and rifampicin resistance. Cochrane Database of Systematic Reviews 2018;8(8):CD012768. [DOI: 10.1002/14651858.CD012768.pub2]

\section{Lawn 2011}

Lawn SD, Zumla Al. Tuberculosis. Lancet 2011;378(9785):57-72. [DOI: 10.1016/S0140-6736(10)62173-3]

\section{Lee 2012}

Lee WK, Van Tonder F, Tartaglia CJ, Dagia C, Cazzato RL, Duddalwar VA, et al. CT appearances of abdominal tuberculosis. Clinical Radiology 2012;67(6):596-604. [DOI: 10.1016/ j.crad.2011.11.003]

\section{Mandal 2011}

Mandal A, Das SK, Bairagya TD. Presenting experience of managing abdominal tuberculosis at a tertiary care hospital in India. Journal of Global Infectious Diseases 2011;3(4):344-7. [DOI: 10.4103/0974-777X.91055]

\section{Martin-Bates 1993}

Martin-Bates E, Tanner A, Suvarna SK, Glazer G, Coleman DV. Use of fine needle aspiration cytology for investigating lymphadenopathy in HIV positive patients. Journal of Clinical Pathology 1993;46(6):564-6. [DOI: 10.1136/jcp.46.6.564]

\section{Mugala 2006}

Mugala DD. Abdominal tuberculosis in Chingola-Zambia: pattern of presentation. East and Central African Journal of Surgery 2006;11(2):41-7.

\section{Namme 2013}

Namme LH, Marie-Solange D, Hugo Bertrand MN, Elvis T, Achu JH, Christopher K. Extrapulmonary tuberculosis and HIV coinfection in patients treated for tuberculosis at the Douala General Hospital in Cameroon. Annals of Tropical Medicine and Public Health 2013;6(1):100-4.

\section{NICE 2016}

National Institute for Health and Care Excellence. Tuberculosis. NICE guideline [NG33]. Published date: January 2016. Last updated: May 2016. www.nice.org.uk/guidance/ng33 (accessed 14 June 2017).

\section{Padmapriyadarsini 2011}

Padmapriyadarsini C, Narendran G, Swaminathan S. Diagnosis \& treatment of tuberculosis in HIV co-infected patients. Indian Journal of Medical Research 2011;134(6):850-65. [DOI: 10.4103/0971-5916.92630]

\section{Palmieri 2002}

Palmieri F, Girardi E, Pellicelli AM, Rianda A, Bordi E, Rizzi EB, et al. Pulmonary tuberculosis in HIV-infected patients presenting with normal chest radiograph and negative sputum smear. Infection 2002;30(2):68-74. [DOI: 10.1007/s15010-002-2062-9]

\section{Review Manager 2014 [Computer program]}

Nordic Cochrane Centre, The Cochrane Collaboration. Review Manager 5 (RevMan 5). Version 5.3. Copenhagen: Nordic Cochrane Centre, The Cochrane Collaboration, 2014.

\section{Riquelme 2006}

Riquelme A, Calvo M, Salech F, Valderrama S, Pattillo A, Arellano $M$, et al. Value of adenosine deaminase (ADA) in ascitic fluid for the diagnosis of tuberculous peritonitis: a metaanalysis. Journal of Clinical Gastroenterology 2006;40(8):705-10.

\section{Rutjes 2006}

Rutjes AW, Reitsma JB, Di Nisio M, Smidt N, Van Rijn JC, Bossuyt PM. Evidence of bias and variation in diagnostic accuracy studies. CMAJ 2006;174(4):469-76. [DOI: 10.1503/ cmaj.050090]

\section{Sanai 2005}

Sanai FM, Bzeizi KI. Systematic review: tuberculous peritonitispresenting features, diagnostic strategies and treatment. Alimentary Pharmacology \& Therapeutics 2005;22(8):685-700. [DOI: 10.1111/j.1365-2036.2005.02645.x]

\section{Schünemann 2016}

Schünemann HJ, Mustafa R, Brozek J, Santesso N, AlonsoCoello P, Guyatt G, et al. GRADE Guidelines: 16. GRADE evidence to decision frameworks for tests in clinical practice and public health. Journal of Clinical Epidemiology 2016;76:89-98. [DOI: 10.1016/j.jclinepi.2016.01.032]

\section{Schünemann in press}

Schünemann HJ, Mustafa RA, Brozek J, Steingart KR, Leeflang M, Murad MH, et al. GRADE guidelines: 21 part 2. Inconsistency, precision, publication bias and other domains for rating the certainty and presenting evidence profiles and summary of findings tables. Journal of Clinical Epidemiology (in press).

\section{Shah 2016}

Shah M, Hanrahan C, Wang ZY, Dendukuri N, Lawn SD, Denkinger $\mathrm{CM}$, et al. Lateral flow urine lipoarabinomannan assay for detecting active tuberculosis in HIV-positive adults. Cochrane Database of Systematic Reviews 2016, Issue 5. [DOI: 10.1002/14651858.CD011420.pub2]

\section{Sharma 2004a}

Sharma MP, Bhatia V. Abdominal tuberculosis. Indian Journal of Medical Research 2004;120(4):305-15. 


\section{Sharma 2004b}

Sharma SK, Mohan A. Extrapulmonary tuberculosis. Indian Journal of Medical Research 2004;120(4):316-53.

\section{Sharma 2005}

Sharma SK, Mohan A, Kadhiravan T. HIV-TB co-infection: epidemiology, diagnosis \& management. Indian Journal of Medical Research 2005;121(4):550-67.

\section{Sharma 2017}

Sharma SK, Ryan H, Khaparde S, Sachdeva KS, Singh AD, Mohan A, et al. Index-TB guidelines: Guidelines on extrapulmonary tuberculosis for India. Indian Journal of Medical Research 2017;145(4):448-63.

\section{Steingart 2006a}

Steingart KR, Henry M, Ng V, Hopewell PC, Ramsay A, Cunningham J, et al. Fluorescence versus conventional sputum smear microscopy for tuberculosis: a systematic review. Lancet Infectious Diseases 2006;6(9):570-81. [DOI: 10.1016/ S1473-3099(06)70578-3]

\section{Steingart 2006b}

Steingart KR, Ng V, Henry M, Hopewell PC, Ramsay A, Cunningham J, et al. Sputum processing methods to improve the sensitivity of smear microscopy for tuberculosis: a systematic review. Lancet Infectious Diseases 2006;6(10):664-74. [DOI: 10.1016/S1473-3099(06)70602-8]

\section{Whiting 2011}

Whiting PF, Rutjes AW, Westwood ME, Mallett S, Deeks JJ, Reitsma JB, et al. QUADAS-2: a revised tool for the quality assessment of diagnostic accuracy studies. Annals of Internal Medicine 2011;155(8):529-36. [DOI: 10.7326/0003-4819-155-8-201110180-00009]

\section{WHO 2006}

World Health Organization. Improving the diagnosis and treatment of smear-negative pulmonary and extrapulmonary tuberculosis among adults and adolescents Recommendations for HIV-prevalent and resource-constrained settings. Available at: www.who.int/hiv/pub/tb/pulmonary/en/. Geneva, 2006. [DOI: WHO/HTM/HIV/2007.01]

\section{WHO 2013a}

World Health Organization. Definitions and reporting framework for tuberculosis: 2013 revision (updated December 2014). apps.who.int/iris/ bitstream/10665/79199/1/9789241505345_eng.pdf. Geneva: World Health Organization, (accessed 14 June 2017).

\section{CHARACTERISTICS OF STUDIES}

Characteristics of included studies [ordered by study ID]

\section{WHO 2013b}

World Health Organization. Systematic screening for active tuberculosis: principles and recommendations. 2013. apps.who.int/iris/ bitstream/10665/84971/1/9789241548601_eng.pdf?ua=1. Geneva: World Health Organization, (accessed 14 June 2017).

\section{WHO 2015}

World Health Organization. The use of lateral flow urine lipoarabinomannan assay (LF-LAM) for the diagnosis and screening of active tuberculosis in people living with HIV. Policy update. 2015. www.who.int/tb/publications/use-of-If-lam-tbhiv/en/. Geneva: World Health Organization, (accessed 14 June 2017).

\section{WHO 2016}

World Health Organization. Consolidated guidelines on the use of antiretroviral drugs for treating and preventing HIV infection. Recommendations for a public health approach - 2nd edition. www.who.int/hiv/pub/arv/arv-2016/en/. Geneva: World Health Organization, (accessed 14 June 2017).

\section{WHO 2017}

World Health Organization. Global tuberculosis report 2017. World Health Organization. Geneva, 2017:1-227.

\section{WHO 2018}

World Health Organization. Global tuberculosis report 2018. World Health Organization. Geneva: World Health Organization, 2018.

\section{Wilkins 1984}

Wilkins EG. Tuberculosis peritonitis: diagnostic value of the ascitic/blood glucose ratio. Tubercle 1984;65(1):47-52.

\section{Wilson 2006}

Wilson D, Nachega J, Morroni C, Chaisson R, Maartens G. Diagnosing smear-negative tuberculosis using case definitions and treatment response in HIV-infected adults. International Journal of Tuberculosis and Lung Disease 2006;10(1):31-8.

\section{References to other published versions of this review Van Hoving 2017}

Van Hoving DJ, Meintjes G, Takwoingi Y, Griesel R, Maartens G, Ochodo EA. Abdominal ultrasound for diagnosing abdominal tuberculosis or disseminated tuberculosis with abdominal involvement in HIV-positive adults. Cochrane Database of Systematic Reviews 2017, Issue 8. [DOI: 10.1002/14651858.CD012777]

Barreiros 2008-h

\section{Study characteristics}




\section{Barreiros 2008-h (Continued)}

Patient characteristics and setting

\section{Country: Germany \\ Setting: Not reported}

High tuberculosis burden country: No

High HIV-associated tuberculosis burden country: No

Sample size: 7 cases (of these 3 HIV-negative); 18 controls (of these 9 HIV-negative)

Median age (range): Cases 41 (27 - 66); Controls 36 (21 - 69)

Gender proportion (M:F): Cases 3:4; Controls 11:7

Proportion on antiretroviral therapy (ART): Not reported

Threshold(s):

- Thickened bowel wall: $>5 \mathrm{~mm}$;

- Intramural abscess: thickened hypervascular bowel wall $>8 \mathrm{~mm}$ with non-vascularized, oval-shaped, intramural mass-like lesions;

- Extramural abscess: Circumscribed hypoechoic or echo-free fluid collections > $10 \mathrm{~mm}$ next to fistula;

- Lymph nodes: Longitudinal diameter $>20 \mathrm{~mm}$;

- Splenomegaly: $>13.5 \mathrm{~cm}$

\footnotetext{
Target condition and reference standard(s)
}

\section{Target condition: Intestinal tuberculosis}

Confirmation of active tuberculosis: “...based on clinical, endoscopic, histologic, radiologic and operative findings including microbiology (in all) and polymerase chain reaction (PCR) (in 5 patients) of biopsies taken during endoscopy."

\section{Flow and timing}

Comparative

\section{Notes}

Second control group of healthy persons not included

4 cases and 9 controls were HIV-positive

Cases had pulmonary tuberculosis only (randomly selected)

Reference standard results not delineated

\section{Methodological quality}

\begin{tabular}{llll}
\hline Item & Authors' judgement & Risk of bias & $\begin{array}{l}\text { Applicability con- } \\
\text { cerns }\end{array}$ \\
\hline
\end{tabular}

\section{DOMAIN 1: Patient Selection}

Was a consecutive or random sample of patients enrolled?
Yes

No 
Barreiros 2008-h (Continued)

Did the study avoid inappropriate exclusions?

Yes

High High

\section{DOMAIN 2: Index Test Ascites}

Were the index test results interpreted without knowledge Yes

of the results of the reference standard?

If a threshold was used, was it pre-specified? Yes

Low

Unclear

\section{DOMAIN 2: Index Test Abdominal lymph nodes}

Were the index test results interpreted without knowledge Yes

of the results of the reference standard?

If a threshold was used, was it pre-specified?

Yes

Low

Unclear

\section{DOMAIN 2: Index Test Splenomegaly}

Were the index test results interpreted without knowledge Yes

of the results of the reference standard?

If a threshold was used, was it pre-specified? Yes

\begin{tabular}{lll}
\hline Unclear & Low \\
\hline
\end{tabular}

\section{DOMAIN 3: Reference Standard}

\section{Is the reference standards likely to correctly classify the No}

target condition?

Were the reference standard results interpreted without Unclear

knowledge of the results of the index tests?

Was incorporation bias avoided? Yes

High

High

\section{DOMAIN 4: Flow and Timing}

Was there an appropriate interval between index test and Unclear reference standard?

\begin{tabular}{ll}
\hline Did all patients receive the same reference standard? & Unclear \\
\hline Were all patients included in the analysis? & Yes \\
\hline Did all patients received a reference standard? & Yes \\
\hline
\end{tabular}

\section{Unclear}

Abdominal ultrasound for diagnosing abdominal tuberculosis or disseminated tuberculosis with abdominal involvement in HIV-positive 
Bobbio 2019-I

\section{Study characteristics}

\begin{tabular}{|c|c|}
\hline Patient sampling & Cross-sectional design \\
\hline \multirow[t]{8}{*}{ Patient characteristics and setting } & Country: South Sudan \\
\hline & Setting: Referral hospital \\
\hline & High tuberculosis burden country: No \\
\hline & High HIV-associated tuberculosis burden country: No \\
\hline & Sample size: 100 \\
\hline & Median age (range): Not available (only categories available) \\
\hline & Gender proportion (M:F): 48:52 \\
\hline & Proportion on antiretroviral therapy (ART): $3 \%$ \\
\hline \multirow[t]{8}{*}{ Index tests } & Sonographer qualification: Clinician trained in ultrasound \\
\hline & Threshold(s): At least one of \\
\hline & - Pericardial effusion; \\
\hline & - Periportal/para-aortic lymph nodes (> $1.5 \mathrm{~cm}$ in diameter); \\
\hline & - Focal splenic lesions; \\
\hline & - Pleural effusion or consolidation of lung; \\
\hline & - Ascites without alternative explanation; \\
\hline & - Focal liver lesion \\
\hline
\end{tabular}

Target condition and reference standard(s)

Target condition: Disseminated tuberculosis

Confirmation of active tuberculosis: Acid-fast bacilli sputum smears, ultrasound, clinical diagnosis

Flow and timing

Comparative

Notes

Methodological quality

$\begin{array}{llll}\text { Item } & \text { Authors' judgement } & \text { Risk of bias } & \begin{array}{l}\text { Applicability con- } \\ \text { cerns }\end{array}\end{array}$

\section{DOMAIN 1: Patient Selection}

Was a consecutive or random sample of patients enrolled?

Was a case-control design avoided? Yes

Did the study avoid inappropriate exclusions?
No

Yes

Yes
High High 
Bobbio 2019-I (Continued)

DOMAIN 2: Index Test Abnormal abdominal ultrasound (lower quality)

Were the index test results interpreted without knowledge of Yes the results of the reference standard?

If a threshold was used, was it pre-specified?

Yes

\begin{tabular}{|c|c|c|}
\hline & Low & Low \\
\hline \multicolumn{3}{|l|}{ DOMAIN 3: Reference Standard } \\
\hline $\begin{array}{l}\text { Is the reference standards likely to correctly classify the target } \\
\text { condition? }\end{array}$ & No & \\
\hline $\begin{array}{l}\text { Were the reference standard results interpreted without knowl- } \\
\text { edge of the results of the index tests? }\end{array}$ & No & \\
\hline \multirow[t]{2}{*}{ Was incorporation bias avoided? } & No & \\
\hline & High & High \\
\hline \multicolumn{3}{|l|}{ DOMAIN 4: Flow and Timing } \\
\hline $\begin{array}{l}\text { Was there an appropriate interval between index test and refer- } \\
\text { ence standard? }\end{array}$ & Yes & \\
\hline Did all patients receive the same reference standard? & No & \\
\hline Were all patients included in the analysis? & Yes & \\
\hline \multirow[t]{2}{*}{ Did all patients received a reference standard? } & No & \\
\hline & High & \\
\hline
\end{tabular}

Dominguez-Castellano 1998-h

\section{Study characteristics}

\begin{tabular}{ll}
\hline Patient sampling & Prospective cross-sectional \\
\hline Patient characteristics and setting & Country: Spain \\
& Setting: Not reported \\
& High tuberculosis burden country: No \\
& High HIV-associated tuberculosis burden country: No \\
& Sample size:116 \\
& Age: $31.56 \pm$ 4.68 years (mean \pm SD) \\
& Gender proportion: Not reported \\
\hline Index tests & Proportion on antiretroviral therapy (ART): Not reported \\
\hline
\end{tabular}

Abdominal ultrasound for diagnosing abdominal tuberculosis or disseminated tuberculosis with abdominal involvement in HIV-positive

Copyright $\odot 2019$ The Authors. Cochrane Database of Systematic Reviews published by John Wiley \& Sons, Ltd. on behalf of The Cochrane

Collaboration. 
Dominguez-Castellano 1998-h (Continued)

Threshold(s):

- Multiple splenic focal lesions: hypoechoic, $<10 \mathrm{~mm}$ diameter, poorly-defined / irregular borders, homogeneous distribution;

- Abdominal adenopathy: hypo or isoechoic, between 1 and $3 \mathrm{~cm}$, around hepatic hilum, spleen, aorta or celiac trunk;

- Hypo or hyperechoic focal liver lesions

Target condition and reference standard(s)

Target condition: Pulmonary tuberculosis, Extra-pulmonary tuberculosis and disseminated tuberculosis (with or without abdominal involvement)

Confirmation of active tuberculosis: Smear microscopy, Lowenstein culture

Flow and timing

\section{Comparative}

Notes

\section{Methodological quality}

\begin{tabular}{llll}
\hline Item & Authors' judgement & Risk of bias & \multicolumn{1}{l}{$\begin{array}{l}\text { Applicability con- } \\
\text { cerns }\end{array}$}
\end{tabular}

\section{DOMAIN 1: Patient Selection}

\begin{tabular}{llll}
\hline Was a consecutive or random sample of patients enrolled? & Yes \\
\hline Was a case-control design avoided? & Yes & \\
\hline Did the study avoid inappropriate exclusions? & Yes & Low & Unclear \\
\hline
\end{tabular}

\section{DOMAIN 2: Index Test Abnormal abdominal ultrasound (higher quality)}

\section{Were the index test results interpreted without knowledge Yes}

of the results of the reference standard?

\begin{tabular}{lll}
\hline If a threshold was used, was it pre-specified? & Yes & Low LW L L L L
\end{tabular}

\section{DOMAIN 3: Reference Standard}

Is the reference standards likely to correctly classify the tar- Yes get condition?

Were the reference standard results interpreted without $\quad$ Yes knowledge of the results of the index tests? 
Dominguez-Castellano 1998-h (Continued)

DOMAIN 4: Flow and Timing

Was there an appropriate interval between index test and Unclear reference standard?

\begin{tabular}{ll}
\hline Did all patients receive the same reference standard? & Unclear \\
\hline Were all patients included in the analysis? & Yes \\
\hline Did all patients received a reference standard? & Yes \\
\hline
\end{tabular}

Unclear

\section{Dominguez-Castellano 1998-I}

\section{Study characteristics}

\begin{tabular}{|c|c|}
\hline Patient sampling & Prospective cross-sectional \\
\hline \multirow[t]{8}{*}{ Patient characteristics and setting } & Country: Spain \\
\hline & Setting: Not reported \\
\hline & High tuberculosis burden country: No \\
\hline & High HIV-associated tuberculosis burden country: No \\
\hline & Sample size:116 \\
\hline & Age: $31.56 \pm 4.68$ years (mean \pm SD) \\
\hline & Gender proportion: Not reported \\
\hline & Proportion on antiretroviral therapy (ART): Not reported \\
\hline \multirow[t]{5}{*}{ Index tests } & Sonographer qualification: "Medical sonographer" \\
\hline & Threshold(s): \\
\hline & $\begin{array}{l}\text { Multiple splenic focal lesions: hypoechoic, }<10 \mathrm{~mm} \text { diame- } \\
\text { ter, poorly-defined / irregular borders, homogeneous distri- } \\
\text { bution; }\end{array}$ \\
\hline & $\begin{array}{l}\text { - Abdominal adenopathy: hypo or isoechoic, between } 1 \mathrm{~cm} \\
\text { and } 3 \mathrm{~cm} \text {, around hepatic hilum, spleen, aorta or celiac } \\
\text { trunk; }\end{array}$ \\
\hline & - Hypo or hyperechoic focal liver lesions \\
\hline
\end{tabular}

\footnotetext{
Target condition and reference standard(s)
}

Target condition: Pulmonary tuberculosis, extra-pulmonary tuberculosis and disseminated tuberculosis (with or without abdominal involvement)

Confirmation of active tuberculosis: Compatible with clinical and radiography findings with improvement to anti-tuberculosis treatment

\section{Flow and timing}


Dominguez-Castellano 1998-I (Continued)

Comparative

$$
\text { Notes }
$$

\section{Methodological quality}

\begin{tabular}{|c|c|c|c|}
\hline Item & $\begin{array}{l}\text { Authors' judge- } \\
\text { ment }\end{array}$ & Risk of bias & $\begin{array}{l}\text { Applicability con- } \\
\text { cerns }\end{array}$ \\
\hline
\end{tabular}

\section{DOMAIN 1: Patient Selection}

\begin{tabular}{lcc}
\hline Was a consecutive or random sample of patients enrolled? & Yes & Yes \\
\hline Was a case-control design avoided? & Yes & Low \\
\hline Did the study avoid inappropriate exclusions? & & Unclear
\end{tabular}

DOMAIN 2: Index Test Abnormal abdominal ultrasound (lower quality)

Were the index test results interpreted without knowledge of the re- Yes sults of the reference standard?

If a threshold was used, was it pre-specified? Yes

\begin{tabular}{lll}
\hline & Low & Low \\
\hline DOMAIN 2: Index Test Splenic lesions &
\end{tabular}

Were the index test results interpreted without knowledge of the re- Yes sults of the reference standard?

\begin{tabular}{llll}
\hline If a threshold was used, was it pre-specified? & Yes & Low & Low \\
\hline DOMAIN 2: Index Test Abdominal lymph nodes & Yes & \\
\hline $\begin{array}{l}\text { Were the index test results interpreted without knowledge of the re- } \\
\text { sults of the reference standard? }\end{array}$ & Yes & Low \\
\hline If a threshold was used, was it pre-specified? & Low
\end{tabular}

\section{DOMAIN 3: Reference Standard}

Is the reference standards likely to correctly classify the target con- No dition?

Were the reference standard results interpreted without knowledge No of the results of the index tests?

Was incorporation bias avoided?

Unclear 
Dominguez-Castellano 1998-I (Continued)

High

Low

\section{DOMAIN 4: Flow and Timing}

Was there an appropriate interval between index test and reference Unclear standard?

\begin{tabular}{ll}
\hline Did all patients receive the same reference standard? & Unclear \\
\hline Were all patients included in the analysis? & Yes \\
\hline Did all patients received a reference standard? & Yes \\
\hline
\end{tabular}

Unclear

\section{Griesel 2019-h}

\section{Study characteristics}

\begin{tabular}{|c|c|}
\hline Patient sampling & Prospective cross-sectional \\
\hline \multirow[t]{8}{*}{ Patient characteristics and setting } & Country: South Africa \\
\hline & Setting: Secondary-level hospitals \\
\hline & High tuberculosis burden country: Yes \\
\hline & High HIV-associated tuberculosis burden country: Yes \\
\hline & Sample size: 377 \\
\hline & $\begin{array}{l}\text { Age: Median (IQR) tuberculosis cases: } 35(30-41) \text {; } \\
\text { Non-tuberculosis controls: } 36 \text { ( } 30-42)\end{array}$ \\
\hline & $\begin{array}{l}\text { Gender proportion (M:F) tuberculosis cases: } 64: 137 \\
\text { Non-tuberculosis controls: 64:112 }\end{array}$ \\
\hline & $\begin{array}{l}\text { Proportion on antiretroviral therapy (ART): tubercu- } \\
\text { losis cases: } 59 / 201(29 \%) \text {; Non-tuberculosis controls: } \\
61 / 176(35 \%)\end{array}$ \\
\hline \multirow[t]{6}{*}{ Index tests } & Sonographer qualification: Trained sonographers \\
\hline & Threshold(s): \\
\hline & $\begin{array}{l}\text { - Lymph nodes (long-axis length: any and } \geq 10 \mathrm{~mm} \text { in } \\
\text { diameter); }\end{array}$ \\
\hline & - Splenic hypoechoic lesions; \\
\hline & - Spleen enlargement $\geq 110 \mathrm{~mm}$; \\
\hline & $\begin{array}{l}\text { - Any one of abdominal, pleural, or pericardial effu- } \\
\text { sions }\end{array}$ \\
\hline
\end{tabular}

Target condition and reference standard(s)

Target condition: Tuberculosis

Confirmation of active tuberculosis: Positive culture for M tuberculosis

Abdominal ultrasound for diagnosing abdominal tuberculosis or disseminated tuberculosis with abdominal involvement in HIV-positive 
Griesel 2019-h (Continued)

Flow and timing

Comparative

Notes

\section{Methodological quality}

\begin{tabular}{|c|c|c|c|}
\hline Item & $\begin{array}{l}\text { Authors' } \\
\text { judgement }\end{array}$ & Risk of bias & $\begin{array}{l}\text { Applicability } \\
\text { concerns }\end{array}$ \\
\hline
\end{tabular}

\section{DOMAIN 1: Patient Selection}

Was a consecutive or random sample of patients enrolled?

Was a case-control design avoided?

Did the study avoid inappropriate exclusions?
Yes

Yes

No

High

Low

\section{DOMAIN 2: Index Test Abnormal abdominal ultrasound (higher quality)}

Were the index test results interpreted without knowledge of the results of the reference standard?

If a threshold was used, was it pre-specified?

Yes

Low

Low

\section{DOMAIN 2: Index Test Ascites}

Were the index test results interpreted without knowledge of the results of Yes the reference standard?

If a threshold was used, was it pre-specified?

Yes

\section{DOMAIN 2: Index Test Splenic lesions}

Were the index test results interpreted without knowledge of the results of Yes the reference standard?

If a threshold was used, was it pre-specified?

\begin{tabular}{|c|c|c|c|}
\hline & Low & Low & \\
\hline \multicolumn{4}{|l|}{ DOMAIN 2: Index Test Abdominal lymph nodes } \\
\hline $\begin{array}{l}\text { Were the index test results interpreted without knowledge of the results of } \\
\text { the reference standard? }\end{array}$ & Yes & & \\
\hline \multirow[t]{2}{*}{ If a threshold was used, was it pre-specified? } & Yes & & \\
\hline & Low & Low & \\
\hline $\begin{array}{l}\text { Abdominal ultrasound for diagnosing abdominal tuberculosis or disseminated tub } \\
\text { ndividuals (Review) }\end{array}$ & culosis with abdominal invo & V-positive & 33 \\
\hline $\begin{array}{l}\text { Copyright } \odot 2019 \text { The Authors. Cochrane Database of Systematic Reviews published by } \\
\text { Collaboration. }\end{array}$ & hn Wiley \& Sons, Ltd. on beha & rane & \\
\hline
\end{tabular}


Griesel 2019-h (Continued)

DOMAIN 2: Index Test Splenomegaly

Were the index test results interpreted without knowledge of the results of Yes the reference standard?

If a threshold was used, was it pre-specified?

Yes

\begin{tabular}{|c|c|c|c|}
\hline & & Low & Low \\
\hline \multicolumn{4}{|l|}{ DOMAIN 3: Reference Standard } \\
\hline Is the reference standards likely to correctly classify the target condition? & Yes & & \\
\hline $\begin{array}{l}\text { Were the reference standard results interpreted without knowledge of the } \\
\text { results of the index tests? }\end{array}$ & Yes & & \\
\hline \multirow[t]{2}{*}{ Was incorporation bias avoided? } & Yes & & \\
\hline & & Low & Low \\
\hline \multicolumn{4}{|l|}{ DOMAIN 4: Flow and Timing } \\
\hline $\begin{array}{l}\text { Was there an appropriate interval between index test and reference stan- } \\
\text { dard? }\end{array}$ & Unclear & & \\
\hline Did all patients receive the same reference standard? & Yes & & \\
\hline Were all patients included in the analysis? & Yes & & \\
\hline \multirow[t]{2}{*}{ Did all patients received a reference standard? } & Yes & & \\
\hline & & Low & \\
\hline
\end{tabular}

Kaneria 2009-I

\section{Study characteristics}

\section{Patient sampling}

Patient characteristics and setting

\section{Case-control}

Country: India

Setting: Not reported

High tuberculosis burden country: Yes

High HIV-associated tuberculosis burden country: Yes

Sample size: 90

Age: Mean (range) Cases: Male 36.4 (24 - 60), Female 33.41 (25 - 60); Controls: Male 39.46 (24 - 60), Female $38.71(25-61)$

Gender proportion: M:F Cases: 31:14; Controls: 30:15 
Kaneria 2009-I (Continued)

Proportion on antiretroviral therapy (ART): Cases: $7 / 45$

(15.6\%); Controls: 15/30 (50\%)

Index tests

Index tests

Target condition and reference standard(s)
Sonographer qualification: Not reported

Threshold(s): Not reported

Target condition: Pulmonary tuberculosis, extra-pulmonary tuberculosis and disseminated tuberculosis (with or without abdominal involvement)

Confirmation of active tuberculosis: Microscopic identification of AFB and compatible clinical findings

\footnotetext{
Flow and timing
}

\section{Comparative}

Notes

\section{Methodological quality}

\begin{tabular}{|c|c|c|c|}
\hline Item & $\begin{array}{l}\text { Authors' judge- } \\
\text { ment }\end{array}$ & Risk of bias & $\begin{array}{l}\text { Applicability } \\
\text { concerns }\end{array}$ \\
\hline
\end{tabular}

\section{DOMAIN 1: Patient Selection}

\begin{tabular}{lcc}
\hline Was a consecutive or random sample of patients enrolled? & Unclear \\
\hline Was a case-control design avoided? & No & \\
\hline Did the study avoid inappropriate exclusions? & Yes & High
\end{tabular}

\section{DOMAIN 2: Index Test Ascites}

Were the index test results interpreted without knowledge of the results of Unclear the reference standard?

\begin{tabular}{lll}
\hline & Unclear Unclear \\
\hline DOMAIN 2: Index Test Splenic lesions &
\end{tabular}

Were the index test results interpreted without knowledge of the results of Unclear the reference standard?

\begin{tabular}{lcl}
\hline If a threshold was used, was it pre-specified? & No & Unclear \\
\hline
\end{tabular}

\section{DOMAIN 2: Index Test Splenomegaly}

Were the index test results interpreted without knowledge of the results of Unclear the reference standard? 
Kaneria 2009-I (Continued)

\begin{tabular}{lcc}
\hline & Unclear & Unclear \\
\hline DOMAIN 2: Index Test Hepatomegaly &
\end{tabular}

\section{DOMAIN 2: Index Test Hepatomegaly}

Were the index test results interpreted without knowledge of the results of Unclear the reference standard?

If a threshold was used, was it pre-specified? No

\begin{tabular}{lll}
\hline DOMAIN 3: Reference Standard & Unclear & Unclear \\
\hline Is the reference standards likely to correctly classify the target condition? & No & Unclear \\
\hline Were the reference standard results interpreted without knowledge of the & Unclear \\
results of the index tests? & High \\
\hline Was incorporation bias avoided? & High \\
\hline DOMAIN 4: Flow and Timing & Unclear \\
\hline Was there an appropriate interval between index test and reference stan- \\
\begin{tabular}{l} 
dard? \\
\hline Did all patients receive the same reference standard?
\end{tabular} \\
\hline $\begin{array}{l}\text { Were all patients included in the analysis? } \\
\text { Did all patients received a reference standard? }\end{array}$ \\
\hline
\end{tabular}

High

Monill-Serra 1997-l

\section{Study characteristics}

Patient sampling

Patient characteristics and setting
Case-control

Country: Spain

Setting: Not reported

High tuberculosis burden country: No

High HIV-associated tuberculosis burden country: No

Sample size: 152

Age: Cases: Mean 30; Range 20 - 49; Controls: Not reported 
Gender proportion: M:F Cases: 56:20; Controls: Not reported

Proportion on antiretroviral therapy (ART): Not reported

Index tests

Target condition and reference standard(s)
Sonographer qualification: Not reported

Threshold(s):

- Lymph nodes > $1.5 \mathrm{~cm}$;

- Splenomegaly long axis $>12 \mathrm{~cm}$ or subjective impression;

- Hypoechoic splenic lesions $0.5 \mathrm{~cm}$ to $1.0 \mathrm{~cm}$ (Not prespecified)

Target condition: Disseminated tuberculosis (with or without abdominal involvement)

Confirmation of active tuberculosis: Microbiological (culture) or histopathological examination

Flow and timing

Comparative

Notes

Controls were HIV-positive with no associated neoplas-

tic illness or opportunistic infection

\section{Methodological quality}

\begin{tabular}{lll}
\hline Item & $\begin{array}{l}\text { Authors' judge- } \\
\text { ment }\end{array}$ & $\begin{array}{c}\text { Risk of bias } \\
\text { Applicability } \\
\text { concerns }\end{array}$ \\
\hline
\end{tabular}

DOMAIN 1: Patient Selection

\begin{tabular}{lcc}
\hline Was a consecutive or random sample of patients enrolled? & Unclear \\
\hline Was a case-control design avoided? & No & \\
\hline Did the study avoid inappropriate exclusions? & No & High \\
\hline
\end{tabular}

\section{DOMAIN 2: Index Test Ascites}

Were the index test results interpreted without knowledge of the results of Unclear the reference standard?

\begin{tabular}{lll}
\hline If a threshold was used, was it pre-specified? & Yes \\
\hline & Unclear Unclear
\end{tabular}

\section{DOMAIN 2: Index Test Splenic lesions}

Were the index test results interpreted without knowledge of the results of Unclear the reference standard? 
Monill-Serra 1997-l (Continued)

\begin{tabular}{lll}
\hline & Unclear & Unclear \\
\hline DOMAIN 2: Index Test Abdominal lymph nodes &
\end{tabular}

\section{DOMAIN 2: Index Test Abdominal lymph nodes}

Were the index test results interpreted without knowledge of the results of Unclear the reference standard?

If a threshold was used, was it pre-specified? Yes

\begin{tabular}{lcc}
\hline & Unclear & Unclear \\
\hline DOMAIN 2: Index Test Splenomegaly & & \\
\hline
\end{tabular}

Were the index test results interpreted without knowledge of the results of Unclear the reference standard?

If a threshold was used, was it pre-specified?

Yes

\begin{tabular}{lll}
\hline & Unclear & Unclear \\
\hline DOMAIN 2: Index Test Hepatomegaly &
\end{tabular}

Were the index test results interpreted without knowledge of the results of Unclear the reference standard?

\begin{tabular}{lll}
\hline If a threshold was used, was it pre-specified? & Yes \\
\hline & Unclear & Unclear \\
\hline
\end{tabular}

\section{DOMAIN 3: Reference Standard}

Is the reference standards likely to correctly classify the target condition? No

Were the reference standard results interpreted without knowledge of the Yes results of the index tests?

\begin{tabular}{lcc}
\hline Was incorporation bias avoided? & Yes & \\
\hline & High & High \\
\hline
\end{tabular}

\section{DOMAIN 4: Flow and Timing}

Was there an appropriate interval between index test and reference stan- Unclear dard?

\begin{tabular}{ll}
\hline Did all patients receive the same reference standard? & Unclear \\
\hline Were all patients included in the analysis? & Yes \\
\hline Did all patients received a reference standard? & Yes \\
\hline
\end{tabular}

Unclear 
Ndege 2019-h

\section{Study characteristics}

\begin{tabular}{|c|c|}
\hline Patient sampling & Prospective cohort \\
\hline \multirow[t]{8}{*}{ Patient characteristics and setting } & Country: Tanzania \\
\hline & Setting: Referral hospital \\
\hline & High tuberculosis burden country: Yes \\
\hline & High HIV-associated tuberculosis burden country: Yes \\
\hline & $\begin{array}{l}\text { Sample size: } 100 \text { (original study size including HIV-neg- } \\
\text { ative } n=191 \text { ) }\end{array}$ \\
\hline & Age: Median 38 years; IQR 32 - 44 years \\
\hline & Gender proportion: M:F 47:53 \\
\hline & Proportion on antiretroviral therapy (ART): 56\% \\
\hline \multirow[t]{6}{*}{ Index tests } & $\begin{array}{l}\text { Sonographer qualification: Board-certified sonogra- } \\
\text { phers }\end{array}$ \\
\hline & Threshold(s): \\
\hline & $\begin{array}{l}\text { Original FASH: pleural or pericardial effusion, ascites, } \\
\text { abdominal lymph nodes }>1.5 \mathrm{~cm} \text {, hypoechogenic le- } \\
\text { sions in the liver or spleen, ileum wall thickening }>4 \\
\mathrm{~mm} \text { or destructed ileum wall architecture; }\end{array}$ \\
\hline & - Splenomegaly > 140 mm in long axis; \\
\hline & - Hepatomegaly $\geq 2 \mathrm{~cm}$ below costal margin; \\
\hline & $\begin{array}{l}\text { - Pleural or pericardial fibrin strands in presence of ef- } \\
\text { fusion }\end{array}$ \\
\hline
\end{tabular}

Target condition and reference standard(s)

Confirmed tuberculosis was defined as $\geq 1$ positive microbiological result from any site confirmed by Xpert MTB/RIF assay and/or bacteriologic culture (growth of $M$ tuberculosis) in sputum, pleural fluid, ascites, cerebrospinal fluid, urine or lymph node aspirate

Flow and timing

Comparative

Notes

\section{Methodological quality}

\begin{tabular}{|c|c|c|c|}
\hline Item & $\begin{array}{l}\text { Authors' judge- } \\
\text { ment }\end{array}$ & Risk of bias & $\begin{array}{l}\text { Applicability } \\
\text { concerns }\end{array}$ \\
\hline
\end{tabular}

DOMAIN 1: Patient Selection

\begin{tabular}{lc}
\hline Was a consecutive or random sample of patients enrolled? & Yes \\
\hline Was a case-control design avoided? & Yes \\
\hline
\end{tabular}

Abdominal ultrasound for diagnosing abdominal tuberculosis or disseminated tuberculosis with abdominal involvement in HIV-positive 
Ndege 2019-h (Continued)

\begin{tabular}{lll}
\hline & Low & High \\
\hline DOMAIN 2: Index Test Abnormal abdominal ultrasound (higher quality) &
\end{tabular}

DOMAIN 2: Index Test Abnormal abdominal ultrasound (higher quality)

Were the index test results interpreted without knowledge of the results of Yes the reference standard?

If a threshold was used, was it pre-specified? Yes

\begin{tabular}{llc}
\hline LOMAIN 2: Index Test Ascites & Low & \\
\hline Were the index test results interpreted without knowledge of the results of & Yes \\
the reference standard? & Yes & Low \\
\hline If a threshold was used, was it pre-specified? & Low
\end{tabular}

\section{DOMAIN 2: Index Test Splenic lesions}

Were the index test results interpreted without knowledge of the results of Yes the reference standard?

\begin{tabular}{lcl}
\hline If a threshold was used, was it pre-specified? & Yes & Low Low \\
\hline
\end{tabular}

\section{DOMAIN 2: Index Test Abdominal lymph nodes}

Were the index test results interpreted without knowledge of the results of Yes the reference standard?

If a threshold was used, was it pre-specified? Yes

\begin{tabular}{lll}
\hline & Low & Low \\
\hline DOMAIN 2: Index Test Splenomegaly & Yes & Yes \\
\hline $\begin{array}{l}\text { Were the index test results interpreted without knowledge of the results of } \\
\text { the reference standard? }\end{array}$ & Low & Low \\
\hline If a threshold was used, was it pre-specified?
\end{tabular}

\section{DOMAIN 2: Index Test Hepatomegaly}

Were the index test results interpreted without knowledge of the results of Yes the reference standard?

If a threshold was used, was it pre-specified? 
Ndege 2019-h (Continued)

Low

Low

\section{DOMAIN 3: Reference Standard}

Is the reference standards likely to correctly classify the target condition? Yes

Were the reference standard results interpreted without knowledge of the Yes results of the index tests?

\begin{tabular}{lcc}
\hline Was incorporation bias avoided? & Yes & Low \\
\hline DomAIN 4: Flow and Timing & Yes \\
\hline $\begin{array}{l}\text { Was there an appropriate interval between index test and reference stan- } \\
\text { dard? }\end{array}$ & Yes & Yes \\
\hline Did all patients receive the same reference standard? & Yes & Low \\
\hline Were all patients included in the analysis? & \\
\hline Did all patients received a reference standard?
\end{tabular}

\section{Ndege 2019-I}

\section{Study characteristics}

\begin{tabular}{|c|c|}
\hline Patient sampling & Prospective cohort \\
\hline \multirow[t]{8}{*}{ Patient characteristics and setting } & Country: Tanzania \\
\hline & Setting: Referral hospital \\
\hline & High tuberculosis burden country: Yes \\
\hline & High HIV-associated tuberculosis burden country: Yes \\
\hline & Sample size: 100 (original study size including HIV-negative $n=191$ ) \\
\hline & Age: Median 38 years; IQR 32 - 44 years \\
\hline & Gender proportion: M:F 47:53 \\
\hline & Proportion on antiretroviral therapy (ART): $56 \%$ \\
\hline \multirow[t]{5}{*}{ Index tests } & Sonographer qualification: Board-certified sonographers \\
\hline & Threshold(s): \\
\hline & $\begin{array}{l}\text { Original FASH: pleural or pericardial effusion, ascites, abdominal lymph nodes }>1.5 \\
\mathrm{~cm} \text {, hypoechogenic lesions in the liver or spleen, ileum wall thickening }>4 \mathrm{~mm} \text { or de- } \\
\text { structed ileum wall architecture; }\end{array}$ \\
\hline & - Splenomegaly > 140 mm in long axis; \\
\hline & - Hepatomegaly $\geq 2 \mathrm{~cm}$ below costal margin; \\
\hline
\end{tabular}

Abdominal ultrasound for diagnosing abdominal tuberculosis or disseminated tuberculosis with abdominal involvement in HIV-positive 
Ndege 2019-I (Continued)

- Pleural or pericardial fibrin strands in presence of effusion

Target condition and reference standard(s)
Confirmed tuberculosis was defined as $\geq 1$ positive microbiological result from any site confirmed by Xpert MTB/RIF assay and/or bacteriologic culture (growth of $M$ tuberculosis) in sputum, pleural fluid, ascites, cerebrospinal fluid, urine or lymph node aspirate. In addition, the identification of acid-fast bacilli in sputum by another health centre, or adenosine deaminase $(A D A) \geq 40 \mathrm{U} / \mathrm{ml}$ in pleural fluid, $\geq 35 \mathrm{U} / \mathrm{ml}$ in pericardial fluid and $\geq 30 \mathrm{U} / \mathrm{ml}$ in ascitic fluid were accepted as microbiological confirmation. Probable tuberculosis was defined as negative microbiological tests in a participant in whom anti-tuberculosis therapy (prescribed based on clinical suspicion or on chest x-ray) in the absence of an alternative diagnosis led to a resolution of clinical signs and symptoms, radiographic and sonographic signs, and to an increase in body weight documented 2 months after start of anti-tuberculosis treatment

Flow and timing

Comparative

$$
\text { Notes }
$$

\section{Methodological quality}

\begin{tabular}{llll}
\hline Item & Authors' judgement & Risk of bias & Applicability concerns \\
\hline
\end{tabular}

DOMAIN 1: Patient Selection

\section{Was a consecutive or random sample of Yes} patients enrolled?

\begin{tabular}{ll} 
Was a case-control design avoided? & Yes \\
\hline $\begin{array}{l}\text { Did the study avoid inappropriate exclu- } \\
\text { sions? }\end{array}$ & Yes
\end{tabular}

\begin{tabular}{lll}
\hline High & Low \\
\hline
\end{tabular}

DOMAIN 2: Index Test Abnormal abdominal ultrasound (lower quality)

\author{
Were the index test results interpreted \\ without knowledge of the results of the \\ reference standard? \\ If a threshold was used, was it pre-speci- Yes \\ fied?

\section{Yes}

(1)


Ndege 2019-I (Continued)

High

Low

\section{DOMAIN 4: Flow and Timing}

Was there an appropriate interval be-

Yes

tween index test and reference standard?

Did all patients receive the same refer- No

ence standard?

Were all patients included in the analysis? Yes

Did all patients received a reference stan- Yes

dard?

Unclear

O'Keefe 1998-h

\section{Study characteristics}

\begin{tabular}{|c|c|}
\hline Patient sampling & Prospective cross-sectional \\
\hline \multirow[t]{8}{*}{ Patient characteristics and setting } & Country: South Africa \\
\hline & Setting: Non-tertiary setting \\
\hline & High tuberculosis burden country: Yes \\
\hline & High HIV-associated tuberculosis burden country: Yes \\
\hline & Sample size: 35 (original study size $n=44$ ) \\
\hline & Age: Mean 32.9; Range 18.4 - 53.3 \\
\hline & Gender proportion: M:F 26:18 \\
\hline & Proportion on antiretroviral therapy (ART): 0/44 (0\%) \\
\hline \multirow[t]{2}{*}{ Index tests } & Sonographer qualification: Radiologist \\
\hline & Threshold(s): Not reported \\
\hline \multirow[t]{2}{*}{ Target condition and reference standard(s) } & $\begin{array}{l}\text { Target condition: Disseminated tuberculosis with ab- } \\
\text { dominal involvement) }\end{array}$ \\
\hline & $\begin{array}{l}\text { Confirmation of active tuberculosis: Microbiological } \\
\text { (culture) or postmortem evidence }\end{array}$ \\
\hline
\end{tabular}

Flow and timing

Comparative

Notes Only 35/44 had ultrasound examination

\section{Methodological quality}

Abdominal ultrasound for diagnosing abdominal tuberculosis or disseminated tuberculosis with abdominal involvement in HIV-positive

Copyright (c) 2019 The Authors. Cochrane Database of Systematic Reviews published by John Wiley \& Sons, Ltd. on behalf of The Cochrane

Collaboration. 
O'Keefe 1998-h (Continued)

$\begin{array}{ll}\text { Item } & \begin{array}{l}\text { Authors' judge- } \\ \text { ment }\end{array}\end{array} \begin{gathered}\text { Risk of bias Applicability } \\ \text { concerns }\end{gathered}$

DOMAIN 1: Patient Selection

Was a consecutive or random sample of patients enrolled? Yes

Was a case-control design avoided? Yes

Did the study avoid inappropriate exclusions? No

\begin{tabular}{llll}
\hline & High & Low \\
\hline
\end{tabular}

\section{DOMAIN 2: Index Test Ascites}

Were the index test results interpreted without knowledge of the results of Unclear the reference standard?

\begin{tabular}{llll}
\hline DOMAIN 2: Index Test Abdominal lymph nodes & Unclear & High & \\
\hline Were the index test results interpreted without knowledge of the results of & Unclear & \\
the reference standard? & No & Unclear & High \\
\hline If a threshold was used, was it pre-specified? & & \\
\hline & & \\
\hline DOMAIN 3: Reference Standard & Yes & Yes \\
\hline Is the reference standards likely to correctly classify the target condition? & & \\
\hline Were the reference standard results interpreted without knowledge of the & Low \\
\hline results of the index tests? & Yes & Low
\end{tabular}

\section{DOMAIN 4: Flow and Timing}

Was there an appropriate interval between index test and reference stan- Unclear dard?

\begin{tabular}{ll}
\hline Did all patients receive the same reference standard? & No \\
\hline Were all patients included in the analysis? & Yes \\
\hline Did all patients received a reference standard? & Yes \\
\hline
\end{tabular}

Unclear 
Sculier 2010-h

\section{Study characteristics}

\begin{tabular}{|c|c|}
\hline Patient sampling & Prospective cross-sectional \\
\hline \multirow[t]{8}{*}{ Patient characteristics and setting } & Country: Cambodia \\
\hline & Setting: "not-for-profit referral hospital" \\
\hline & High tuberculosis burden country: Yes \\
\hline & High HIV-associated tuberculosis burden country: No \\
\hline & Sample size: 212 \\
\hline & $\begin{array}{l}\text { Age: Median (IQR) } 34(29-41.5) \text { years (included participants < } \\
18 \text { years) }\end{array}$ \\
\hline & Gender proportion: M 40\%, F 60\% \\
\hline & Proportion on antiretroviral therapy (ART): Not reported \\
\hline \multirow[t]{7}{*}{ Index tests } & Sonographer qualification: "Trained radiologist" \\
\hline & Threshold(s): \\
\hline & - Any lymph nodes $\geq 1.2 \mathrm{~cm}$; \\
\hline & - Ascites; \\
\hline & - Hepatomegaly; \\
\hline & - Splenomegaly; \\
\hline & $\begin{array}{l}\text { - Hepatic or splenic hypoechoic lesions with or without organ } \\
\text { enlargement }\end{array}$ \\
\hline \multirow[t]{2}{*}{ Target condition and reference standard(s) } & $\begin{array}{l}\text { Target condition: Disseminated tuberculosis (with or without } \\
\text { abdominal involvement) }\end{array}$ \\
\hline & Confirmation of active tuberculosis: Culture \\
\hline
\end{tabular}

\section{Flow and timing}

\section{Comparative}

\begin{tabular}{|c|c|c|c|}
\hline Notes & Substudy & & \\
\hline \multicolumn{4}{|l|}{ Methodological quality } \\
\hline Item & $\begin{array}{l}\text { Authors' judge- } \\
\text { ment }\end{array}$ & Risk of bias & $\begin{array}{l}\text { Applicability con- } \\
\text { cerns }\end{array}$ \\
\hline \multicolumn{4}{|l|}{ DOMAIN 1: Patient Selection } \\
\hline Was a consecutive or random sample of patients enrolled? & Yes & & \\
\hline Was a case-control design avoided? & Yes & & \\
\hline \multirow[t]{2}{*}{ Did the study avoid inappropriate exclusions? } & Yes & & \\
\hline & & Low & High \\
\hline
\end{tabular}


Sculier 2010-h (Continued)

DOMAIN 2: Index Test Abnormal abdominal ultrasound (higher quality)

Were the index test results interpreted without knowledge of the re- Yes sults of the reference standard?

If a threshold was used, was it pre-specified? Yes

Low

High

\section{DOMAIN 3: Reference Standard}

Is the reference standards likely to correctly classify the target con- Yes dition?

Were the reference standard results interpreted without knowledge Yes of the results of the index tests?

\begin{tabular}{lll}
\hline Was incorporation bias avoided? & Yes & Low High \\
\hline DOMAIN 4: Flow and Timing & Unclear \\
\hline $\begin{array}{l}\text { Was there an appropriate interval between index test and reference } \\
\text { standard? }\end{array}$ & Yes \\
\hline Did all patients receive the same reference standard? & Yes \\
\hline Were all patients included in the analysis? & Low \\
\hline Did all patients received a reference standard?
\end{tabular}

Sinkala 2009-I

\section{Study characteristics}

\begin{tabular}{|c|c|}
\hline Patient sampling & Prospective cross-sectional \\
\hline \multirow[t]{8}{*}{ Patient characteristics and setting } & Country: Zambia \\
\hline & Setting: "secondary and tertiary care hospital" \\
\hline & High tuberculosis burden country: Yes \\
\hline & High HIV-associated tuberculosis burden country: Yes \\
\hline & Sample size: 31 \\
\hline & $\begin{array}{l}\text { Age: Mean (SD) All: } 33.4 \text { (8.3) years (in text: mean } 33.1 \text { range } 18 \text { - 54); tu- } \\
\text { berculosis: } 30.7 \text { (6.9); No tuberculosis: } 39.8 \text { (8) }\end{array}$ \\
\hline & Gender proportion: M:F All: 8:23; tuberculosis: 7:15; No tuberculosis: 1:8 \\
\hline & Proportion on antiretroviral therapy (ART): Not reported \\
\hline
\end{tabular}

Abdominal ultrasound for diagnosing abdominal tuberculosis or disseminated tuberculosis with abdominal involvement in HIV-positive individuals (Review)

Copyright (C) 2019 The Authors. Cochrane Database of Systematic Reviews published by John Wiley \& Sons, Ltd. on behalf of The Cochrane

Collaboration. 
Sinkala 2009-I (Continued)

Index tests

Sonographer qualification: Not reported

Threshold(s): Not reported
Target condition: Abdominal tuberculosis

Confirmation of active tuberculosis: “... definitive diagnosis of tuberculosis was made by demonstration of $M$ tuberculosis infection via positive bacteriological culture and/or granulomatous inflammation on histopathological examination with positive Ziehl-Neelsen (ZN) staining on microscopy. A presumptive diagnosis of tuberculosis was made when granulomatous inflammation was seen on microscopy, or when visual inspection on laparoscopy was consistent with tuberculosis and the patient's clinical response to anti-tuberculous treatment was good. Laparoscopic features felt to be consistent with tuberculosis for the purpose of making a presumptive diagnosis were the presence of tubercles, fibro adhesive peritonitis, or caseating lymphadenopathy."

Flow and timing

\section{Comparative}

\section{Notes}

Ultrasound used as part of inclusion and exclusion criteria (selection bias)

\section{Methodological quality}

\begin{tabular}{llll}
\hline Item Authors' judgement & Risk of bias & \multicolumn{1}{l}{$\begin{array}{l}\text { Applicability con- } \\
\text { cerns }\end{array}$}
\end{tabular}

\section{DOMAIN 1: Patient Selection}

Was a consecutive or random sample of patients en- Yes
rolled?

\begin{tabular}{llll}
\hline Was a case-control design avoided? & Yes & \\
\hline Did the study avoid inappropriate exclusions? & Yes & Low & High \\
\hline
\end{tabular}

\section{DOMAIN 2: Index Test Ascites}

Were the index test results interpreted without knowledge Yes of the results of the reference standard?

If a threshold was used, was it pre-specified? No

\begin{tabular}{lll}
\hline Low & Unclear \\
\hline
\end{tabular}

\section{DOMAIN 2: Index Test Abdominal lymph nodes}

Were the index test results interpreted without knowledge Yes

of the results of the reference standard?

If a threshold was used, was it pre-specified? 
Sinkala 2009-I (Continued)

DOMAIN 2: Index Test Splenomegaly

Were the index test results interpreted without knowledge Yes

of the results of the reference standard?

If a threshold was used, was it pre-specified?

No

\begin{tabular}{llll}
\hline & Unclear & Unclear \\
\hline DOMAIN 2: Index Test Hepatomegaly & & \\
\hline $\begin{array}{l}\text { Were the index test results interpreted without knowledge } \\
\text { of the results of the reference standard? }\end{array}$ & No & Unclear \\
\hline \begin{tabular}{l} 
If a threshold was used, was it pre-specified? \\
\hline DOMAIN 3: Reference Standard
\end{tabular} & No & \\
\hline $\begin{array}{l}\text { Is the reference standards likely to correctly classify the } \\
\text { target condition? }\end{array}$ & No & High \\
\hline $\begin{array}{l}\text { Were the reference standard results interpreted without } \\
\text { knowledge of the results of the index tests? }\end{array}$ & Yes \\
\hline Was incorporation bias avoided? & High \\
\hline
\end{tabular}

\section{DOMAIN 4: Flow and Timing}

Was there an appropriate interval between index test and Unclear
reference standard?

\begin{tabular}{ll}
\hline Did all patients receive the same reference standard? & Yes \\
\hline Were all patients included in the analysis? & Yes \\
\hline Did all patients received a reference standard? & Yes \\
\hline
\end{tabular}

Low

Weber 2018-h

\section{Study characteristics}

\begin{tabular}{ll}
\hline Patient sampling & Prospective controlled cohort \\
\hline Patient characteristics and setting & Country: India \\
& Setting: Tertiary setting \\
& High tuberculosis burden country: Yes \\
& High HIV-associated tuberculosis burden country: Yes \\
\hline
\end{tabular}

Abdominal ultrasound for diagnosing abdominal tuberculosis or disseminated tuberculosis with abdominal involvement in HIV-positive

Copyright $\odot 2019$ The Authors. Cochrane Database of Systematic Reviews published by John Wiley \& Sons, Ltd. on behalf of The Cochrane

Collaboration. 
Weber 2018-h (Continued)

Sample size: 81 (original study size including HIV-negative $n=425$ )

Age: Overall median (IQR) 43 (31.5 - 55); HIV only 43 (38 - 48) (included participants $<18$ years)

Gender proportion: Overall: M 328/425 (77\%); HIV-positive M 56/81 (69\%)

Proportion on antiretroviral therapy (ART): 29/81 (35.8\%)

Index tests

Sonographer qualification: Clinician trained in the study's ultrasound protocol but without formal ultrasound training

Threshold(s):

- FASH: at least 1 of pericardial or pleural effusion, focal liver or splenic lesions, or abdominal lymphadenopathy;

- Pericardial effusion: qualitative assessment;

- Focal liver lesions: Size $2 \mathrm{~mm}$ to $15 \mathrm{~mm}$; multiple in appearance;

- Focal splenic lesions: Size $2 \mathrm{~mm}$ to $15 \mathrm{~mm}$; multiple in appearance;

- Abdominal lymphadenopathy: Max diameter at least $15 \mathrm{~mm}$

Target condition and reference standard(s)

Target condition: Pulmonary tuberculosis and extra-pulmonary tuberculosis

Confirmation of active tuberculosis: “...'confirmed tuberculosis' (i.e., positive fluorescent microscopy, polymerase chain reaction, or tuberculosis culture)..."

\section{Flow and timing}

\section{Comparative}

\begin{tabular}{ll}
\hline Notes & Includes patients $\geq 16$ years \\
& “...therapeutic and diagnostic management was fully the responsibility \\
of the attending hospital doctor." & Additional info received from authors \\
\hline
\end{tabular}

\section{Methodological quality}

\begin{tabular}{llll}
\hline Item & Authors' judgement & Risk of bias & $\begin{array}{l}\text { Applicability con- } \\
\text { cerns }\end{array}$ \\
\hline
\end{tabular}

\section{DOMAIN 1: Patient Selection}

Was a consecutive or random sample of patients en- Yes rolled?

\begin{tabular}{llll}
\hline Was a case-control design avoided? & Yes & \\
\hline Did the study avoid inappropriate exclusions? & Yes & High \\
\hline
\end{tabular}

\section{DOMAIN 2: Index Test Abnormal abdominal ultrasound (higher quality)}


Weber 2018-h (Continued)

Were the index test results interpreted without knowledge No of the results of the reference standard?

If a threshold was used, was it pre-specified?

Yes

Unclear

Low

\section{DOMAIN 2: Index Test Ascites}

Were the index test results interpreted without knowledge No of the results of the reference standard?

If a threshold was used, was it pre-specified? Yes

Unclear Low

\section{DOMAIN 2: Index Test Splenic lesions}

Were the index test results interpreted without knowledge No

of the results of the reference standard?

\begin{tabular}{llll}
\hline If a threshold was used, was it pre-specified? & Yes & Low Unclear & Low
\end{tabular}

\section{DOMAIN 2: Index Test Abdominal lymph nodes}

Were the index test results interpreted without knowledge No

of the results of the reference standard?

If a threshold was used, was it pre-specified?

Yes

\begin{tabular}{lll}
\hline & Unclear & Low \\
\hline DOMAIN 3: Reference Standard &
\end{tabular}

\section{DOMAIN 3: Reference Standard}

Is the reference standards likely to correctly classify the Yes target condition?

Were the reference standard results interpreted without Yes knowledge of the results of the index tests?

Was incorporation bias avoided? Yes

Low

High

\section{DOMAIN 4: Flow and Timing} Was there an appropriate interval between index test and Yes
reference standard?

\begin{tabular}{ll}
\hline Did all patients receive the same reference standard? & No \\
\hline Were all patients included in the analysis? & Yes \\
\hline Did all patients received a reference standard? & Yes \\
\hline
\end{tabular}

Abdominal ultrasound for diagnosing abdominal tuberculosis or disseminated tuberculosis with abdominal involvement in HIV-positive 50 individuals (Review)

Copyright (c) 2019 The Authors. Cochrane Database of Systematic Reviews published by John Wiley \& Sons, Ltd. on behalf of The Cochrane Collaboration. 
Weber 2018-I

\section{Study characteristics}

\begin{tabular}{|c|c|}
\hline Patient sampling & Prospective controlled cohort \\
\hline \multirow[t]{8}{*}{ Patient characteristics and setting } & Country: India \\
\hline & Setting: Tertiary setting \\
\hline & High tuberculosis burden country: Yes \\
\hline & High HIV-associated tuberculosis burden country: Yes \\
\hline & Sample size: 81 (original study size including HIV-negative $n=425$ ) \\
\hline & $\begin{array}{l}\text { Age: Overall median (IQR) } 43(31.5 \text { - 55); HIV only } 43(38-48) \text { (included participants }< \\
18 \text { years) }\end{array}$ \\
\hline & Gender proportion: Overall: M 328/425 (77\%); HIV-positive M 56/81 (69\%) \\
\hline & Proportion on antiretroviral therapy (ART): $29 / 81(35.8 \%)$ \\
\hline \multirow[t]{7}{*}{ Index tests } & $\begin{array}{l}\text { Sonographer qualification: Clinician trained in the study's ultrasound protocol but } \\
\text { without formal ultrasound training }\end{array}$ \\
\hline & Threshold(s): \\
\hline & $\begin{array}{l}\text { - FASH: at least } 1 \text { of pericardial or pleural effusion, focal liver or splenic lesions, or } \\
\text { abdominal lymphadenopathy; }\end{array}$ \\
\hline & - Pericardial effusion: qualitative assessment; \\
\hline & - Focal liver lesions: Size $2 \mathrm{~mm}$ to $15 \mathrm{~mm}$; multiple in appearance; \\
\hline & - Focal splenic lesions: Size $2 \mathrm{~mm}$ to $15 \mathrm{~mm}$; multiple in appearance; \\
\hline & - Abdominal lymphadenopathy: Max diameter at least $15 \mathrm{~mm}$ \\
\hline
\end{tabular}

Target condition and reference standard(s) Target condition: Pulmonary tuberculosis and extra-pulmonary tuberculosis

Confirmation of active tuberculosis: “...'clinical tuberculosis' (no microbiological confirmation, but clinical tuberculosis diagnosis and tuberculosis treatment initiated)..."

\section{Flow and timing}

Comparative

$\begin{array}{ll}\text { Notes } & \text { Includes patients } \geq 16 \text { years } \\ \text { “...therapeutic and diagnostic management was fully the responsibility of the at- } \\ \text { tending hospital doctor." } \\ \text { Additional info received from authors }\end{array}$

\section{Methodological quality}

\begin{tabular}{llll}
\hline Item & Authors' judgement & Risk of bias & Applicability concerns \\
\hline
\end{tabular}

Abdominal ultrasound for diagnosing abdominal tuberculosis or disseminated tuberculosis with abdominal involvement in HIV-positive 
Weber 2018-I (Continued)

\section{DOMAIN 1: Patient Selection}

Was a consecutive or random sample of pa- $\quad$ Yes tients enrolled?

Was a case-control design avoided? Yes

Did the study avoid inappropriate exclusions? Yes

Low High

\section{DOMAIN 2: Index Test Abnormal abdominal ultrasound (lower quality)}

Were the index test results interpreted with- No out knowledge of the results of the reference standard?

If a threshold was used, was it pre-specified? Yes

\begin{tabular}{|c|c|c|}
\hline & Unclear & High \\
\hline \multicolumn{3}{|l|}{ DOMAIN 3: Reference Standard } \\
\hline $\begin{array}{l}\text { Is the reference standards likely to correctly } \\
\text { classify the target condition? }\end{array}$ & No & \\
\hline $\begin{array}{l}\text { Were the reference standard results interpret- } \\
\text { ed without knowledge of the results of the in- } \\
\text { dex tests? }\end{array}$ & No & \\
\hline \multirow[t]{2}{*}{ Was incorporation bias avoided? } & No & \\
\hline & High & Unclear \\
\hline \multicolumn{3}{|l|}{ DOMAIN 4: Flow and Timing } \\
\hline $\begin{array}{l}\text { Was there an appropriate interval between in- } \\
\text { dex test and reference standard? }\end{array}$ & Yes & \\
\hline $\begin{array}{l}\text { Did all patients receive the same reference } \\
\text { standard? }\end{array}$ & No & \\
\hline Were all patients included in the analysis? & Yes & \\
\hline $\begin{array}{l}\text { Did all patients received a reference stan- } \\
\text { dard? }\end{array}$ & Yes & \\
\hline
\end{tabular}

Low

Suffix (h) indicates higher-quality reference standard; suffix $(\mathrm{l})$ indicates lower-quality reference standard

Characteristics of excluded studies [ordered by study ID] 


\begin{tabular}{|c|c|}
\hline Study & Reason for exclusion \\
\hline Abiri 1985 & Descriptive study \\
\hline Agarwal 2010 & No reference standard \\
\hline Akinkuolie 2008 & Descriptive study \\
\hline Aubry 1994 & Descriptive study \\
\hline Barthwal 2005 & Descriptive study \\
\hline Batra 2000 & Descriptive study \\
\hline Chen 2009 & Descriptive study \\
\hline Clarke 2007 & Descriptive study \\
\hline Emby 2002 & Descriptive study \\
\hline Feng 2016 & Ineligible index test \\
\hline Giordani 2013 & Descriptive study \\
\hline Heller 2010a & Descriptive study \\
\hline Heller 2013 & Descriptive study \\
\hline Heller 2017 & Descriptive study \\
\hline Ibrahim 2005 & Descriptive study \\
\hline Jain 1995 & Ineligible patient population \\
\hline Kedar 1994 & Descriptive study \\
\hline Landoni 2002 & Descriptive study \\
\hline Ouedraogo 2016 & Only abnormal index test reported \\
\hline Patel 2011 & Only abnormal index test reported \\
\hline Porcel-Martin 1998 & Descriptive study \\
\hline Sheikh 1999 & Descriptive study \\
\hline Solomon 1998 & Not a diagnostic accuracy study \\
\hline Soriano 1991 & Descriptive study \\
\hline Spalgais 2013 & Descriptive study \\
\hline Spalgais 2017 & No reference standard \\
\hline Tarantino 2003 & Descriptive study \\
\hline Tarantino 2004 & Descriptive study \\
\hline
\end{tabular}

Abdominal ultrasound for diagnosing abdominal tuberculosis or disseminated tuberculosis with abdominal involvement in HIV-positive 


\begin{tabular}{ll}
\hline Study & Reason for exclusion \\
\hline Tshibwabwa 2000 & Ineligible patient population \\
\hline Wafai 2017 & Descriptive study \\
\hline
\end{tabular}

\section{Characteristics of ongoing studies [ordered by study ID]}

\section{PACTR201712002829221}

\begin{tabular}{ll}
\hline Trial name or title & Ultrasound in managing tuberculosis: A randomized controlled two-center study \\
\hline $\begin{array}{l}\text { Target condition and refer- } \\
\text { ence standard(s) }\end{array}$ & $\begin{array}{l}\text { Target condition: Extrapulmonary tuberculosis } \\
\text { Reference standard: Not stipulated }\end{array}$ \\
\hline Index and comparator tests & $\begin{array}{l}\text { Index test: eFASH (extended focused assessment with sonography for HIV and tuberculosis) and a } \\
\text { management algorithm } \\
\text { Comparator group: Standard of care (Management according to the decision of the treating physi- } \\
\text { cian) }\end{array}$ \\
\hline Starting date & September 2018 \\
\hline Contact information & mrohacek@ihi.or.tz \\
\hline Notes & \\
\hline
\end{tabular}

\section{A T A}

Presented below are all the data for all of the tests entered into the review.

\section{Table Tests. Data tables by test}

\begin{tabular}{lll}
\hline Test & No. of studies & No. of participants \\
\hline 1 Abnormal abdominal ultrasound (higher quality) & 5 & 879 \\
\hline 2 Abnormal abdominal ultrasound (lower quality) & 4 & 397 \\
\hline 3 Ascites & 8 & 891 \\
\hline 4 Splenic lesions & 6 & 916 \\
\hline 5 Abdominal lymph nodes & 8 & 917 \\
\hline 6 Splenomegaly & 6 & 775 \\
\hline 7 Hepatomegaly & 4 & 373 \\
\hline
\end{tabular}




\section{Test 1. Abnormal abdominal ultrasound (higher quality).} Review: Abdominal ultrasound for diagnosing abdominal tuberculosis or disseminated tuberculosis with abdominal involvement in HIV-positive individuals
Test: 1 Abnormal abdominal ultrasound (higher quality)

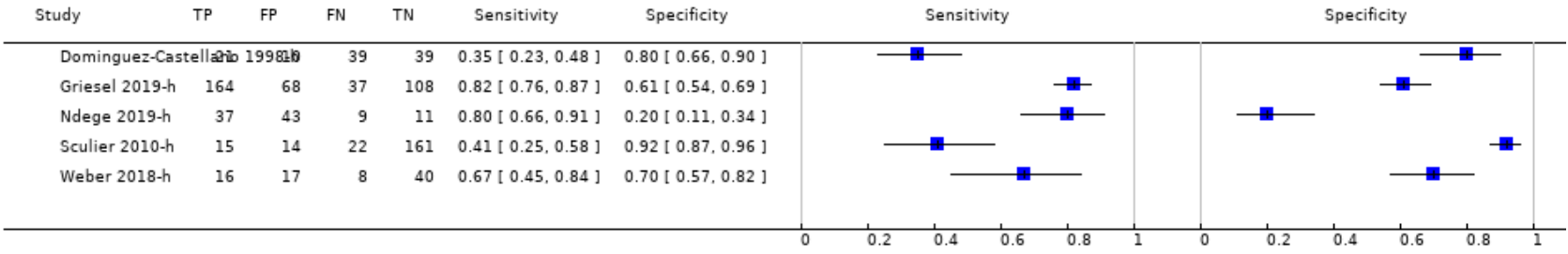

Test 2. Abnormal abdominal ultrasound (lower quality).

Review: Abdominal ultrasound for diagnosing abdominal tuberculosis or disseminated tuberculosis with abdominal involvement in HIV-positive individuals

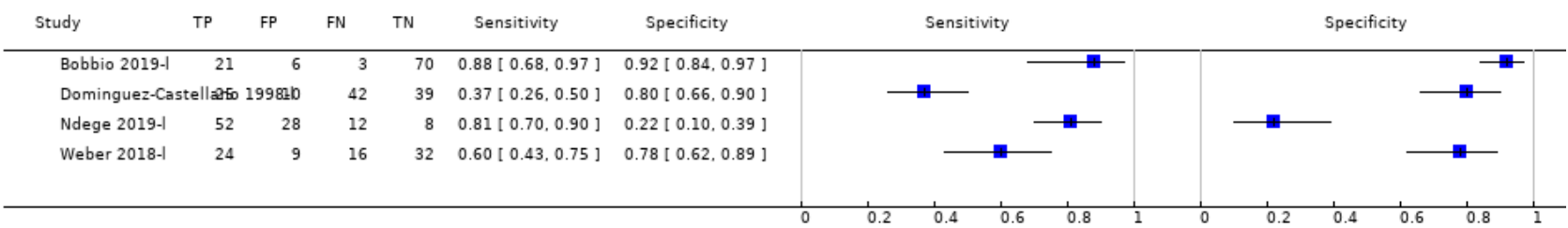

Test 3. Ascites.

Review: Abdominal ultrasound for diagnosing abdominal tuberculosis or disseminated tuberculosis with abdominal involvement in HIV-positive individuals

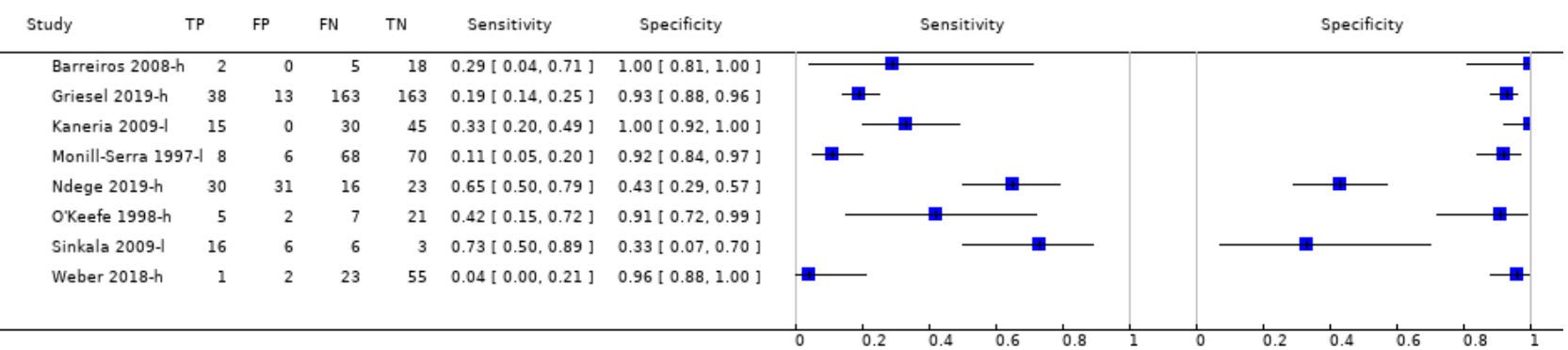

Test 4. Splenic lesions.

Review: Abdominal ultrasound for diagnosing abdominal tuberculosis or disseminated tuberculosis with abdominal involvement in HIV-positive individuals

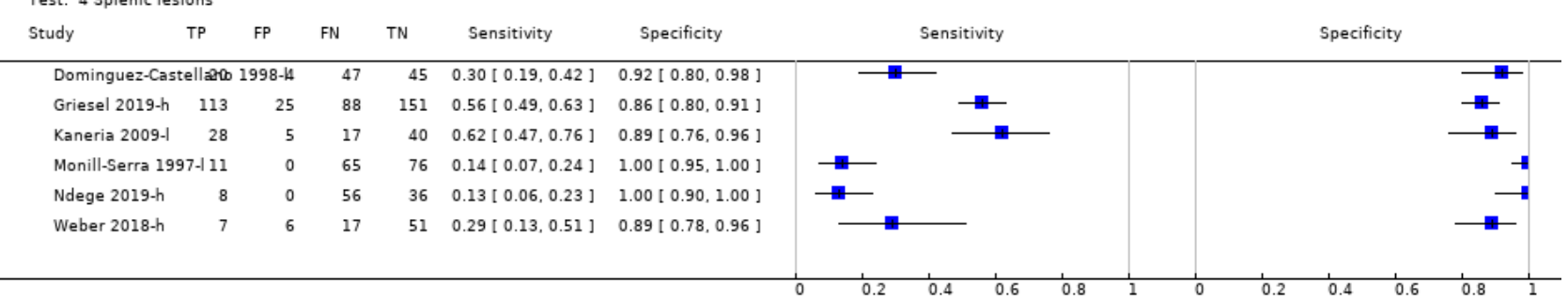


Test 5. Abdominal lymph nodes.

Review: Abdominal ultrasound for diagnosing abdominal tuberculosis or disseminated tuberculosis with abdominal involvement in HIV-positive individuals Test: 5 Abdominal lymph nodes

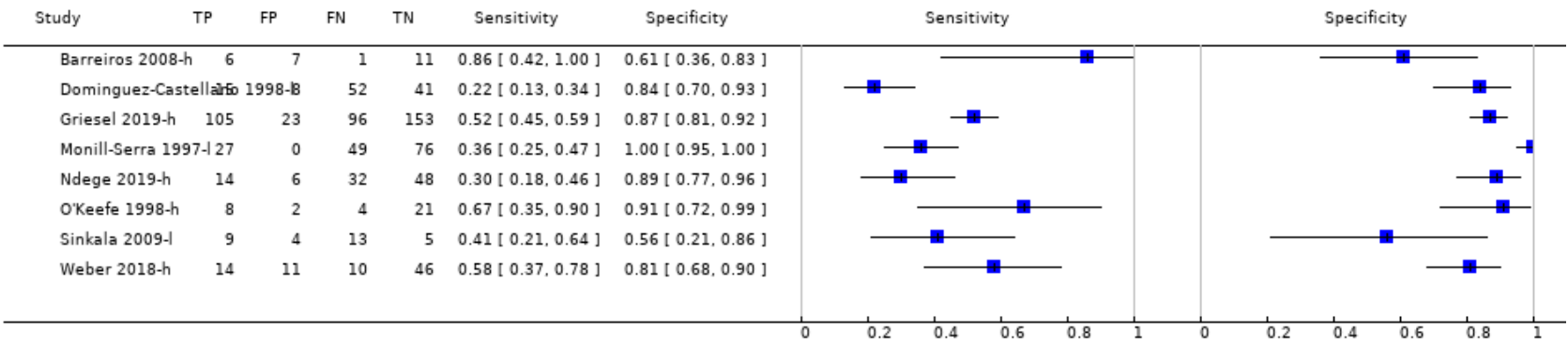

Test 6. Splenomegaly.

Review: Abdominal ultrasound for diagnosing abdominal tuberculosis or disseminated tuberculosis with abdominal involvement in HIV-positive individuals Test: 6 Splenomegaly

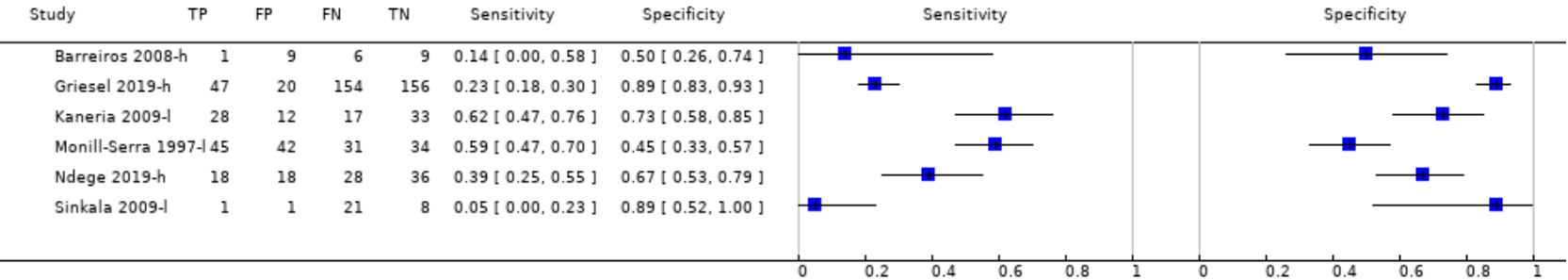

Test 7. Hepatomegaly.

Review: Abdominal ultrasound for diagnosing abdominal tuberculosis or disseminated tuberculosis with abdominal involvement in HIV-positive individuals 7 Hepatomegaly

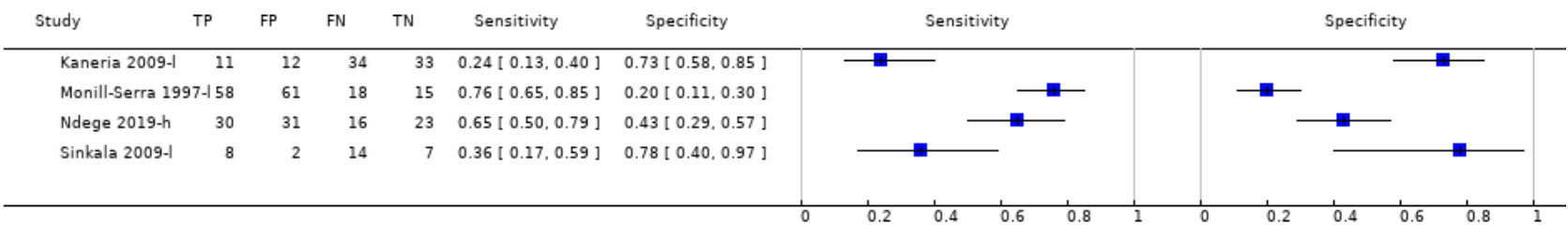

\section{ADDITIONAL TABLES}




\begin{tabular}{|c|c|c|c|c|c|c|c|}
\hline $\begin{array}{l}\text { Author (publication } \\
\text { year) }\end{array}$ & Study design & Country & $\begin{array}{l}\text { Clinical set- } \\
\text { ting }\end{array}$ & Target condition definition & $\begin{array}{l}\text { Qualification } \\
\text { of person per- } \\
\text { forming index } \\
\text { test }\end{array}$ & Sample size & $\begin{array}{l}\text { Tuberculosis- } \\
\text { proportion in } \\
\text { study }\end{array}$ \\
\hline Barreiros 2008-h & Case-control & Germany & Not reported & Gastro-intestinal tuberculosis & Not reported & $\begin{array}{l}25^{a} \text { ( } 7 \text { cases, } 18 \text { pul- } \\
\text { monary tuberculosis } \\
\text { controls) }\end{array}$ & - \\
\hline Bobbio 2019-l & $\begin{array}{l}\text { Cross-section- } \\
\text { al }\end{array}$ & South Sudan & $\begin{array}{l}\text { Referral hos- } \\
\text { pital }\end{array}$ & Extra-pulmonary tuberculosis & $\begin{array}{l}\text { Trained non-ra- } \\
\text { diologist }\end{array}$ & 100 & $24 \%$ \\
\hline $\begin{array}{l}\text { Dominguez-Castel- } \\
\text { lano 1998-h; } \\
\text { Dominguez-Castel- } \\
\text { lano 1998-l }\end{array}$ & $\begin{array}{l}\text { Cross-section- } \\
\text { al }\end{array}$ & Spain & Not reported & Extra-pulmonary tuberculosis & Sonographer & 116 & $\begin{array}{l}55 \% \text { (higher) } \\
58 \% \text { (lower) }\end{array}$ \\
\hline Griesel 2019-h & $\begin{array}{l}\text { Cross-section- } \\
\text { al }\end{array}$ & South Africa & $\begin{array}{l}\text { Non-tertiary } \\
\text { hospital }\end{array}$ & Culture-positive tuberculosis & Sonographer & 377 & $53 \%$ \\
\hline Kaneria 2009-I & Case-control & India & Not reported & $\begin{array}{l}\text { Pulmonary tuberculosis, ex- } \\
\text { tra-pulmonary tuberculosis, } \\
\text { disseminated tuberculosis }\end{array}$ & Not reported & $\begin{array}{l}90 \text { ( } 45 \text { cases, } 45 \text { HIV-pos- } \\
\text { itive controls without } \\
\text { any pathology) }\end{array}$ & - \\
\hline Monill-Serra 1997-I & Case-control & Spain & Not reported & Disseminated tuberculosis & Not reported & $\begin{array}{l}152 \text { (76 cases, } 76 \text { HIV- } \\
\text { positive controls with- } \\
\text { out any pathology) }\end{array}$ & - \\
\hline $\begin{array}{l}\text { Ndege 2019-h; Ndege } \\
\text { 2019-I }\end{array}$ & Cohort & Tanzania & $\begin{array}{l}\text { Referral hos- } \\
\text { pital }\end{array}$ & $\begin{array}{l}\text { Pulmonary tuberculosis, ex- } \\
\text { tra-pulmonary tuberculosis, } \\
\text { disseminated tuberculosis }\end{array}$ & $\begin{array}{l}\text { Board-certified } \\
\text { sonographers }\end{array}$ & $\begin{array}{l}100 \text { (191 original study } \\
\text { sample) }\end{array}$ & $\begin{array}{l}\text { 46\% (higher) } \\
64 \% \text { (lower) }\end{array}$ \\
\hline O'Keefe 1998-h & $\begin{array}{l}\text { Cross-section- } \\
\text { al }\end{array}$ & South Africa & $\begin{array}{l}\text { Non-tertiary } \\
\text { hospital }\end{array}$ & Disseminated tuberculosis & Radiologist & $\begin{array}{l}35 \text { ( } 44 \text { original study } \\
\text { sample) }\end{array}$ & $34 \%$ \\
\hline Sculier 2010-h & $\begin{array}{l}\text { Cross-section- } \\
\text { al }\end{array}$ & Cambodia & $\begin{array}{l}\text { Referral hos- } \\
\text { pital }\end{array}$ & Disseminated tuberculosis & Radiologist & 212 & $18 \%$ \\
\hline Sinkala 2009-l & $\begin{array}{l}\text { Cross-section- } \\
\text { al }\end{array}$ & Zambia & $\begin{array}{l}\text { Tertiary hos- } \\
\text { pital }\end{array}$ & Abdominal tuberculosis & Not reported & 31 & $71 \%$ \\
\hline $\begin{array}{l}\text { Weber 2018-h; Weber } \\
\text { 2018-l }\end{array}$ & Cohort & India & $\begin{array}{l}\text { Tertiary hos- } \\
\text { pital }\end{array}$ & Disseminated tuberculosis & $\begin{array}{l}\text { Trained non-ra- } \\
\text { diologist }\end{array}$ & $\begin{array}{l}81 \text { ( } 425 \text { original study } \\
\text { sample) }\end{array}$ & $30 \%$ (higher) \\
\hline
\end{tabular}




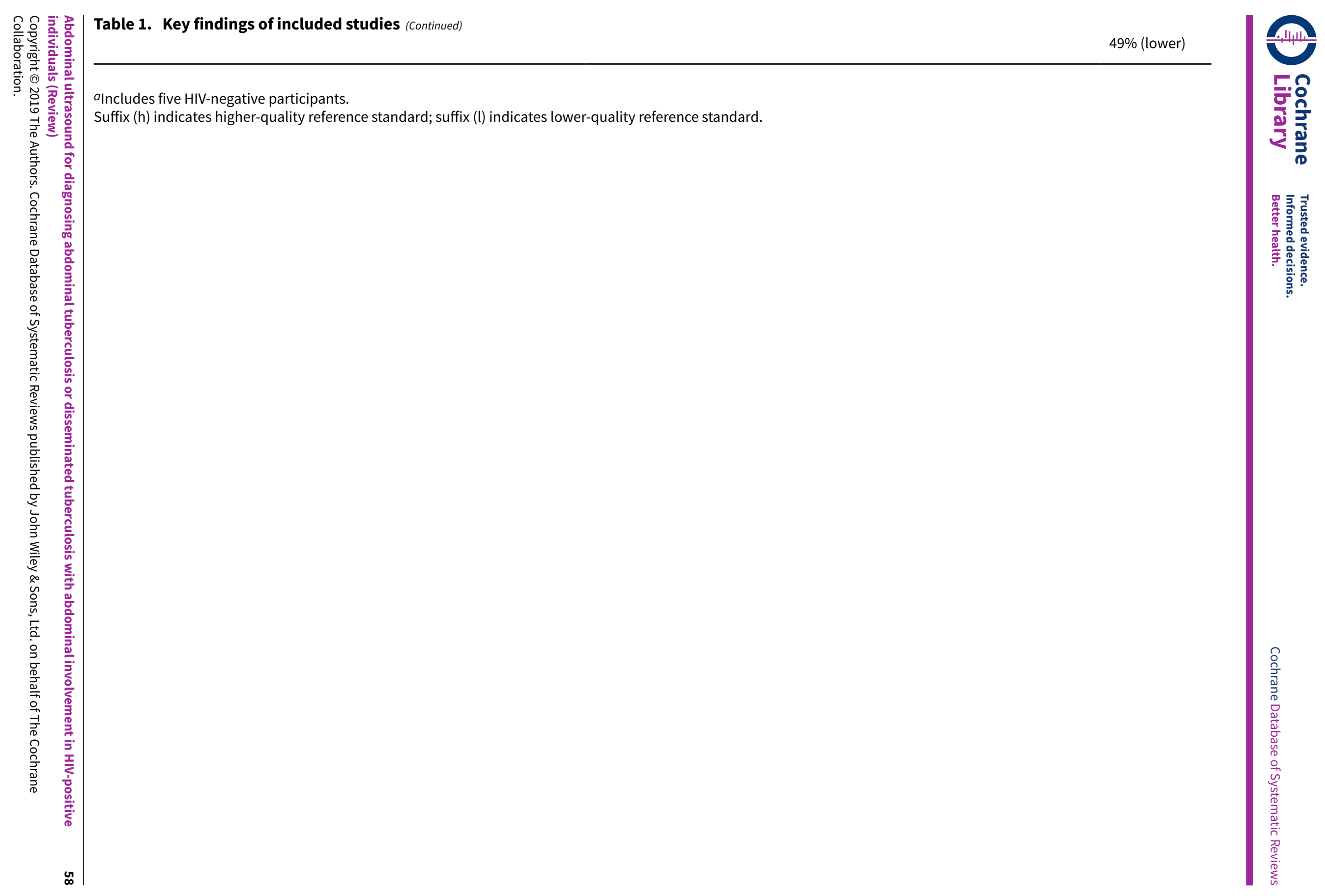


Table 2. Indext test threshold and reference standard of included studies

\begin{tabular}{lll}
\hline $\begin{array}{l}\text { Author (publication } \\
\text { year) }\end{array}$ & Index test variable included (threshold) & Reference standard quality and definition \\
\hline Barreiros 2008-h & Ascites (any) & $\begin{array}{l}\text { Lower: Clinical, endoscopic, histologic, radiolog- } \\
\text { ic and operative findings including microbiology } \\
\text { and polymerase chain reaction of biopsies taken } \\
\text { with longitudinal diameter }>20 \mathrm{~mm})\end{array}$ \\
& Splenomegaly $(>135 \mathrm{~mm})$ & \\
\hline
\end{tabular}

Bobbio 2019-1 Any abnormality (Presence of $\geq 1$ : i) pericardial effusion, ii) periportal/para-aortic lymph nodes (> $15 \mathrm{~mm}$ diameter), iii) focal splenic lesions, iv) pleural effusion or consolidation of the lung, v) ascites without alternative explanation)
Lower: Sputum microscopy OR clinical reasons OR Focused Assessment with Sonography in HIV-associated tuberculosis (FASH)

\begin{tabular}{lll}
\hline Dominguez-Castel- & Any abnormality (presence of $\geq 1:$ i) multiple hypoechoic \\
lano 1998-h; & splenic lesions $(<10 \mathrm{~mm})$, ii) any abdominal adenopathy, & Higher: Microscopy OR culture \\
$\begin{array}{l}\text { Dominguez-Castel- } \\
\text { lano 1998-l }\end{array}$ & iii) hypo- or hyperechoic liver lesions) & $\begin{array}{l}\text { diographic indications and response to treat- } \\
\text { ment }\end{array}$
\end{tabular}

\section{Griesel 2019-h}

$$
\begin{aligned}
& \text { Any abnormality (presence of } \geq 1: \text { i) abdominal lymph } \\
& \text { nodes (any size), ii) splenic hypoechoic lesions, iii) } \\
& \text { splenomegaly ( } \geq 110 \mathrm{~mm} \text { ), iv) any one of abdominal, } \\
& \text { pleural, or pericardial effusions) } \\
& \text { Ascites (any) } \\
& \text { Lymphadenopathy (any size) } \\
& \text { Splenic lesions (hypoechoic) } \\
& \text { Splenomegaly ( } \geq 110 \mathrm{~mm} \text { ) }
\end{aligned}
$$

\begin{tabular}{|c|c|c|}
\hline Kaneria 2009-I & $\begin{array}{l}\text { Ascites (any) } \\
\text { Hepatomegaly (not defined) } \\
\text { Lymphadenopathy (diameter > } 15 \mathrm{~mm} \text { ) }\end{array}$ & $\begin{array}{l}\text { Lower: Lymphocytic predominance and elevat- } \\
\text { ed adenosine deaminase (ADA) levels in pleural } \\
\text { or ascitic fluid OR granulomatous lymphadenitis } \\
\text { and acid-fast bacilli in lymph node OR sputum } \\
\text { microscopy }\end{array}$ \\
\hline & $\begin{array}{l}\text { Splenic lesions (multiple, hypoechoic, } 5 \mathrm{~mm} \text { to } 10 \mathrm{~mm} \\
\text { diameter) } \\
\text { Splenomegaly (not defined) }\end{array}$ & \\
\hline Monill-Serra 1997-I & $\begin{array}{l}\text { Ascites (any) } \\
\text { Hepatomegaly (not defined) } \\
\text { Lymphadenopathy (> } 15 \mathrm{~mm} \text { diameter) } \\
\text { Splenic lesions (hypoechoic nodes) } \\
\text { Splenomegaly (long axis }>120 \mathrm{~mm} \text { or subjective impres- } \\
\text { sion) }\end{array}$ & $\begin{array}{l}\text { Lower: Blood culture positive for } M \text { tuberculosis } \\
\text { OR medullary bone or liver biopsy with granulo- } \\
\text { matous inflammation or culture positive for } M \\
\text { tuberculosis OR microbiological or histopatho- } \\
\text { logical confirmation in } \geq 2 \text { non-contiguous ex- } \\
\text { tra-pulmonary sites }\end{array}$ \\
\hline $\begin{array}{l}\text { Ndege 2019-h; Ndege } \\
\text { 2019-l }\end{array}$ & $\begin{array}{l}\text { Any abnormality (presence of } \geq 1: \text { i) pleural or pericardial } \\
\text { effusion, ii) ascites, iii) abdominal lymph nodes }>15 \mathrm{~mm} \text {, } \\
\text { iv) hypoechogenic lesions in the liver or spleen, v) ileum } \\
\text { wall thickening }>4 \mathrm{~mm} \text { or destructed ileum wall archi- } \\
\text { tecture) }\end{array}$ & $\begin{array}{l}\text { Higher: Xpert MTB/RIF assay and/or bacteriolog- } \\
\text { ic culture (growth of } M \text { tuberculosis) } \\
\text { Lower: Positive Xpert MTB/RIF assay and/or } \\
\text { bacteriologic culture (growth of } M \text { tuberculosis) } \\
\text { OR acid-fast bacilli in sputum OR raised adeno- }\end{array}$ \\
\hline
\end{tabular}

Abdominal ultrasound for diagnosing abdominal tuberculosis or disseminated tuberculosis with abdominal involvement in HIV-positive 
Table 2. Indext test threshold and reference standard of included studies

\section{Ascites (any)}

Hepatomegaly (not defined)

Lymphadenopathy (> $15 \mathrm{~mm}$ diameter)

Splenomegaly (not defined) sine deaminase (ADA) levels in pleural, pericardial or ascitic fluid OR negative microbiological tests and improvement 2 months after start of anti-tuberculosis treatment

$\begin{array}{ll}\text { O'Keefe 1998-h } & \text { Ascites (any) } \\ & \text { Lymphadenopathy (not defined) }\end{array}$

Sculier 2010-h

Any abnormality (presence of $\geq 1:$ i) any lymph nodes $\geq$ $12 \mathrm{~mm}$, ii) ascites, iii) hepatomegaly, iv) splenomegaly, v) hepatic or splenic hypoechoic lesions with or without organ enlargement)

$\begin{array}{ll}\text { Sinkala 2009-l } & \text { Ascites (any) } \\ \text { Hepatomegaly (not defined) } \\ \text { Lymphadenopathy (not defined) } \\ \text { Splenomegaly (not defined) }\end{array}$

Weber 2018-h; Weber 2018-l

Any abnormality (presence of $\geq 1$ : i) pericardial or pleurlymphadenopathy)

Ascites (any)

Hepatomegaly (not defined)

Lymphadenopathy ( $\geq 15 \mathrm{~mm}$ diameter)

Splenic lesions (multiple, hypoechoic, $2 \mathrm{~mm}$ to $5 \mathrm{~mm}$ diameter)
Higher: Positive mycobacterial blood or bone marrow cultures OR positive mycobacterial cultures from 2 or more other sites OR post mortem evidence

Higher: Positive culture for $M$ tuberculosis from any site

Lower: Positive bacteriological culture OR granulomatous inflammation with positive ZiehlNeelsen (ZN) staining on microscopy OR granulomatous inflammation on microscopy OR visual inspection on laparoscopy consistent with tuberculosis (presence of tubercles, fibro-adhesive peritonitis, or caseating lymphadenopathy) and favourable response to anti-tuberculous treatment

Higher: Positive fluorescent microscopy, polymerase chain reaction, or tuberculosis culture Lower: Microbiological confirmation (fluorescent microscopy, polymerase chain reaction, culture) OR clinical diagnosis and anti-tuberculous treatment initiated

Suffix $(\mathrm{h})$ indicates higher quality reference standard; suffix $(\mathrm{l})$ indicates lower quality reference standard

Table 3. Summary estimates of sensitivity and specificity for any abnormality and individual abdominal ultrasound findings

\begin{tabular}{|c|c|c|c|c|c|c|}
\hline $\begin{array}{l}\text { Abdominal ultrasound find- } \\
\text { ing }\end{array}$ & $\begin{array}{l}\text { Num- } \\
\text { ber of } \\
\text { stud- } \\
\text { ies }\end{array}$ & $\begin{array}{l}\text { Number of } \\
\text { participants } \\
\text { (tuberculosis- } \\
\text { cases) }\end{array}$ & $\begin{array}{l}\text { Pooled sensitivity } \\
(95 \% \mathrm{Cl}) \%\end{array}$ & $\begin{array}{l}\text { Pooled specificity } \\
(95 \% \mathrm{CI}) \%\end{array}$ & $\begin{array}{l}\text { Range of } \\
\text { sensitivi- } \\
\text { ty } \%\end{array}$ & $\begin{array}{l}\text { Range of } \\
\text { specificity } \\
\%\end{array}$ \\
\hline $\begin{array}{l}\text { Any abnormality (high- } \\
\text { er-quality reference stan- } \\
\text { dard) }\end{array}$ & 5 & $879(368)$ & 63 (43 to 79 ) & 68 (72 to 87 ) & 35 to 82 & 20 to 92 \\
\hline $\begin{array}{l}\text { Any abnormality (lower-qual- } \\
\text { ity reference standard) }\end{array}$ & 4 & 397 (149) & 68 (45 to 85 ) & 73 (41 to 91 ) & 37 to 88 & 22 to 92 \\
\hline Splenic lesions & 6 & $916(477)$ & Not calculated & Not calculated & 13 to 62 & 86 to 100 \\
\hline
\end{tabular}

Abdominal ultrasound for diagnosing abdominal tuberculosis or disseminated tuberculosis with abdominal involvement in HIV-positive $\mathbf{6 0}$ individuals (Review)

Copyright $\odot 2019$ The Authors. Cochrane Database of Systematic Reviews published by John Wiley \& Sons, Ltd. on behalf of The Cochrane Collaboration. 
Table 3. Summary estimates of sensitivity and specificity for any abnormality and individual abdominal ultrasound findings (Continued)

\begin{tabular}{lcccccc}
$\begin{array}{l}\text { Intra-abdominal lymph } \\
\text { nodes }\end{array}$ & 8 & $917(455)$ & Not calculated & Not calculated & 22 to 86 & 56 to 100 \\
\hline Ascites & 8 & $891(433)$ & Not calculated & Not calculated & 4 to 73 & 33 to 100 \\
\hline Splenomegaly & 6 & $775(397$ & Not calculated & Not calculated & 5 to 62 & 45 to 89 \\
\hline Hepatomegaly & 4 & $373(189)$ & Not calculated & Not calculated & 24 to 76 & 20 to 78 \\
\hline
\end{tabular}

\section{AP P E N DICES}

\section{Appendix 1. Search strategy}

Ovid MEDLINE ${ }^{\circledR}$ Epub Ahead of Print, In-Process \& Other Non-Indexed Citations, Ovid MEDLINE ${ }^{\circledR}$ Daily and Ovid MEDLINE ${ }^{\circledR}<1946$ to Present>

1 extrapulmonary tuberculosis.mp.

2 Peritonitis, Tuberculous/ or Tuberculosis, Gastrointestinal/ or Tuberculosis, Hepatic/

3 abdominal tuberculosis.mp.

4 Tuberculosis, Hepatic/ or liver tuberculosis.mp. or gastric tuberculosis.mp. or intestinal tuberculosis.mp.

5 Tuberculosis, Miliary/

6 disseminated tuberculosis.mp.

71 or 2 or 3 or 4 or 5 or 6

8 HIV infection.mp. or HIV Infections/

$9 \operatorname{exp~HIV/~}$

10 human immunodeficiency virus.mp.

11 Acquired Immunodeficiency Syndrome/ or acquired immunodeficiency syndrome.mp.

12 (acquired immun* and deficiency syndrome).mp.

$13\left(\left(\right.\right.$ HIV $^{\star}$ adj2 (people or person* or patient $\left.\left.^{\star}\right)\right)$ or PLHIV).mp.

148 or 9 or 10 or 11 or 12 or 13

157 and 14

16 Radiography, Abdominal/

17 X-Ray Diffraction/ or x-ray ${ }^{\star} . \mathrm{mp}$.

18 (ultrasound or barium).mp.

19 Tomography, X-Ray Computed/

20 (comput* adj2 tomograph*).mp.

21 Magnetic Resonance Imaging/

22 (MRI or CAT).mp.

23 Ultrasonography/ or ultrasonograph*.mp.

Abdominal ultrasound for diagnosing abdominal tuberculosis or disseminated tuberculosis with abdominal involvement in HIV-positive individuals (Review)

Copyright $\odot 2019$ The Authors. Cochrane Database of Systematic Reviews published by John Wiley \& Sons, Ltd. on behalf of The Cochrane Collaboration. 
24 Bacteriological Techniques/ or Sputum/ or sputum specimen.mp.

25 liquid culture system.mp.

26 Xpert MTB*.mp.

27 Genotype MTBDR*.mp.

28 (lipoarabinomannan or LAM or LF-LAM).mp.

29 QuantiFERON-TB-Gold.mp. or Tuberculin Test/ or tuberculin.mp.

30 Diagnostic Imaging/ or Point-of-Care Systems/

31 (Laparotomy or laparoscopy or fine needle aspiration).mp.

32 CD4 Lymphocyte Count/

33 Ascites/diagnosis or Ascites/microbiology or Paracentesis/ or Laparoscopy/

34 colonoscopy.mp. or Colonoscopy/

3516 or 17 or 18 or 19 or 20 or 21 or 22 or 23 or 24 or 25 or 26 or 27 or 28 or 29 or 30 or 31 or 32 or 33 or 34

3615 and 35

\section{Embase 1947-Present, updated daily}

1 tuberculosis.mp. or tuberculosis/

2 (Abdominal or gastroenteric or gastrointestinal or intestinal or hepatic or liver or splenic).mp.

31 and 2

4 abdominal tuberculosis/

5 miliary tuberculosis/

6 HIV infection.mp. or Human immunodeficiency virus infection/

7 human immunodeficiency virus.mp.

8 acquired immune deficiency syndrome/

$9\left(\left(\right.\right.$ HIV $^{\star}$ adj2 (people or person* ${ }^{\star}$ r patient $\left.\left.{ }^{\star}\right)\right)$ or PLHIV).mp.

106 or 7 or 8 or 9

11 abdominal ultrasound.mp.

$12 \mathrm{X}$ ray/ or radiography/ or X ray*.mp.

13 (ultrasound or barium).mp.

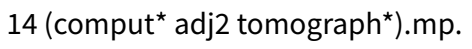

15 Magnetic Resonance.mp. or nuclear magnetic resonance/

16 Ultrasonography.mp. or echography/

17 sputum analysis/ or sputum cytodiagnosis/ or sputum culture/

18 microbiological examination/

19 liquid culture/

20 (Xpert MTB* or Genotype MTBDR*).mp.

Abdominal ultrasound for diagnosing abdominal tuberculosis or disseminated tuberculosis with abdominal involvement in HIV-positive

Copyright ( 2019 The Authors. Cochrane Database of Systematic Reviews published by John Wiley \& Sons, Ltd. on behalf of The Cochrane

Collaboration. 
21 (lipoarabinomannan or LAM or LF-LAM).mp.

22 (QuantiFERON-TB-Gold or Tuberculin Test).mp.

23 "point of care system"/

24 (Laparotomy or laparoscopy).mp

25 ascites fluid analysis/ or ascites/ or ascites fluid cytology/

26 colonoscopy/

2711 or 12 or 13 or 14 or 15 or 16 or 17 or 18 or 19 or 20 or 21 or 22 or 23 or 24 or 25 or 26

283 and 10 and 27

\section{BIOSIS Previews}

You searched for: TOPIC: ("liver tuberculosis" or "gastric tuberculosis" or "intestinal tuberculosis" or "abdominal tuberculosis".) AND TOPIC: (HIV or AIDS or "acquired immunodeficiency syndrome") AND TOPIC: (ultrasound or ultrasonography or scan or "Magnetic Resonance Imaging" or MRI or tomography)

Timespan: All years. Indexes: BIOSIS Previews.

\section{Web of Science Core Collection}

You searched for: TOPIC: ("liver tuberculosis" or "gastric tuberculosis" or "intestinal tuberculosis" or "abdominal tuberculosis") AND TOPIC: (HIV or AIDS or "acquired immunodeficiency syndrome") AND TOPIC: (ultrasound or ultrasonography or scan or "Magnetic Resonance Imaging" or MRI or tomography)

Timespan: All years. Indexes: SCI-EXPANDED, SSCI, CPCI-S, CPCI-SSH

\section{ClinicalTrials.gov and WHO ICTRP}

tuberculosis and ultrasound, tuberculosis and ultrasonography, tuberculosis and MRI

Appendix 2. QUADAS-2 tool tailored to the context of the review

\begin{tabular}{lllll}
\hline Domain & Patient selection & Index test & Reference standard & Flow and timing \\
\hline $\begin{array}{lllll}\text { Descrip- } \\
\text { tion }\end{array}$ & Methods of patient selection & $\begin{array}{l}\text { How index test was } \\
\text { conducted and report- } \\
\text { ed }\end{array}$ & $\begin{array}{l}\text { How reference standard } \\
\text { was conducted and re- } \\
\text { ported }\end{array}$ & $\begin{array}{l}\text { Describe patients that } \\
\text { did not receive and time } \\
\text { interval between index } \\
\text { test or reference stan- } \\
\text { dard }\end{array}$ \\
\end{tabular}

$\begin{array}{ll}\text { Sig- } & \text { Consecutive or random sam- } \\ \text { nalling } & \text { ple of patients? }\end{array}$
nalling ple of patients? questions (yes, no, or unclear) ed consecutive enrolment or random sampling of pa-
Index test results interpreted without knowledge of the results of reference standard? tients.

- No if patients were purposefully selected, for example based on previous test results (other tests or reference standard).

- Unclear if the study did not explicitly state consecutive enrolment or random sampling, and it was unclear how patients were sampled.
Reference standard likely to correctly classify the target condition?

- Yes if the higher quality reference standard was used (that is, culture, microscopic identification of acid-fast bacilli, or Xpert MTB/RIF).

- No if the lower quality reference standard was used (that is, not coupled with any mentioned in higher quality reference).
Was there an appropriate interval between index test and reference standard?

- Yes if abdominal ultrasound and the reference standard(s) (samples taken or clinical diagnosis made) were performed at the same time or if the time interval is less than one week.

- No if the time period between ultrasound and

Abdominal ultrasound for diagnosing abdominal tuberculosis or disseminated tuberculosis with abdominal involvement in HIV-positive 63 individuals (Review)

Copyright $\odot 2019$ The Authors. Cochrane Database of Systematic Reviews published by John Wiley \& Sons, Ltd. on behalf of The Cochrane Collaboration. 
with knowledge of the reference standard results.

- Unclear if insufficient information on how ultrasound (and test combinations) was interpreted.

\section{Was a case-control design} avoided?

- Yes if a case-control design was not used.

- No if patients with known disease (cases) and patients without the disease (controls) were clearly enrolled (such that participants are unrepresentative of the spectrum of patients seen in clinical practice).

- Unclear if the study design used was not clearly reported.

Did the study avoid inappropriate exclusions?

- Yes if no patients were excluded after inclusion in the study.

- No if specific populations were excluded (for example, pregnant patients, elderly), or patients with high CD4 counts were excluded because of low clinical suspicion of TB.

- Unclear if unreported or insufficient information given to make a decision.

- Unclear if insufficient information on the reference standard(s) used.

Pre-specified threshold used?

- Yes if the study states the use of one, prespecified, cut-off value, for example, "abdominal lymph nodes greater than $10 \mathrm{~mm}$ in the shortest diameter were deemed as a positive result".

- No if multiple cut-off values were evaluated and an optimal one (based on maximising test accuracy) was subsequently chosen.

- Unclear if a cut-off was used but was not reported, or only one cut-off value was reported, but was not explicitly pre-specified in the study.
Reference standard results interpreted without knowledge of the results of index test?

- Yes if results of the reference standard are interpreted without knowledge of ultrasound results. However, the clinical reference standard may incorporate ultrasound.

- No if results of the reference standard were interpreted with knowledge of ultrasound results

- Unclear if there is insufficient information on whether or not the reference standard results were interpreted with knowledge of ultrasound results

Was incorporation bias avoided (inclusion of index test as part of the reference standard)?

- Yes if abdominal ultrasound was not used as part of the reference standard.

- No if abdominal ultrasound formed part of the reference standard.

- Unclear if insufficient information given to make a decision. the reference standard is more than one week.

- Unclear if insufficient or no information on the time interval.
Did all patients receive a reference standard?

- Yes if all participants received a reference standard.

- No if one or more participants did not receive a reference standard.

- Unclear if there is insufficient information to determine whether or not all patients received a reference standard.
Did all patients receive the same reference standard?

- Yes if study participants received the same reference standard (regardless of ultrasound result).

- No if participants did not receive the same reference standard.

- Unclear if there is insufficient information to determine whether or not all patients received the same reference standard.

Were all patients included in the analysis?

- Yes if all participants recruited into the study were included in the analysis. 
- No if some participants recruited into the study were excluded in the analysis.

- Unclear if unreported or insufficient information given to make a decision.

\begin{tabular}{|c|c|}
\hline $\begin{array}{l}\text { Risk of bi- } \\
\text { asa(high, } \\
\text { low, or } \\
\text { unclear) }\end{array}$ & $\begin{array}{l}\text { Could the selection of patients } \\
\text { have introduced bias? }\end{array}$ \\
\hline
\end{tabular}

Applic- Are there concerns that the inability cluded patients do not match concerns the review question?

(high, low, or unclear)

- High if participants received ultrasound in a tertiary care

\section{Could the conduct or interpretation of the index test have intro- duced bias?}

Are there concerns that the index test, its conduct, or interpretation differs from the review question? (referral) centre or if asymptomatic HIV-positive participants included.

- Low if participants received ultrasound in any setting, or if HIV-positive individuals with presumptive abdominal tuberculosis or disseminated tuberculosis with abdominal involvement included.

- Unclear if insufficient information to make a decision.
- High if, for example, specially trained radiologists performed the ultrasound.

- Low if non-radiologists performed the ultrasounds.

- Unclear if insufficient information to make a decision.
Could the reference standard, its conduct, or its interpretation has introduced bias?
Could the patient flow have introduced bias?
Are there concerns that the target condition as defined by the reference standard does not match the review question?

- High if studies did not speciate mycobacteria isolated in culture or clinically diagnosed TB cases were not followed up to evaluate treatment response.

- Low if studies did speciate mycobacteria isolated in culture or clinically diagnosed TB cases improved on anti-TB therapy.

- Unclear if insufficient information to make a decision.
Not applicable

Abbreviations: TB: tuberculosis

\section{aGrading criteria for 'Risk of bias' assessment}

- If all signalling questions for a domain are answered 'yes' then we will judge the risk of bias to be 'low'.

- If any signalling question is answered 'no' this will flag the potential for bias and we will judge risk of bias with a senior review author.

- If all signalling questions or most of them were answered 'no', then we will judge the risk of bias as 'high'.

- We will assign the 'unclear' category when the study authors report insufficient data to permit a judgment.

\section{CONTRIBUTIONS OF AUTHORS}

Daniël J van Hoving and Eleanor A Ochodo wrote the protocol with input from Yemisi Takwoingi, Rulan Griesel, Graeme Meintjes, and Gary Maartens. Daniël J van Hoving and Rulan Griesel reviewed articles for inclusion and extracted data. Discrepancies were resolved by Graeme Meintjes. Eleanor A Ochodo analysed the data with input from Yemisi Takwoingi. Daniël J van Hoving and Eleanor A Ochodo interpreted the analyses and drafted the manuscript. Graeme Meintjes, Gary Maartens and Yemisi Takwoingi provided critical revisions to the manuscript. All review authors read and approved the final manuscript draft.

\section{DECLARATIONSOF INTEREST}

Daniël J van Hoving has no conflicts of interest to declare.

Graeme Meintjes has no conflicts of interest to declare.

Abdominal ultrasound for diagnosing abdominal tuberculosis or disseminated tuberculosis with abdominal involvement in HIV-positive 
Yemisi Takwoingi has no conflicts of interest to declare.

Rulan Griesel has no conflicts of interest to declare.

Gary Maartens has no conflicts of interest to declare.

Eleanor A Ochodo has no conflicts of interest to declare.

\section{SOURCES OF SUPPORT}

\section{Internal sources}

- South African Medical Research Council, South Africa.

- Liverpool School of Tropical Medicine, UK.

\section{External sources}

- Department for International Development, UK.

Project number 300342-104

- Wellcome Trust Foundation, UK.

Grant: 109939

- Wellcome Trust Foundation, UK.

Grant: 098316

- South African Research Chairs Initiative of the Department of Science and Technology and National Research Foundation, South Africa. Grant: 64787

- National Research Foundation incentive funding, South Africa.

UID: 85858

- TB and HIV Collaborating Centres Programme, South African Medical Research Council, South Africa.

RFA\# SAMRC-RFA-CC: TB/HIV/AIDS-01-2014

\section{DIFFERENCES BETWEEN PROTOCOLANDREVIEW}

We amended the protocol title from Abdominal ultrasound for diagnosing abdominal tuberculosis or disseminated tuberculosis with abdominal involvement in HIV-positive adults to Abdominal ultrasound for diagnosing abdominal tuberculosis or disseminated tuberculosis with abdominal involvement in HIV-positive individuals.

Our review differed from the Cochrane protocol in several ways (Van Hoving 2017). In the protocol we stated a secondary objective to determine the diagnostic accuracy of combinations of abdominal ultrasound and existing tests (chest radiograph, full blood count) for detecting abdominal tuberculosis or disseminated tuberculosis with abdominal involvement in HIV-positive individuals. However, we could not find any study that evaluated abdominal ultrasound as an add-on test or in combination with other tests, and we therefore did not report on this.

The MEDION database is not active anymore and has not been searched.

In the protocol, we stated that we would have one primary meta-analysis at individual patient level. However we decided to have two sets of primary meta-analyses; one with $2 \times 2$ tables generated with a higher-quality reference standard and the other with a lowerquality reference standard. As stated in the analysis section, some studies produced two data points (with higher-quality and lower-quality reference standards). Because we did not want to lose information by only selecting one data point for each study and also to produce meaningful results, we present two sets of meta-analyses. We used Stata instead of SAS for all analyses.

Due to insufficient data we did not investigate all potential sources of heterogeneity as stated in the protocol (including clinical setting, and ultrasound training level).

We defined adults in the protocol as participants aged 18 years or older. Two studies included participants under 18 years (older than 15 years) (Sculier 2010-h; Weber 2018-h; Weber 2018-l). We included the studies as i) the number of paediatric cases was low, ii) many countries manage 15 -year-old patients as adults, and iii) the results would be valuable for policy making. However, we have downgraded the certainty of the evidence for applicability concerns due to indirectness.

Abdominal ultrasound for diagnosing abdominal tuberculosis or disseminated tuberculosis with abdominal involvement in HIV-positive 
We judged publication bias using three criteria: for-profit interest, only studies detected that produce precise estimates of high accuracy despite small sample size, and knowledge about studies that were conducted but are not published.

\section{N DEX TERMS}

\section{Medical Subject Headings (MeSH)}

AIDS-Related Opportunistic Infections [*diagnostic imaging]; HIV Infections [ ${ }^{\star}$ complications]; Randomized Controlled Trials as Topic; Tuberculosis [ ${ }^{*}$ diagnostic imaging]; Ultrasonography [ ${ }^{*}$ methods]

\section{MeSH check words}

Humans 